\title{
THROUGH THEIR EYES: INSIGHTS FROM THE LIVED EXPERIENCES OF BLIND YOUTH IN UGANDA
}

\author{
BY \\ ARIANNA S. JEZARI
}

\begin{abstract}
A THESIS SUBMITTED TO THE FACULTY OF GRADUATE AND POSTDOCTORAL AFFAIRS IN PARTIAL FULFILLMENT OF THE REQUIREMENTS FOR THE DEGREE OF:
\end{abstract}

\author{
MASTER OF ARTS \\ IN \\ ANTHROPOLOGY
}

CARLETON UNIVERSITY

OTTAWA, ONTARIO

(C) 2012

ARIANNA JEZARI 
Library and Archives

Canada

Published Heritage

Branch

395 Wellington Street

Ottawa ON K1A ON4

Canada
Bibliothèque et

Archives Canada

Direction du

Patrimoine de l'édition

395 , rue Wellington

Ottawa ON K1A ON4

Canada
Your file Votre référence

ISBN: 978-0-494-93596-5

Our file Notre référence

ISBN: $978-0-494-93596-5$
NOTICE:

The author has granted a nonexclusive license allowing Library and Archives Canada to reproduce, publish, archive, preserve, conserve, communicate to the public by telecommunication or on the Internet, loan, distrbute and sell theses worldwide, for commercial or noncommercial purposes, in microform, paper, electronic and/or any other formats.

The author retains copyright ownership and moral rights in this thesis. Neither the thesis nor substantial extracts from it may be printed or otherwise reproduced without the author's permission.
AVIS:

L'auteur a accordé une licence non exclusive permettant à la Bibliothèque et Archives Canada de reproduire, publier, archiver, sauvegarder, conserver, transmettre au public par télécommunication ou par l'Internet, prêter, distribuer et vendre des thèses partout dans le monde, à des fins commerciales ou autres, sur support microforme, papier, électronique et/ou autres formats.

L'auteur conserve la propriété du droit d'auteur et des droits moraux qui protege cette thèse. $\mathrm{Ni}$ la thèse ni des extraits substantiels de celle-ci ne doivent être imprimés ou autrement reproduits sans son autorisation.
In compliance with the Canadian Privacy Act some supporting forms may have been removed from this thesis.

While these forms may be included in the document page count, their removal does not represent any loss of content from the thesis.
Conformément à la loi canadienne sur la protection de la vie privée, quelques formulaires secondaires ont été enlevés de cette thèse.

Bien que ces formulaires aient inclus dans la pagination, il n'y aura aucun contenu manquant. 


\begin{abstract}
This thesis examines the lived experiences of blind youth in Gulu, Uganda. A key purpose of this research is to understand how social perceptions of blind people and blindness affect the life opportunities, experiences, and self-perceptions of blind individuals. This includes blind individuals' ideas about their selfhood and self-worth, their access to avenues of empowerment, primarily education, employment, information, and health services, and their roles as individuals in the larger social world.

I argue that although there have been some attempts made by the Ugandan government to better integrate blind individuals within society, and educational institutions, they still remain marginalized and poorly incorporated within these settings. Analysis of life story narratives from blind youth as well as findings from focus group discussions with friends and family of blind individuals, and working professionals in the field of disability, reveal areas that can be improved in order to enhance the quality of life and education for blind people in Uganda, and their integration within schools and society.
\end{abstract}




\section{ACKNOWLEDGEMENTS}

This thesis would not have been possible without the emotional and financial support of my parents, Marsha and Michael Jezari, and Aunt Manijeh. I would like to thank them and my partner, Mehdi Hamdad, for their patience, motivation, understanding, and continuous support.

I would also like to thank my supervisor, Dr. Louise de la Gorgendiere for her guidance, encouragement, and constant dedication, and my committee members, Dr. Blair Rutherford and Dr. Gurli A. Woods, for their valuable insight and feedback about my thesis.

This thesis also would not have been possible without my wonderful initial contacts, Marilyn Bland and Sandra Washburn, who found me a place to live and introduced me to further contacts in Gulu.

Lastly, I would like to dedicate this thesis to the friends I made in Gulu, who opened themselves and their hearts to me; their stories, kindness, sincerity, and faith have been an inspiration in my own life. 


\section{TABLE OF Contents}

CHAPTER ONE: INTRODUCTION......................................................

General Overview....................................................

Background, Study Questions, and Significance.............................2

The Issue: Experiences of the Blind in Uganda..............................

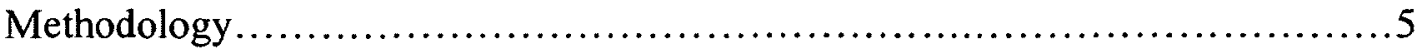

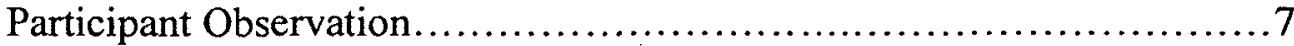

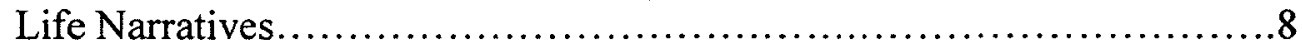

Focus Groups.....................................................

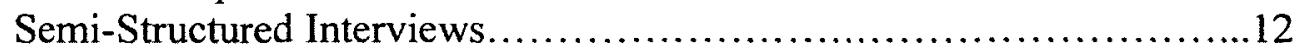

Limitations and Constraints...................................... 13

Data Analysis.......................................................

Chapter Summaries....................................................

CHAPTER TWO: BACKGROUND TO UGANDAN CONTEXT AND THEORY..............18

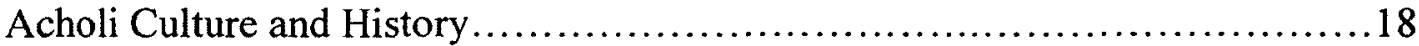

Historical Context of Disability in Uganda.................................22

Disability Prior to 1970 s.......................................23

Disability Movement and Constitutional Revisions.....................24

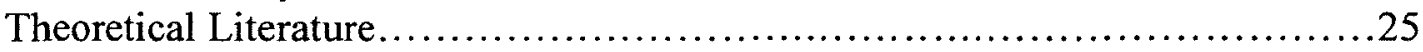

Anthropology of Disability ....................................... 25

Theoretical Framework .............................................28

Conclusion .................................................................

CHAPTER THREE: SOCIAL CONTEXT OF BLINDNESS.............................33

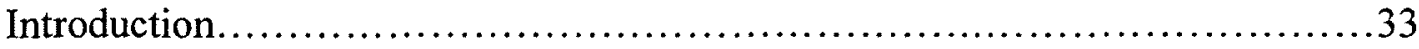

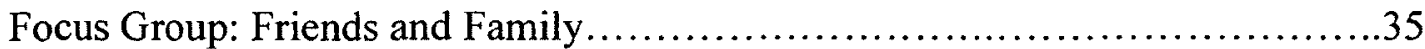

Focus Group: Workers with the Blind ...................................43

Social Perceptions and Beliefs............................................48

Liminality and Marginalization.........................................5

Integration of Blind Persons in Uganda ....................................55

Social Integration.................................................. 55

Family Role in Integration........................................

Integration within Educational Settings.............................59

Gender..........................................................64

Discussion: Social Construction of Disability and its Effects..................68

CHAPTER FOUR: LIFE STORIES AND THEMATIC ANALYSIS........................71

Introduction............................................................. 71

Gulu Town and Meba High School.......................................74

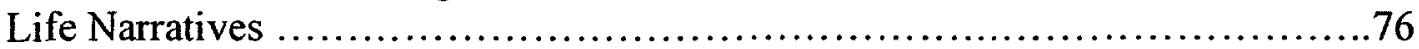

Bashir..............................................................

Malcolm..............................................................

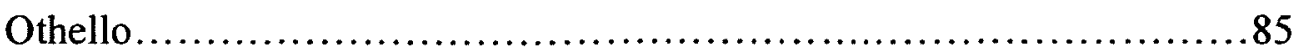




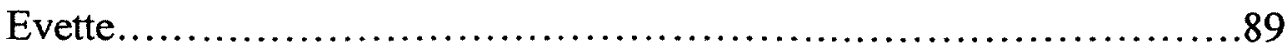

Albert................................................................

Angel............................................................ 100

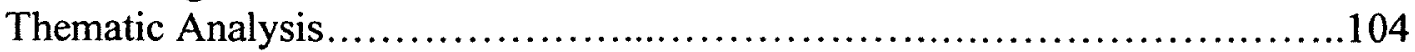

Stigma..........................................................

Communitas........................................................ 109

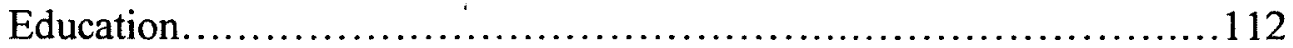

Personhood/Selfhood ..............................................115

CHAPTER FIVE: Economics, Politics, AND DisabILITY.......................121

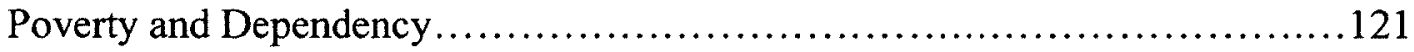

Access and Opportunities for Blind Persons................................. 126

Access to Information............................................. 126

Access to Education.............................................. 128

Access to Employment........................................138

Access to Health Services........................................136

Ugandan Government, Local leaders, and the Blind...........................138

Discussion: Structural Violence and Social Suffering........................141

CHAPTER SIX: CONCLUSION...............................................145

General Overview.................................................. 145

Summary of Main Findings and Suggestions............................. 146

Anthropology and Disability.............................................. 151

Future Directions.................................................... 52

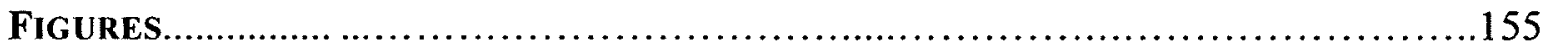

Appendix A: Sample Questions for Life Story .................................. 159

Appendix B: Sample Questions for Focus Group with Friends and

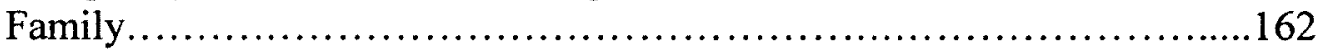

Appendix C: Sample Questions for Focus Group with Workers of the Blind...........163

Appendix D: Sample Questions for Semi-Structured Interviews with Blind Community Members..........................................................164

Appendix E: Sample Questions for Semi-Structured Interview with a NUDIPU Board Member/Primary School Teacher..................................... 165

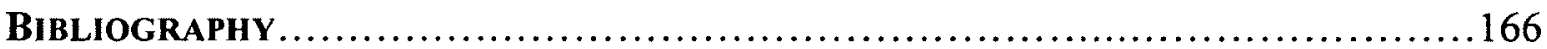




\section{CHAPTER ONE: INTRODUCTION}

\section{General OVERVIEW}

There are people everywhere who must live with biological impairments that cannot be cured and that inhibit, to some extent, their ability to perform certain functions. However, the significance of an impairment always depends on more than its biological nature; it is shaped by the human circumstances in which it exists (Ingstad and Whyte 1995:ix). This thesis examines the social, political, and economic factors that both prevent and promote the integration of blind individuals within Ugandan society and Ugandan educational institutions.

In this thesis I explore the role of the individual (e.g., coping mechanisms, selfperceptions, and ideas of selfhood) through the collection of life-story narratives of blind individuals' experiences during youthhood. Through the use of semi-structured interviews and focus groups I further inquire how the individual is made and affected by the role of the family and the social world (e.g., cultural perceptions of blindness, relations and interactions with teachers, peers, and fellow community members in educational and school settings, and cultural values placed on notions of achieving full womanhood and manhood in Uganda). Furthermore, I explore the influences and impacts of public policy (e.g., the workings of governmental structures and institutions and the degree of opportunity given to blind individuals to access avenues of empowerment) on the lives of the blind. I examine how the external world shapes and influences life experiences and subjective feelings of blind individuals, focusing on youth in Uganda, and how these external forces function as barriers to prevent full integration and empowerment within society. 


\section{BaCKGROUnd, Study Questions, AND SignificanCE}

My initial interest in studying the social effects that blindness and visual impairment have on the life-quality of an individual began during my undergraduate career at the University of North Texas in Denton, Texas. My involvement with a philanthropic project, Service for Sight ${ }^{1}$, frequently exposed me to blind individuals living in my own community and taught me more about their lives. During this time, I was exposed to Art of the Eye-- an exhibition supported by Service for Sight--which presents artwork of visually impaired and blind individuals. The exhibition focuses on the impact of visual impairment on the artists' perceptions--communicating to viewers that that which society may view as a 'disability' or 'handicap' is actually a unique window for the creation of imaginative and inspirational artwork. At this point, I really started to understand what people meant by 'disability does not mean inability.'

Through Service for Sight, I also was involved with Dallas Lighthouse for the Blind, ${ }^{2}$ where I volunteered for a few hours every couple of months between August 2008 and May 2010. On one particular visit to the Dallas Lighthouse, I was able to reunite with my visually-impaired high school teacher, who, like many other blind individuals I have met, is a living contradiction to social perceptions and ideas about the blind. Through my relationship with her, I learned of an opportunity to travel to Uganda and study the lives of the blind. I seized the chance and immediately began to formulate thesis questions of personal interest for further inquiry.

\footnotetext{
' Service for Sight is the philanthropic focus of Delta Gamma Fraternity which is dedicated to preventing blindness and preserving vision.

${ }^{2}$ Dallas Lighthouse for the blind is an organization located in Dallas, Texas that provides work-related training to blind individuals, assists in finding jobs for them, and encourages their empowerment for selfsufficient living.
} 
My primary research objective in Uganda was to understand the lived experiences of blind youth; however, I also focused on gaining an in-depth knowledge of cultural perceptions of blindness and their effects, and outlining the role of governmental institutions in the lives of the blind, specifically education and schooling. Therefore, the fundamental research questions for this study include:

- What are cultural perceptions of blindness? How do Ugandans view, treat, and react to blind individuals? What are blind persons' perceived roles in society? How are teachers, peers, and/or community members enabling or disabling blind youth to thrive and flourish in school and society?

- What are the lived experiences of blind youth in Uganda? How have stigma and cultural perceptions affected the unfolding of blind youths' lives? What coping mechanisms do they employ in order to deal with difficulties in their social world?

- How do blind youth perceive themselves and their 'disability'? How is this selfperception influenced by others? Do blind individuals accept the social constructions of themselves and their so-called "disability?" Do they resist them? How is this done?

- What are the impacts of disability on youthhood? How do decisions, experiences, and contextual situations during blind individuals' youthhood influence their opportunities for positive living in the future?

- To what degree are blind individuals stigmatized or marginalized in society? How have stigma and/or negative perceptions of blindness affected their social 
relationships, access to avenues of empowerment (e.g. education, employment, information, health services) and/or economic opportunities?

Accounts of life narratives and lived experiences are significant in anthropological research, as they present the voices of individuals who are often unheard and overlooked in their own societies, and even in academic inquiry. The study I have conducted is valuable to academia as it contributes to our understanding of the subjective experiences of blind youth--a voice that has yet to be included in scholarly literature--as well as illuminating the perceptions of Ugandan society members on blindness and blind people. By focusing on the life stories, 'illness' narratives, and experiences of the blind, a deeper understanding of their lives is possible. This understanding can contribute to improving their life quality, assist in developing ideas for better integration within classrooms, communities, and society, and reveal that societal perceptions of blindness and attitudes towards blind people are actually far more disabling than the physical impairment itself. Moreover, the interviews and focus groups with knowledgeable and experienced persons working with blind individuals in schools and communities reveal areas in need of further attention, development, and training.

\section{THE ISSUE: EXPERIENCES OF THE BLIND IN UGANDA}

One in every ten people-- 600 million individuals-- lives "with a disability significant enough to make a difference in their daily lives" (Groce 2005:215). Moreover, approximately $80 \%$ of the world's disabled population lives in developing countries (ibid). Such statistics make a study on disability issues within an international context an imperative. Furthermore, disabled individuals, living in developing countries, "are the last to be considered for social and economic initiatives" (Laclave 2005:23-24). The 
voices of persons with disabilities are unheard and their most basic needs are often withheld or unattainable due to specific social and local contexts.

Within Uganda, individuals with disabilities are among the poorest and most stigmatized members of society. Disabled individuals face social inequalities ranging from negative perceptions of community members, chronic poverty, social marginalization, lack of access to education, employment, health services and information, and attacks from society about their personhood and value as citizens. The social, political and economic environment which society has created for blind individuals has prevented the blind from full societal integration, has contributed to negative experiences in their social world, has generated negative feelings about their self-worth, and has acted as a vehicle of disempowerment.

\section{Methodology}

This thesis is based on qualitative research methods that explore the lived experiences of blind youth in Ugandan schools and Ugandan society. Research methods for this study consist of four primary components that assist in contextualizing the difficulties blind youth are facing in the country today: participant-observation, life-story narratives, semi-structured interviews, and focus groups.

My research began with a literature review on disability studies within anthropology, and focused on themes of lived experience, personhood, and stigma. Following the review, my primary data collection took place between June 2011 and September 2011 in Gulu, Uganda. I spent all of June and the early part of July doing exclusive participant-observation, which made it possible for me to establish relationships with potential study participants at Meba High School and within the 
community. Semi-structured interviews, life-story narratives, and focus groups were collected between mid-July and near the end of September.

I conducted all interviews and collected all life-story narratives with blind students and society members in private, away from common areas, in order to mitigate any form of emotional, social, or economic harm. A translator was hired to assist in semistructured interviews with the older blind community members who lacked proficiency in the English language. The translator's services were also used for the focus group that took place with friends and family-members of blind individuals. The translator had preexisting knowledge of disability issues in the country; he was a recent graduate of Kyambogo University in Kampala, Uganda, and held a degree in disability studies and rehabilitation. Wilfred, the translator, was also interviewed on a separate occasion and provided supplementary comments based on his knowledge of disability issues within the country.

Wilfred and I were the only individuals present during the semi-structured interviews in order to avoid discomfort and ensure the utmost privacy for study participants. All life-story participants, with the exception of Angel, had adequate knowledge of English, thus, Wilfred was not present during the collection of five of the six life-story narratives.

Prior to the interviews and focus groups, I notified study participants that our conversations would be recorded with their permission. Notes were taken during interviews and audio recordings were transcribed for further analysis. All individuals were given pseudonyms in my notes, in my own computerized records, and in this thesis. 


\section{Participant Observation}

Participant-observation is believed to a significant component within anthropological fieldwork and is noted as the "queen of anthropological field methods because of its combination of empathy and detachment which [allows] an ethnographer to alternate the native's point of view with an objective stance" (Robben 2007:445).

Participant-observation is a research strategy employed by anthropologists to assist them in familiarizing themselves with study participants and the field. In order for an anthropologist to better understand a foreign society, Hortense Powdermaker (1996:9) explains that:

The anthropologist has traditionally immersed himself in it, learning as far as possible, to think, see, feel, and sometimes act as a member of its culture and at the same time as a trained anthropologist from another culture. This is the heart of the participant observation method involvement and detachment. Its practice is both an art and a science. Involvement is necessary to understand the psychological realities of a culture, that is, its meanings for the indigenous members. Detachment is necessary to construct the abstract reality: a network of social relations, including the rules and how they function - not necessarily real to the people studied.

Through participant-observation, it is possible for an anthropologist to become both an insider and an outsider of a given society. "As an insider, the fieldworker learns what behavior means to the people themselves, [and] as an outsider, the fieldworker observes, experiences and makes comparisons in ways an insider can or would not" (Sluka and Robben 2007:2).

During the first month and a half in Uganda, I spent time familiarizing myself with Meba High School students and teachers, along with blind community members and various individuals working with a blind population. Through the use of exclusive participant-observation I was able to establish relationships with potential study- 
participants and better learn the difficulties that blind individuals are encountering in their schools, communities, society, and in their personal lives.

As an active participant and observer in the blind annex at Meba High School, I spent time daily with students, assisting them with lessons, while casually getting to know them and, at the same time, letting them get to know me. I participated in their activities, which included goal ball, ${ }^{3}$ music practice, socializing time; I even attended a couple of class lessons. During the infrequent opportunities I was given to attend class lessons, I was able to observe student-teacher and student-student interactions, as well as, class functions. In the evenings I recorded my observations and reflections in a notebook to make better sense of my experiences during the day. This period of participantobservation was critical in expanding my knowledge of both the field and studyparticipants prior to interviews.

\section{LIFE NARRATIVES}

A life narrative approach in data collection methodology can also be understood as a "person-centered ethnography" (Crapanzano 1984:954). A defining feature of a life narrative approach is that it "deals with aspects of an individual life. The structure, content, and sense of personhood and individuality that a life story conveys will be rooted in cultural conceptions of persons and individuals, and of what 'makes' a life and a story in more formal terms" (Monks and Frankenberg 1995:107). Furthermore, life stories and 'disability narratives' of impaired or disabled individuals are "valued tools in the investigation of personal experience" (ibid). Langness and Frank (1981:24) give the following reasons for a life narrative approach in anthropology:

\footnotetext{
${ }^{3}$ Goal ball is a sport for the blind (and sighted individuals who are wearing a blindfold). It requires players to use their auditory senses in order to prevent a jingling ball to pass beyond the goal line.
} 
(1) to portray a culture; (2) for literary purposes; (3) to portray aspects of culture change; (4) to illustrate some aspect of culture not usually portrayed by other means (such as women's view of their culture); (5) to communicate something not otherwise communicated (for example, the humanistic side of anthropology or, more typically, the "insider's" view of culture); or (6) to say something about deviants or other unusual cases.

Modern ethnographic accounts by anthropologists have attempted to "increase the voice of the other through more active involvement of research participants in the coproduction of ethnographic accounts, narratives, or texts" (Sluka and Robben 2007:19). In writing life history accounts both the researcher and the study participant are "presented together within a single narrative ethnography" (Tedlock 1991:69).

Life-story narratives were collected from five blind youth and two blind adults through lengthy unstructured and semi-structured interviews, providing a valuable window into their lives and personal experiences. Although two of the life narrative participants were adults, their interviews focused on their experiences during youthhood and the subsequent impacts it made on their lives. Of the seven life-story narratives, six are included in this thesis. The one youth participant excluded spoke very little about his personal life experiences, but included a wealth of knowledge on the contextual situation for the blind in Uganda. Information provided by this individual, Komogum, is used throughout the thesis as a background to various topics, and while his narrative is not present in this thesis, his voice is included. Interviews with life-story participants were conducted in a style similar to casual conversation, beginning with inquiry into the onset of their blindness and life-adjustments that were necessary had they not been born blind. Participants discussed growing up in Uganda as blind individuals, including their difficulties in society and school, relationships with family members, peers, teachers, and 
other blind persons. They further detailed negative and/or positive experiences they have had at home, in school and in society. Interviews covered social notions participants made toward personhood and ideas they have toward selfhood. Life-story participants discussed how family members, peers and society understand their blindness, how they treat them because of it, and the attitudes these individuals have towards their blindness. I further attempted to learn about their own perspective of their blindness, beliefs, concerns, coping mechanisms used when dealing with negativity from peers, teachers, family members, and the community, goals and aspirations for the future, and barriers they felt prevented empowerment and full integration within society. For the interviews conducted with the two blind adults, I excluded questions about their current experiences in school, as these were not relevant. Rather, I inquired into their experiences during youthhood and what life impacts those experiences have had. (A full list of questions used is available in Appendix A - modified questions are included for interviews with the blind adults).

\section{Focus Groups}

Focus groups "are in-depth group interviews" which "have several strengths that make them particularly useful for facilitating research that reflects the social realities of a cultural group" (Hughes and DuMont 1993:776). A focus group can reveal the views of a small consensus of members in society (Wilson 1997:211). Many scholars (Hughes and DuMont 1993; Smithson 2000; Warr 2005; Kitzinger 1995) discuss the benefits of groupmember homogeneity by including individuals in a focus group that come from similar social classes, pre-existing social groups, or similar backgrounds. When focus groups include individuals from pre-existing groups they "can re-create aspects of their social 
relations as participants exchange opinions" (Warr 2005:201). However, this does not mean that focus groups are naturalistic interactions between individuals, "but facilitating focus groups with people who are known to each other can generate interactions and discussions of 'real-life' scenarios that are not entirely contrived" (ibid). In such focus groups, participants may also be more at ease when discussing certain topics or issues that are not frequently brought up in regular conversation in society (Warr 2005:202).

Taking into consideration the benefits of group homogeneity, I constructed two focus groups of similar categories of individuals in society that functioned as a forum for discussion. One focus group was comprised of five individuals who were either direct relatives of a blind person or their close friend. The individuals participating in this focus group included: a mother of a blind person, a daughter of a blind person, a wife of a blind person, a nephew of a blind person, and the best friend of a blind person. The discussion included topics such as personal and social perceptions of blindness, community treatment and reaction to the blind and their impact, major challenges in Uganda for the blind, some of the challenges faced for being in close association to a blind individual, and a discussion on gender within disability issues was covered. (For the full list of questions see Appendix B).

The second focus group was comprised of four individuals who were all working with blind individuals in their jobs. There were two teachers, one college graduate who studied disability and rehabilitation in university, and a director of the disability section in an Orphanage/Primary School. The discussions covered participants' initial interests in working with blind youth, how their chosen profession has affected their life within the social community, and personal challenges they have encountered within their line of 
work. They detailed challenges and barriers that the blind are currently facing in Uganda, and gave explanations as to why these challenges exist in the country. Participants described the structures and institutions that exist in the country to benefit the blind, critiqued how those structures functioned, and talked about their feelings on their workings. Lastly, they discussed opportunities open to blind individuals living in the country, and examined the role that education has in the life-quality of a blind person. (For the full list of these questions see Appendix C).

Information collected from focus groups was quite beneficial to this study because it provided a background in understanding the social, political, and economic situation for the blind in Uganda.

\section{SEMI-STRUCTURED INTERVIEWS}

To better grasp the experiences of blind youth in Uganda, semi-structured interviews with older blind community members, from the ages of 35 to 60 , were conducted. The only pre-condition for participants was that they were either born blind, or had become blind at a young age, thus experiencing youthhood as a blind person. I purposely chose not to include interviews of individuals who had become blind at an older age as I wanted to understand how blindness affects an individual over a longer period of time, from youthhood and beyond. Furthermore, the social context of individuals who become blind at an old age is slightly different from that of those who are blind earlier in life. I met all the older blind community members who participated in this study at a gathering which takes place at St. Joseph's Orphanage/Primary School monthly. I interviewed a total of four individuals: two males and two females. Interviews began with questions about their personal backgrounds, then moved to questions dealing 
with the social context of blindness, and ended with questions focusing on political and economic issues within Uganda. (For the full list of these questions see Appendix D).

A semi-structured interview was also conducted with a board member of the National Union for Disabled Persons in Uganda (NUDIPU), Frank, who is also a teacher of a primary school in Uganda. I was introduced to Frank by one of his former pupils, Malcolm, who is a life-story participant. I met with Frank at the NUDIPU head office in Kampala during my last week in Uganda. Our conversation lasted for about 40 minutes and topics ranged from his experiences with NUDIPU, his thoughts on its functioning, his knowledge of access and opportunities open for the blind, his opinions on the functioning of government programs for the blind, and his experiences as a primary school teacher. (For the full list of these questions see Appendix E).

\section{LiMITATIONS AND CONSTRAINTS}

One of the limitations of this study is that when interviewing blind youth I only included individuals who were currently enrolled in educational institutions; I did, however, interview a few older blind community members, who did not previously attend any formal schooling. Therefore, many voices remain to be heard or expressed, especially the several hundreds of blind youth who are not visible in society and remain ignored at home. Including these individuals in my study would have further enriched it; however, accessing blind youth kept at home is nearly impossible. Primarily, it is often that society-members are unaware of the existence of these individuals in many cases.

The exclusion of these voices from this study was an initial concern of mine. I was worried that I would not be able to adequately detail the lives of blind youth in Uganda without including blind youth withheld from attending educational institutions. 
However, even blind youth who were enrolled in schools were facing numerous social barriers in society. Moreover, to the benefit of this study, older blind community members, most of whom did not attend school, were able to detail some of the economic and social difficulties they have faced from being kept at home as a result of lack of education and/or social stigmas. Although these interviews do not act as a replacement for the voices of blind youth at home, the stories contribute to a better understanding of the general difficulties of blind youth.

A further limitation of this thesis is that it only includes the voices of blind individuals, their supporters, and individuals who are closely related to them. There is a lack of insight on perceptions of disabilities from outside community members who are unfamiliar with any blind person. Although there are interviews included in this thesis from sighted community members discussing cultural perceptions of blindness and speaking about the present barriers in the country for the blind, further insight into disability issues may have been possible by including the voices of sighted individuals without relation and support of blind people.

Additionally, during my visits to Meba High School, I was constrained to spending my time in the annex with the blind students. I was only able to attend two classroom lessons; therefore, information I collected about the way the classroom functioned was primarily from information provided by blind students, and very little from personal observations. Also, if given more time in Uganda, it would have been beneficial for this research to include the voices and perspectives of youth who were not blind in order to fully understand difficulties during youthhood and how they are related to the difficulties and struggles of blind youth. 
Furthermore, in terms of the semi-structured interviews conducted with elderly blind community members, this study is limited to the knowledge of blind activists in the community who attempt to attend monthly gatherings for the blind. Factors like transportation, access to information, and extent of socialization in the community pose barriers for most blind individuals to reach such gatherings; therefore, these voices are also not included. Lastly, the geographic reach is limited to one district in Uganda: Gulu.

\section{Data ANALYsis}

The collection of data and its analysis was accomplished through the use of grounded theory. The benefits of grounded theory are that it "offers a systematic method by which to study the richness and diversity of human experience and to generate relevant, plausible theory which can be used to understand the contextual reality of social behavior" (Hutchinson 1988:126 - 127).

Once I returned from Uganda, audio recordings from interviews with study participants were played back and transcribed verbatim. From there, the transcriptions were coded and grouped into similar themes that had emerged in various conversations with individuals. I focused on identifying similarities, differences, and overlaps within thematic categories. As further analysis of themes continued, theoretical backgrounds to study data were developed.

\section{Chapter Summaries}

Chapter Two begins by exploring the historical context of the study's setting by giving a relatively recent history of Gulu, Uganda and the Acholi ethnic group over the past few decades. Following this, an overview of the history of disability issues in Uganda is given from the era and influence of colonization to the disability movement in 
the late 1980s with the formation of the National Union of Disabled Persons in Uganda (NUDIPU). The second section of Chapter Two examines past collaboration between anthropology and disability, following an outline of theories and theorists.

Chapter Three begins with an introduction of the two focus groups conducted. It includes the questions asked and a brief summary of the dialogues. Following this, the social context of disability in Uganda is examined, beginning with common cultural perceptions and beliefs community members harbor of the blind. The examination of the role of the social world and its impacts on the lives of blind individuals continue as the chapter goes on to explore the social oppression of the blind in Uganda. In this section, I analyze how perceptions of blind people, as a liminal category in society (they are not seen as full functioning members nor are they removed), have contributed to their marginalization in society. This section is followed by an exploration of the current integration of blind individuals within society, the family, and educational settings. I then go on to examine differences in social opportunities and status between blind males and females. Finally, the chapter ends with a discussion and overview, arguing that blindness is a social construction and cultural perceptions of disability contribute to its formation.

Chapter Four introduces the six life-story participants and their personal narratives. Following their stories is an analysis of themes that arose during multiple interviews. The chapter examines the effects of social stigma in the lives of blind people. It further explores the use of communitas--a community formed by individuals facing social liminality together as a means of support--as a coping mechanism for stigma and marginalization in society (Turner 1969:96-97). The role of education and schooling, and 
the impacts on the lives of blind youth, is examined. The chapter ends with an examination on the relationship between disability and personhood and how this has influenced blind individuals' self-perceptions and ideas about selfhood.

Chapter Five looks at the political and economic issues tied to disability. The chapter begins by examining the relationship between poverty and disability in Uganda, focusing on how blind individuals' marginalization and social oppression have forced many blind people into chronic poverty, which further separates them from the rest of society. The chapter looks at blind individuals' access to education, employment, information, and health services - the degree of opportunity open to them and various factors that work as barriers. The role and workings of the Ugandan government and local leaders are also examined. This section explores various issues including misrepresentation, corruption, and misinformation by the government, and how these have contributed to blind individuals' disempowerment. The chapter ends with a discussion on the role of structures and institutions on social suffering.

The final chapter, Chapter Six, ends with a general overview and a summary of main study findings. Suggestions given by study participants are included, followed by a reexamination of the collaboration between anthropology and disability studies. Lastly, areas in need of further research are included. 


\section{CHAPTER TWO: BACKGROUND TO UgANDAN CONTEXT AND THEORY}

\section{ACHOLI CUlture AND History}

\section{Ethnic division and years of terror}

Uganda's history is both long and intricately filled with political unrest, war, and terror. Cheney explains that since Uganda's independence in 1962, Uganda has seen seven changes of government, all of which have been severely violent (2007:169). Much of the violence in the country is attributable to the result of ethnic division between people living in northern and southern Uganda. ${ }^{4}$

During the era of colonialization, the British reserved the introduction of industry and cash crop production to the south, leaving the north as a reservoir of cheap labor to be employed in the south. Consequently, the country became divided into productivity zones in the south and east based on the production of coffee, cocoa, cotton rubber, and non-productivity zones; the non-productivity zones primarily existed in the northern and western parts of the country and were mainly associated with unskilled labor (Doom and Vlassenroot 1999:7). However, this was not the starkest difference between the two localities; the most well-known division between northern and southern Uganda was in armed services recruitment. While northern Ugandans made up the majority of recruits for the army, southern Ugandans took on civil servant positions and their lands were targeted for economic development (Cheney 2007:169). The Acholi people, "far from being 'born warriors', were transformed into a 'military ethnocracy', a decisive step towards the formation of a proto-nation (Doom and Vlassenroot 1999:8). As a result, British colonial rule effectively created socio-economic divisions between northern and

\footnotetext{
${ }^{4}$ While there are a number of different ethnic groups found in both northern and southern Uganda, the Acholi ethnic group comprises the majority of the population in northern Uganda, while the Buganda ethnic group makes up the south.
} 
southern Uganda, which consequently led to the marginalization of the north and further growth and development of the south.

Milton Obote became the first prime minister of independent Uganda in 1962; during which northern Ugandans continued to primarily hold military positions in the country (Cheney 2007:169). Obote inherited an armed forces dominated by the Acholi, who viewed their profession of arms as their 'natural vocation' (Doom and Vlassenroot 1998:8). The Buganda, who were the largest ethnic group in Uganda, made up $16 \%$ of the population but only 5\% of the army; on the other hand, the northern Acholi and Langi made up $19 \%$ of the population and $61 \%$ of the army (Cheney 2007:170). Even though northern Ugandans were the most economically disadvantaged, they possessed and controlled the "instruments of violence: the armed forces" (ibid). This Acholi identity was essentially created by colonial powers. The Acholi were chosen to be the military backbone of the country and thus a separate culture and identity was born amongst them. This new Acholi identity is a key component in understanding the original tensions between northern Uganda and the rest of the country after independence.

Idi Amin became the military commander in 1971 after overthrowing Obote; once in power, he killed many Acholi officers and replaced them with ones who had ethnic ties to himself, primarily individuals from Lugbara, Nubian, and $\mathrm{Kakwa}^{5}$ ethnic groups (Cheney 2007:170). During his administration, Amin began to rearrange the power balance within the military by firing Acholi officers and in some extreme cases executing them (Ramos 2010:58). From the very beginning, every oppositional force found it necessary to use military might to argue their point of view (Doom and

\footnotetext{
${ }^{5}$ The Lugbara ethnic group lives in the West Nile region of Uganda; they are also found in Southern Sudan, along with the Kakwa people. The Nubian ethnic group is originally from Northern Sudan and Southern Egypt.
} 
Vlassenroot 1998:8). Amin took this much further than anyone else; he used the army as a tool to his advantage to defeat politicians in 1971. Although "Amin's regime indiscriminately tortured or killed just about anybody for whatever reason, Acholi officers were among those most likely to be targeted for murder" (ibid). Amin "launched a reign characterized by gross human rights abuses, and the torturing and killing of thousands: in 1977 Amnesty International estimated 300,000 dead" (Baker 2001:6). The Acholi and Langi, among others, were particularly targeted. Amin's regime became completely destructive until he was driven from power. Shortly after Amin, Obote returned to power in 1980 with the help of anti-government elements that had organized armed forces in Tanzania. Under Obote's rule, again Acholi and Langi soldiers began to reign over the military (Cheney 2007:170). During Obote's second rule, the country was predominantly Acholi-controlled. This was one of the worst periods of the country; Uganda witnessed a great deal of bloodshed and terror, and many in the country feared for their lives. Individuals who were living in Kampala during Obote's second ruling expressed that this period was "the worst period of oppression" the country had faced yet (ibid). From 1980 to 1985, Uganda experienced both excessive tyranny and anarchy. Obote's military ultimately attempted to punish and murder many of Amin's supporters and many others.

The political climate in 1981 was thus extremely unstable when Museveni's National Resistance Army (NRA) was established. Museveni believed there was no room in Uganda for the political entities that existed. He had no faith in the multi-party system and feared they would worsen ethnic tensions (Ramos 2010:58). Museveni and the NRA took power in 1986 and forced the Acholi to move north, causing a charged 
environment in northern Uganda that led to the formation of several rebel groups--most notably the Uganda People‘s Defense Army (UPDA) and Alice Auma Lakwena's Holy Spirit Movement (HSM) (ibid:59). Lakwena had great support from the Acholi; however, Lakwena's movement was destroyed by the new NRA government.

Several months later, Joseph Kony claimed that he had inherited Lakwena's powers. In the beginning, Kony's rebellion was largely spiritual and was not exceptionally violent relative to other African rebellions. However, in the early 1990 s, his Lord's Resistance Army (LRA) turned their guns on the Acholi and carried out large scale attacks on civilians (Cheney 2007:172). The Acholi witnessed large-scale devastation. Due to the LRA, approximately 500,000 to 800,000 people were living in internally displaced camps set up by the government in northern Uganda at the end of 2003 -over half of the Acholi population (Dunn 2004:139). Additionally, the LRA abducted as many as 20,000 children between 1990 and 2005 and had either killed them or forced them to serve as sex slaves or soldiers (ibid). Children were abducted because they were believed to be easier to mold and control. When children were abducted they were usually tied to one another and forced to march without rest or food; if they showed any resistance, they were beaten or killed (Cheney 2007:173). The LRA destroyed "the fabric of society and a generation of Acholi children, by abducting them and turning them into traumatized killers" (Acker 2004:343). Since the beginning of the conflict, it has been estimated that 66,000 children have been abducted from their homes into the LRA (Ramos 2010:66). In summary, the "execution of non-combatants, the abduction of children and adults for use as foot soldiers, sex slaves and porters, the rounding up of 
civilians in camps [totals at] 1,200,000 at the end of 2003" (Acker 2004:335-336). By the end of 2005, 90 percent of Acholi people were internally displaced.

\section{Northern Uganda after the war}

Under the authority of Museveni, the NRA attempted to restore and rebuild the "tarnished pearl of Africa." During this time, Museveni initiated a ten-point program to restore order, addressing corruption, security, and democracy; he stated that "those who emphasize ethnicity are messengers of perpetual backwardness" (ibid:8). Although unitary discourses were made in some sectors of the government, most of the population continued to view Acholi people unfavorably:

It is still common today for people in central Uganda to regard people from northern Uganda as backward, primitive and warlike. James Kazini, a non-Acholi and long-time member of the Ugandan army's high command, illustrated this tendency when he blamed all military violence on the Acholi. 'If anything, it is local Acholi soldiers causing the problems. It's the cultural background of the people here: they are very violent. It's genetic,' he claimed in an interview with Human Rights Watch. (Finnstrom 2006:204)

Moreover, the economic, political, and social marginalization from mainstream development of Acholi people is quite significant. The "proportion of households below the poverty line in the north when compared to the rest of Uganda is not only low, but actually increased from 1997 to 2000, in contrast to other regions" (Acker 2004:337).

As a means of coping from years of social torture, in addition to their continued marginalization, Acholi have shared communal experiences and rituals which "have helped to shape contemporary Acholi identity" (Finnegan 2010:437). Much of the past two decades, which have been primarily composed of terror and violence, have been "embodied in the Acholi cultural rituals," permitting them "to embrace their struggles in a less isolating manner" (ibid). Since disabled individuals in Ugandan society remain 
socially excluded, even from their own ethnic groups, they are unable to channel their pain and frustrations in solidarity with others, which has contributed to difficult lived experiences.

\section{HistoriCal CONTEXT OF DisabiLITY IN UGaNDa}

\section{Disability Prior to 1970s}

The historical processes and contexts of disability have influenced the social constructs of disabilities and disabled people. Many of the stereotypes and discriminatory attitudes towards disabled individuals have been formed and fostered over time by the dominant culture within historical colonial contexts (Dei et al. 2006:216). In the majority of developing countries, disability issues are bound intimately to a colonial past (Grech 2009:772). In the 1950s and 1960s, during the era of colonialization, disabled individuals living in Uganda were subjects of charity and institutionalization, which disconnected them from their families and loved ones. By keeping individuals with disabilities in institutions, religious and charity groups would continually remind disabled individuals that they were fortunate enough to be taken care of by them--rather than having to beg for a living on the streets (Kangere 2003:2). Additionally, disabled individuals were separated on medical grounds. Depending on the severity of their disability, some were locked away in institutions to 'protect' the general public; this was primarily the case with individuals labeled to be mentally ill (ibid). The inmates were separated from their families from long periods of time, and consequently became dependent on the institutions in which they lived. 


\section{Disability Movement ANd Constitutional REvisions}

Soon after Museveni's National Resistance Movement (NRM) came into power in 1986 (after many years of civil war), 17 disability organizations joined together in 1987 to form the National Union of Disabled People in Uganda (NUDIPU). NUDIPU, which was established during the UN Decade of Disabled Persons, is an umbrella organization through which new discourse on disability rights flowed into the country (Whyte and Muyinda 2005:293). Not only did NUDIPU provoke a new disability rights discourse, but it was a primary component in nationalizing discourse and advocating a Ugandan version of disability policy and politics. With its representation in the Constituent Assembly ${ }^{6}$ for the first time in 1995, NUDIPU ensured that disabled people and their rights would be mentioned within laws established for the country; specifically, it ensures "the rights of women, children, minorities, and persons with disabilities and requires the state to take affirmative action in favor of marginalized groups" (ibid). In Article 35(1) of the Ugandan constitution, amended in 1995, it explicitly states that "persons with disabilities have a right to respect and human dignity and the State and society shall take appropriate measures to ensure that they reach their full mental and physical potential."

The Ugandan Government not only declared the respect of disabled individuals to be necessary but has also made attempts for education to be accessible to all learners in the country-- including disabled individuals. The inclusive education of disabled persons was first addressed in 1996 within the Persons with Disability Act. This Act states that "an inclusive educational system is [one] where able-bodied children study together with children with disabilities. The schools should be accessible with wide door entrances,

\footnotetext{
${ }^{6}$ The Constituent Assembly is the legislative body that comes together in the constitutional convention for the purpose of drafting the constitution.
} 
ramps, accessible latrines/ toilets, and with a relatively flat environment. They should also have special teaching aids and facilities for PWDs [Persons with Disabilities] and special needs teachers" (Ugandan National Action on Physical Disability 2010:12). That primary objective of the Persons with Disability Act is to provide quality education to meet any learner's special and diverse needs. However, I argue that although attempts have been made by the Ugandan government to include blind individuals within society and educational institutions, they still remain marginalized and poorly integrated within these settings.

\section{THEORETICAL LITERATURE}

\section{ANTHRopology OF DisabiLITY}

Although anthropologists are not strangers to studying disability issues, they are underrepresented among disability-studies scholars. Anthropologists have continued to produce significant ethnographies of great relevance to the study of disability; however, they are not explicitly identified as works of disability scholarship (Whyte and Ingstad 2007:6). Kasnitz and Shuttleworth explain that anthropologists have remained distant from a commitment to helping develop disability studies as a genuine concentration within the social sciences, which, they argue, has been both a loss for disability studies and a lost opportunity for anthropologists (2001:23). There are many scholars who do not come from an anthropological background who make reference to cultural implications within disability issues, and there are many medical anthropologists who have not fully made a transition to disability studies. In the book Disability and Culture (Ingstad and Whyte, 1995), many of the articles engage in cultural issues within disability studies, written by scholars lacking anthropology degrees (Kasnitz and Shuttleworth 2001:27). 
Anthropology's unique approach in studying otherness and difference makes its engagement within disability studies not only beneficial, but necessary. Individuals are impaired if they experience or are perceived to experience physiological or behavioral statuses or processes that are socially identified as problems (Kasnitz and Shuttleworth 2001:20). The word in itself, disability, implies that the individual is unable to carry out a certain function; however, this is heavily dependent on societal conditions. Differently abled individuals who are provided with the necessary resources to allow them to carry out their daily lives are not disabled, because they are able to function in society independently.

Given that perceptions and understandings of disabilities are contextual, anthropology's unique holistic approach can benefit disability studies both methodologically and theoretically. By examining how people act, studying what they believe, and discovering the connections between their actions and beliefs, anthropologists can gain access into the world of others (Obbo 2006:160). Once acquiring this perspective and critical cultural understanding, anthropologists can enrich disability scholarship. Anthropological research conducted within specific local and cultural contexts can contribute to a disability-studies perspective that includes policy changes as a major goal. Kasnitz and Shuttleworth $(2001: 27)$ state that the three general objectives for the engagement and collaboration of anthropology and disability studies should be:

1) to further the understanding of the lives of disabled persons crossculturally 2) to improve the quality of life for disabled persons; and 3) to promote a mutual engagement and collaboration in research and curriculum development by anthropologists and other scholars looking at disability. 
When studying disability issues, it is necessary to move away from the clinic and to focus on the community. Cultural assumptions about abled and disabled bodies and their personhood must be understood in the context of individuals' day to day social interactions in order to benefit the lives of those being studied (Whyte and Ingstad 1995:4). An anthropology of disability should find inspiration in both the study of individual experiences and through discourse analysis (Whyte 1995:280).

Blind individuals are marginalized in Uganda because they have yet to be fully integrated within society and institutions. What we know about disability is that it is a process of exclusion and othering, which is created by the dominant group around notions of normalcy, functionality, and ability. It is not necessarily a negative attribute that individuals possess; rather, it is something that the dominant culture assigns to bodies that are seen to be different when compared to prevailing standards. While conducting crosscultural research on disability, the most basic question to ask is, "how [do] biological impairments relate to personhood and to culturally defined differences among persons" (Whyte and Ingstad 1995:10). Other important questions as mentioned by Whyte (1995) that should be posed include: Are disabled individuals valued differently within society than other members? How does having an impairment affect an individual's possibilities, opportunities, and citizenship? How does the culture indicate that those in the culture should act or feel towards persons who are categorized as disabled? What structures exist in the culture that facilitate the functioning of persons with disabilities? How do differences of gender, class, ethnicity, and sexual orientation figure in disability culture and understanding? Do people with impairments accept the construction of themselves 
that are offered or do they resist them? What are disabled individuals' subjective experiences?

Although anthropology has engaged in disability issues in the past, there is still a greater need for anthropological scholarship within this area. By understanding how disabled individuals are socially oppressed, excluded, marginalized, and, most importantly, the reason why: anthropologists can provide an emic perspective of disability issues within a culture, and can assist to improve the quality of life for disabled individuals. This can be done through the collection and presentation of voices and stories of marginalized individuals in society. Oftentimes it is these individuals who are overlooked in development projects and research inquiry. By focusing on the narratives of marginal groups in society, and presenting their findings in academic works, anthropologists are able to make important contributions to development projects in a given society within social, political, and economic realms by presenting insights from those who are often not seen or heard by development policy-makers.

\section{THEORETICAL FraMEWORK}

The historical context of disability in Uganda has shaped the thoughts and behaviors community members have toward blind individuals. The way the majority of society associates with blind people is discrediting of their true abilities. It has limited the life opportunities of blind individuals and negatively affected their lived experiences. These negative societal behaviors towards blind people are evidenced in Chapter Four from verbal narratives collected from blind youth. In this thesis, I employ different theoretical perspectives from various anthropologists and academics in order to make better sense of the difficulties the blind are currently facing. The different theoretical 
concepts incorporated include: stigma, liminality, communitas, personhood and selfhood, social suffering, and structural violence. These notions are fully explored within their appropriate contexts in various sections of the thesis, however, a general overview of each is provided in this section.

In the past, anthropological research on disability "has been conceptualized in terms of a relatively few theoretical notions, the most notable of which are liminality and stigma" (Shuttleworth 2004:264). Stigma can be understood as a discrediting attribute that distinguishes certain members of society based on differences. Stigma is formulated when social expectations placed on performance in society are not met, or individuals lack certain functions perceived as necessary to carry out daily activities. The study of stigma has "contributed significantly to understanding the socio-cultural construction of certain chronic illnesses and impairments" (ibid). In Chapter Four, I use Erving Goffman's (1963) theory of stigma to further examine personal lived experiences by blind youth.

I use the concept of liminality in Chapter Three to explore a permanent state the blind are categorized within. They are neither seen as fully functioning and contributing members of society, nor are they seen to be non-members. This liminal status places them in a position of marginalization and social oppression. I use Murphy et al. (1988) to explore the permanent liminal status of blind people, which is different from the use of this concept by many other anthropologists (e.g., Turner 1967; Reid-Cunningham 2009; Devlieger 1999; Ingstad and Whyte 1995; Striker 1999; Goffman 1963) who have described liminality only as a transitory phase. 
As society marginalizes blind individuals, giving them a liminal status, society simultaneously constructs their social identities and formulates ideas about their personhood. Personhood is the status of being a person; it is the self as a social entity, which is imposed by members in a society or community. The concept of personhood brings into question what makes a person in a given society. The development of personhood begins at birth, which is only the first step in the process of an individual forming his or her social identity. However, it is important to note that personhood is not just the feature of an individual, but rather, it is formed through their interactions in the social world. Personhood can be "understood as an outcome of power relations, as an unstable project subject to constant negotiation and debate" (Morgan 1996:63).

Significantly, many life-story participants described negative attributes that were placed on their social identities that limited different avenues of empowerment. In order to make sense of these associations, in Chapter Four I utilize a theory from Benedict Ingstad and Susan Reynolds Whyte (1995) which examines disability through the general theoretical lens of personhood.

The notion of communitas, which is a formed community of individuals facing marginalization or liminality in society together, is explored in relation to collected life histories of blind youth in Chapter Four. As a response to negative social perceptions towards them, the blind create bonds amongst themselves as a coping mechanism; this is done to create positive meanings of their blindness and ease difficulties faced in society. In order to examine how this is done, I employ ideas from Victor Turner $(1967 ; 1969$; $1985 ; 1992)$ and Carol Goldin (1984) who have done research on community formation amongst blind people. 
When examining structural violence and social suffering, I broaden my focus from the micro-level issues affecting blind people to the macro-level problems existing within the government. Structural violence can be understood as "social arrangements that put individuals and populations in harm's way. The arrangements are structural because they are embedded in the political and economic organization of our social world; they are violent because they cause injury to people (typically, not to those responsible for perpetuating such inequalities)" (Farmer et al. 2006:1686). I consider how lack of access to basic needs and resources has placed blind individuals in heightened rates of poverty and has made them a significantly vulnerable category in society. I explore how a critical medical anthropology (CMA) perspective can be useful when studying these topics, as it is influenced by political-economy. While examining these issues, I utilize theories from Paul Farmer (1996 and 2006) on structural violence, Arthur Kleinman, Veena Das, and Margaret Lock (1996) on social suffering, and Merrill Singer (2004) on the application of critical medical anthropology in theoretical research.

\section{CONCLUSION}

The theoretical concepts employed in this thesis assisted in making sense of my research findings after transcribing interviews and focus group discussions with study participants. I will further examine the theories briefly discussed in this chapter alongside the presentation of my research findings in the subsequent three chapters (Chapters Three, Four, and Five).

The immediate chapter to follow, Chapter Three, presents and analyzes information collected from focus groups with friends and family members of blind individuals and working professionals in the field of disability. Discussions with these 
individuals covered a variety of different topics, including: social perceptions of disability, the liminal and marginal status of the blind, their integration within society, the family, and educational institutions, and issues of gender amongst blind people. An overview of each focus group discussion will be given, followed by an analysis of themes. The following chapter will then close with a discussion on the social construction of disability, while considering past anthropological debates within this area. 


\section{CHAPTER THREE: SOCIAL CONTEXT OF BLINDNESS IN UGANDA}

\section{INTRODUCTION}

In order to gain a more complete perspective on the social complexities for the blind in Uganda, two focus groups were conducted. The first focus group included five friends and family members of blind individuals: ${ }^{7}$ Derrick, Diane, Beth, Lillian, and Amanda. Derrick has a blind uncle; Diane's closest friend is a blind woman; Beth has a blind daughter; Lillian has a blind husband; and Amanda has a blind mother. All individuals identified themselves as a primary caregiver for their blind friend or family member. All focus group participants were currently cohabitating with a blind individual at the time of the focus group and had also been involved in the blind individual's life for more than 20 years. Although initially unfamiliar with one another, the parallel backgrounds that the focus-group participants had with blind individuals made the group discussion flow easily and without force, as participants realized they had many similarities from their past and current situations.

Participants for this focus group were recruited at a monthly gathering at St. Joseph's Orphanage/Primary School in Gulu for blind community members. The individuals who were included in the first focus group were accompanying a blind individual to the gathering. All individuals present at the gathering were informed about the focus group, and participants were recruited based on their relation to the blind individual. A goal of this focus group was to include varied perspectives of experience; therefore, all individuals had a different relationship to a blind person. The focus group lasted two hours; questions and responses were given in Acholi, which required the

\footnotetext{
${ }^{7}$ Although some of these five individuals had seen each other before, none of them had spoken with one another prior to the focus group.
} 
assistance of a translator. Focus group participants traveled to my place of residence, which is where this focus group was conducted. Areas of discussion that were covered focused on personal and social perceptions of blindness, including how they believe their blind friend or family member acquired their blindness. Community treatment and reactions to the blind and their impacts were discussed, in addition to the treatment they faced in society for being in close association with them. The focus group also covered major challenges in Uganda today for blind people and challenges the caregivers are currently facing. Lastly, a discussion of gender within disability issues was covered.

The second focus group included four individuals ${ }^{8}$ who were currently working with blind students and community members: Odon, ${ }^{9}$ Albert, ${ }^{10}$ Wilfred, and Samson. Odon and Albert ${ }^{11}$ worked in the blind annex at Meba High School. Wilfred ${ }^{12}$ was a recent graduate of Kyambogo University with a degree in Disability and Rehabilitation. Samson worked in the special needs and disability section of St. Joseph's Orphanage/Primary School. Since all individuals knew each other prior to the focus group, their conversation was very relaxed, and their remarks constructively built on one another. The focus group lasted a little over an hour and was conducted in English. Focus group participants traveled to my place of residence, which is also where this focus group was conducted. Participants began the conversation describing their initial interests in

\footnotetext{
${ }^{8}$ Since there are very few disability workers in the country, all individuals were familiar with one another prior to the focus group and were relatively good friends. Of these four, Odon and Samson have been trained in special needs education.

${ }^{9}$ Odon considers himself to be visually impaired because he uses glasses to see. Although he has perfect vision with his lenses, he went through schooling as a partially blind student in an annex. He has complete knowledge of Braille and the functioning of an annex.

${ }^{10}$ Albert participated in the life story interview in Chapter Four.

"Odon and Albert who work together in the annex have known each other since they attended school with one another at Meba Primary. Odon was 2 years ahead of Albert.

${ }^{12}$ An interview with Wilfred was also conducted in private at a separate time. Wilfred was also the individual hired to be my translator for interviews.
} 
working with blind and disabled individuals, and how their chosen profession has affected their life within the social community. Next they detailed the challenges and barriers that blind people are currently facing in Uganda. Additionally, participants gave explanations as to why these challenges exist in the country. Participants then discussed their own personal challenges within their line of work. Participants described the structures and institutions that exist in the country to benefit blind individuals, critiqued how those institutions are currently functioning, and talked about their feelings toward institutional workings. Lastly, the focus group ended with a discussion about the opportunities open to blind individuals living in the country; participants additionally examined the role education can play in the life-quality of a blind person.

The subsequent section includes the discussion that took place with friends and family members of blind persons, followed by the discussion with workers in the field of disability. Following the sections covering focus group discussions are current issues that exist within the social context of disability in Uganda. Topics examined include: perceptions and beliefs of blindness; marginalization in society; integration of blind people within society, the family, and educational institutions; issues of gender within disability; and the problems of disability amongst youth and young adults.

\section{Focus Group: FriendS AND FAMILY}

\section{Topic 1: Perceptions of BLINDNess}

The first topic posed to focus group participants concerned their personal perceptions of blindness and how they believed their friend or family member became blind. Both Beth and Derrick acknowledged blindness primarily as a medical condition. Beth used an example of her daughter's experience with measles to justify her response, 
explaining that her daughter became blind as a repercussion of late treatment for her sickness. Derrick's response supported Beth's; he explained that he had met many individuals who only became blind after being struck with a poorly treated illness. While both individuals accepted medical explanations for the cause of blindness, they did believe to a small extent that blindness could also be brought on by witcheraft.

Diane, Lillian, and Amanda did not accept medical explanations of blindness; they primarily believed blindness was caused by another's act of witchcraft or as punishment by god for a parent's sin. Diane considered sight as the most important sensory organ and believed that losing it could only be punishment for bad behavior. Diane explained that her friend became blind because the mother did not follow necessary traditional guidelines during pregnancy and was hence punished via her daughter. Lillian attributed her husband's blindness to witchcraft--performed out of jealousy--after he landed a high-ranking government position. Amanda also believed that jealously caused her mother's co-wife to perform witchcraft against Amanda. She explained that her mother's blindness began right after visiting the home co-wife's home. Diane, Lillian, and Amanda agreed that blindness could be a medical condition, but that it is always initiated by witchcraft.

\section{Topic 2: Social Reactions to Blindness and Blind People}

The second topic presented to study participants was in regards to examples and personal experiences they have seen of how community members have treated their blind friend or family member. Participants were further asked how they believe it has affected the life of the blind individual they know. All participants mutually agreed that some people are severely negative toward blind individuals. Participants explained that in most 
cases community members are reluctant to help a blind individual if they see him/her struggling in society. If a community member witnesses a blind person in the process of accidentally harming him or herself, by walking into a danger zone for example, they usually will make no effort to rescue or assist. Participants discussed amongst themselves different ways in which they had witnessed society members react to blind individuals. They expressed that in all cases, community members limited their association with blind individuals as much as possible. Beth gave an example of her blind daughter walking through town in need of directions; when the daughter asked another individual for help, the individual responded with harshness towards her, asking who she thought she was talking to, before walking away. Diane gave an example of her blind friend who attended a funeral and prepared a meal to bring. As soon as it was discovered that a blind woman had made the meal, the food was thrown away and was no longer served to the guests. Participants explained that negative treatment from society occurs on a daily basis, mostly through the hurtful things community members say. Derrick explained that his blind uncle at times would be walking down the street minding his own business when suddenly someone would yell abuses at him from the side of the road.

Participants felt the main impact that community members' reactions had on the lives of the blind was isolation. They explained that Acholi people enjoy spending time laughing, joking, and talking together as a community, but blind people are never a part of such social time. They explained that people have too much fear towards the blind, which makes it difficult to enjoy their company and be 'easy and free' with them. Derrick explained that blind people live very lonely lives because they spend the majority of their time indoors without anyone who cares about them or supports them. Other participants 
agreed with Derrick's statement that blind individuals are not seen as part of the community, and as people who can make important contributions to it; therefore, they are ignored and left out.

\section{TOPIC 3: Social TREaTMENT TOWARDS CAREgIVERS OF THE BLIND}

The third topic posed was concerned with focus group participants' personal experiences and examples of how community members have reacted or treated them for being closely associated with a blind person. I further asked them how these treatment have affected their own lives and social, political, and economic positions in society. Every individual in the focus group expressed a degree of stigma and isolation that came with their association to a blind person. Diane, who is the only individual in the focus group that is not related to a blind person, explained that she is constantly faced with community members asking her why she wastes her time in a friendship with a blind person, as they believe she will never gain any benefits in that relationship. Beth explained that her social stigma is the same degree as her daughter's. She expressed that many individuals in society and some in her own family believe she is the cause of her daughter's blindness. This attitude has caused her to experience a strong degree of isolation and social stigma, and to often be overlooked and left out of community decisions and meetings. Derrick agreed with Beth's feelings of being removed from the community. He went on to give a personal example of visiting a hospital. When he went to inquire about a medical service from the front desk receptionist who was familiar with his blind uncle, he was turned away and told not to bring 'that stuff' there. In other words, Derrick was turned away because of being related to his uncle, which implies that by this relationship, Derrick also carries the burden of being perceived to be affected by 
witchcraft. The implication of this behavior from medical support staff towards community members who have a blind individual in their family is that regardless of the degree of education individuals will acquire to became professionals in their field, including their knowledge of medical conditions that cause blindness, they can still be influenced by customary and traditional beliefs that say blindness is a cause of witchcraft.

Amanda admitted that when she was looking for work, she faced some negativity from employers who were familiar with her mother. Lillian explained that she is also as isolated from the community as her blind husband. Lillian is never invited to any functions, mostly because they believe she will bring her husband with her. Participants shared feelings of isolation from society and discrimination that affected their potentials in various ways. They considered blindness to have a strong effect on social relationships and social status not only for those who are blind, but also for themselves.

\section{TOPIC 4: Challenges AND BARRIERS}

The fourth topic posed to focus group participants was in regards to their personal views on some of the biggest challenges and barriers facing blind individuals currently in Uganda. They were then further asked about some of their own personal barriers for being closely associated with a blind person. Participants discussed various barriers that prevent blind individuals from thriving in society. The first area they discussed dealt with environmental barriers, explaining that it is impossible for a blind person to move about without having a white cane ${ }^{13}$ to help guide them, but "the blind do not have white canes to move around the town; if they have the cane and they are properly trained, they will have the ability to move around and become more a part of the community" they said.

\footnotetext{
${ }^{13} \mathrm{~A}$ white cane is used by blind and visually impaired persons as a mobility device to assist in moving through their environments.
} 
Participants also explained that the majority of blind people do not have access to these items; there are very few blind individuals who have acquired white canes from NGOs working in the country.

The second area brought into the discussion was family barriers. Derrick explained that when he and his uncle were in the process of working on an incomegenerating project to raise and sell pigs and chickens, they were constantly told by family members that they are wasting their time. The family shunned their activities and was unsupportive of their efforts. Diane explained that her friend's family has been a major barrier in her life. When it comes to improving her life opportunities, the family does not see any benefits in investing in the education of their blind daughter. They believe it is a waste of money, and as a result Diane's friend did not have the opportunity to go to school.

The next issue discussed was social barriers, which included negative perceptions and discrimination. Focus group participants concluded that the social understandings of blindness contributed to blind individuals' lack of inclusion in society, schools, and ability to find employment. The last barrier the group covered was institutional barriers. Participants explained that many individuals working for blind persons (i.e. local and national representatives) have personal motives for profit gain and could not care less about assisting blind citizens: "If the blind are sent money from NGOs, it is mostly pocketed by district leaders; the blind do not usually receive the money" (Derrick).

Participants identified two areas that present challenges to blind individuals. The first challenge is a lack of education and knowledge: "Most of the blind do not have knowledge or ability. They have not gone to school so they cannot go look for work. 
Also, they do not know their options, so they are unable to participate in social, economic, and political activities" (Beth). Participants went on to explain that a blind individual's lack of knowledge contributes to their ignorance on what can be done to mobilize themselves: "They are not aware of what is happening or what options they have" (Beth). The second issue the focus group members identified was lack of support. They explained that blind people are not supported from any direction. None of them could recall any government or organizational support for personal initiatives their blind relative or friend received. They explained that a lack of community and social support has acted as a barrier to being integrated into society, to access education, and to find employment.

Focus group participants agreed that the two areas that present the most challenge for themselves, as a close relative of a blind person, are negative social treatment experienced in society and their own lack of knowledge. They felt unaware of channels they could access to help improve the lives of their blind child, husband, friend, uncle, and mother. Derrick explained that it would be beneficial for caregivers to be educated in how to lend emotional support a blind person, as well as to be trained in technical concepts, such as the correct way to guide the blind person when walking together. The other focus group participants reacted very positively to this suggestion, and expressed that they, too, would feel a small degree of training would make a huge impact on the support they could provide.

\section{TOPIC 5: BLINDNESS AND GENDER}

The last topic covered in the discussion was concerned with focus group participants' knowledge about the differences in experience between blind females and 
blind males. All participants agreed that there are significant differences between the experiences of a blind male versus a blind female. They explained that blind males are always the beneficiaries of government initiatives, if those initiatives actually reach the ground. They acknowledged that blind males are more likely to be educated, as well as to find employment: "If you want to see how bad it really is, you only have to look at the amount of blind girls in school compared to boys. It is less than half" said Beth.

They went on to discuss the double discrimination blind women face in society. Focus group participants that had a female blind friend or relative (Beth, Diane, and Amanda) explained that much of what is known about the challenges blind people are facing in the country are significantly intensified for the blind women they associate with. Beth explained that her daughter, who is currently finishing her last year in school, has not once been approached by a respectable man. She explained that most of the men who are interested in being with her daughter are either disabled themselves or have their own problems (i.e. drunkards). Diane explained that the man that her friend is married to is also blind, acknowledging Beth's comment that respectable sighted men will not marry blind women. Amanda said that her mother currently does not have a partner, as most of the men who had been in her life had left her. The focus group explained that the position of inferiority blind woman are placed in makes them vulnerable to rape and to men taking advantage of them. They were all in mutual agreement that gender is a major issue for blind women topics.

This focus group conducted with friends and family of blind individuals was significant in outlining some of the social problems facing blind people in society currently, notably, the beliefs community members hold towards blind people, their 
marginalization in community, social, and family life, and issues of gender within disability. The second focus group conducted, which included working professionals in the field of disability, centered on topics that included personal experiences in their profession and feelings they had about necessary improvements. The discussion then went on to broader topics, which included their knowledge about challenges and barriers facing blind people in Uganda today and structures and institutions that are made to assist in the integration and function of blind individuals in social, political, and economic life. Study participants were asked to include their personal thoughts, experiences, and relevant examples throughout our conversation.

\section{Focus Group: Workers With BLIND PeOPle}

\section{Topic 1: Working Professional with Blind People}

The first topic posed to study participants was concerned with understanding their initial interest for working with disabled persons and further inquired into how their chosen profession has consequently affected their life in social, political, and economic terms. All focus group participants had chosen to work with disabled individuals based on personal reasons and past experiences. Samson explained that his son was born deaf, which propelled his interest to work with disabled children. Wilfred had two cousins who were disabled: one was deaf and the other mentally handicapped. He explained, "Life has not been easy for them, so when I found out there is a degree I could take in Uganda, I wanted to make a difference." Additionally, Odon had perfect vision with corrective lenses but he went through formal schooling in an annex to learn how to read and write braille because many of his closest friends were blind. Albert is blind himself and, therefore, believed he had a deep understanding of the difficulties blind people encounter 
in Uganda, which was why he wanted to work within this field: to continue helping young blind individuals reach their full potential.

When the participants spoke about how their professions have affected their lives, Samson, Odon, and Wilfred raised a common issue: their work had brought on many challenging and overwhelming situations in their personal lives. Albert, however, explained that the work he does is quite plentiful, and he seemed quite content in his position. Wilfred explained, "When you are working with people with disabilities, there is not much money; you are mostly sacrificing to help others." Odon added to Wilfred's comments by stating the work he and Albert do in the annex is double that of other teachers, because of the extra time they spend transcribing students' assignments, even though they are not paid any more than the other teachers, he explains this further by saying:

Most qualified teachers run away to greener pastures; they look for better paying work. Special needs teachers are suppose to get incentives to get this extra education, even better pay, but what ends up happening is we take on more work, and our pay is not different. Qualified teachers usually will go on to do what they see as better things. They prefer to look for better places, to become head teachers, to serve on boards, or to go on to higher offices. Our work is too much. (Odon 21/09/2011)

Samson and Odon both hinted at an interest in looking for new areas of work. Samson was in the process of getting a new degree in development studies at Gulu University. $\mathrm{He}$ explained that negative attitudes toward him happened on a daily basis. Moreover, when he first chose to go into this line of work, he was left by his wife because community members told her she would continue to produce disabled children, because of their deaf son. He explained: "Even up to now, I have old friends of mine who will come visit me in Gulu and tell me I am working in the wrong place." 


\section{TOPIC 2: CHALLENGES AND BARRIERS}

The second topic presented in the focus group questioned study participants' knowledge of pressing challenges and barriers blind people are currently facing in society. Due to the extended knowledge of these issues and prolonged background working with blind people, I further asked them to explain what they attribute the cause of these challenges has stemmed from for the blind.

Focus group participants were in agreement that there is dire need to improve the current situation in Uganda for the blind. Samson explained that blind people are "facing serious problems" because they are "socially, economically, and politically lagging behind the rest of society." Participants discussed the relationship of disabled individuals with poverty and dependency, explaining that it is a cycle from which they are unable to break free. One area they all agreed needed serious attention was blind individuals' education. Participants felt that not only did the blind need to be given more support to continue their education, but there is also a desperate need to improve conditions for them within educational facilities.

A barrier they identified as preventing them from accessing these venues of success was, in part, the negative attitudes from society: "People still hold negative attitudes toward the blind because they think they are a result of witchcraft so they face severe discrimination, which prevents them from participating in activities that can empower them" (Wilfred).

\section{TOPIC 3: NECESSARY IMPROVEMENTS}


The third topic posed to study participants was concerned with their opinions on areas within their profession they saw as lacking in order to assist blind people in reaching their full potential in society. I further asked them about areas they saw had been making positive contributions to the lives of blind individuals. Focus group participants agreed that they felt their work to be a step in the positive direction; however, they all felt that improvements were necessary in their line of work. Samson explained, "I know if I was not doing this job, there would not be someone who could come and take my place right away. That is why I have been doing this difficult work for over six years now." The same was true for Odon and Albert, who, although they worked excessively hard to transcribe documents for students and derived no extra benefits, were relatively happy to make contributions to the enhancement of their students' education. Wilfred has worked in many different fields - from studying mobility issues within disability to working on sports integration for blind youth. He also described his position to be one where he is able to provide disabled individuals a degree of optimism and hope for bettering their lives and their situations.

The improvements participants felt were necessary in their line of work varied but they could be placed in three categories: (1) development and access to more resources; (2) further emotional and psychological-support training for their positions; and (3) greater support from the government, schools, and the general public. All participants felt that the work they were doing would be far easier if the other members in their workplace and community supported and assisted them. Odon and Albert identified the stigma that existed from other teachers within the high school where they worked as a main component. They explained that teachers would return graded assignments to them at a 
leisurely pace, and even acted negatively towards them at times. Samson went on to contribute to Odon's and Albert's statements by saying “[some St. Joseph's workers] relate to me with stigma and are very unhelpful. When a blind person comes here, they will just tell him you wait here for Samson; they will not ask him what do you need, or why you are here. Not knowing they may not be here to see me, they will just tell him to wait around until I come." Of the three areas the group identified needing improvements for them to help blind individuals reach their full potential, support was the most important. They expressed that support was necessary from all realms of society, beginning with the family and including community members and government officials.

\section{TOPIC 4: STRUCTURES AND INSTITUTIONS}

The last topic posed to study participants was in regards to their knowledge of structures and institutions that currently exist in the country working on behalf of blind people. I further asked participants about their opinions towards the way these institutions are functioning and reasons behind why they believe them to be running poorly. Participants began by discussing the role of the Ugandan government in the integration of blind individuals within society and school. They all agreed that the government was ineffective on behalf of the blind. As Albert explained, "A negative perception towards blind individuals is even in the government. They think, why spend more money on qualified teachers to better educate the blind students when their education is useless anyway." They felt that, across the board, all institutions were lagging in the services they provided to the blind, including educational institutions, health facilities, and government programs. 
The main factors they identified as the root causes of these problems were governmental corruption and negative perceptions toward people with disabilities. They believed that the initial negative perceptions toward individuals with impairments created carelessness on the part of the government to invest time in money developing services for the disabled. Therefore, not only are schools and other institutions lagging in resources to assist in the studies of the blind, but the blind are rendered somewhat immobile because the government does not want to invest money on white canes. All participants felt that there was a lack of government support to improve conditions for blind people.

The following sections of this chapter examine the social context of blindness in Uganda, using information raised in both the focus group discussions and semi-structured interviews. The first section discusses the cultural perceptions and beliefs that community members have of blind individuals.

\section{Social Perceptions ANd Beliefs}

An explanation for the cause of disability is rarely limited to a biomedical level of understanding for many individuals interviewed in this study; it is usually influenced by various societal perceptions and beliefs. If a biomedical explanation is accepted, it is not always sufficient. The most popular explanation for blindness in Uganda is witchcraft. Since many Ugandans dread witchcraft, a blind person and their whole family might be socially stigmatized from this belief that links blindness to witchcraft. Such a perception affects blind individuals because it restricts others' social interaction with them out of fear or suspicion. 
In some cases, the cause of blindness is attributed to witchcraft motivated by envy. For example, a family who distinguishes themselves from others through their prosperity can be affected by others' envy or jealousy, which may lead to witchcraft being practiced against the family and this could result in a child who is disabled. Study participant, Komogum ${ }^{14}$ identified his visual impairment as the result of witchcraft, to which he also attributed the fact that it, limited his circle of social relations:

People fear to walk with me sometimes. They feel so much shame. Sometimes you think you should not be alive because you are denied everywhere. Before I became blind, I was so popular and I had everything...then people started to get jealous of me; one night this woman did some witchcraft and threw something in the fire that got into my eye and made me blind. (Komogum 14/08/2011)

Another cause of blindness is attributed to disobedience, specifically by the mother; women who do not adhere to food proscriptions and sex taboos during pregnancy are believed to be at risk for delivering a blind child. These taboos include eating certain foods or abstaining from others. A child born with a disability might signify to the parents that they did not respect the food taboos. In the following quotation, Odon talks about his mother's failure to adhere to food restrictions during his childhood, which caused him to have a visual impairment:

If you are born as an Odon (with your feet first, rather than your head), your mother should not eat food cooked with salt at her home. She should not eat salt until the child is old enough to perform certain ceremonies. When you go eat salt in your home then the child will become blind. Many people say this is the cause of my blindness. Up to now, people from my home-village blame my mother. (Odon 21/09/2011)

\footnotetext{
${ }^{14}$ Komogum is a blind student in his fourth year at MHS. He is 17 years old and became blind from measles at age two. Information from our conversation will be used throughout this thesis. Komogum shared many insights about the social, economic and political situation for the blind in Uganda. However, because he did not speak extensively about his personal life, his story was not included in the Chapter Four life narratives.
} 
In these instances, it is not only the blind individual who is socially stigmatized. The burden is carried by the associated family member as well. Odon's mother is thus perceived by family members as a disobedient and defiant member of society; her social status has been hindered because she did not respect certain food beliefs during the pregnancy and childhood of Odon.

When the cause of the disability cannot be understood, god as an absolute and unknown force remains the only possibility and the final cause of blindness. Focus group participant, Diane, explained, "Blindness is the worst thing that could happen to someone. Every other sensory organ would be better to lose than sight. I think blindness is a punishment from god for a past sin, only because you are losing the most valuable thing you have to live well." Historically speaking, "loss of sight has always been considered as the greatest misfortune to befall an individual next to loss of life itself' because "sight plays such a dominant role in the activities of men that it is universally considered the most important of the human senses" (Lowenfeld 1975:244).

Since sight is seen as such an important sensory organ, loss of it is considered to be the "most disabling affliction that puts the individual into an inferior position as compared with those who can see" (Lowenfeld 1975:244). The inferior status a person is given because they are blind, or associate with blind people, was discussed by focus group participants. Derrick explained, "An uneducated sighted person feels far more superior to an educated blind person. Blind people have a constant reminder from society telling them that they are blind; community members do not let them forget their place in society." Study participants felt as though being blind had a strong influence on social relationships and status because it could automatically hinder an individual's status in 
society, and affect all persons who associate with the blind. Therefore, friends and relatives of the blind are equally stigmatized and socially shunned in society.

Since punishment from god is a common explanation of blindness, blind people to some extent are seen as being moral failures. For this reason, blindness is not believed to be something that necessarily happens 'by chance' to just anyone; rather, the person who becomes blind is "responsible for his own blindness" (Monbeck 1973:11). The negative perceptions community members hold toward individuals they see as moral failures are evident in the interactions they have with them. As focus group participant Beth explained, "People try to limit their contact with the blind and try not to interact with them. If a person has a child, they will not let their child play with a blind child, fearing that the child will acquire the impairments from being too close to them."

Since the explanations of blindness are so grave in nature, it is almost impossible for a blind individual to disassociate himself from his blindness. His blindness is his/her featured characteristic, and an identifying trait that society will relate to the person's social identity. The blindness is not as much a problem as "it is the way in which the blindness becomes the primary area of identification in interaction, pushing back into relative insignificance other roles which the blind person may be prepared to fill" (Lukoff 1960:23). This was a common theme found in the life story narratives detailed in Chapter Four. Many felt they had multiple identities to be chosen from, which included being a student, a son or daughter, a musician, or even a member of a certain church; however, unlike their sighted counterparts, their blindness was their most eminent and defining feature. The way members of society deal with the blind is on the basis of their 
impairment. Blindness, before anything else, takes precedence in evaluating a blind person's social identity.

\section{LIMINALITY AND MARGINALIZATION}

The stigmatized status of the blind in Uganda explains the adverse reactions community members will have toward them. The negative treatment some community members practice include: the use of derogatory and offensive language; marginalization; social exclusion from community gatherings and functions; physical abuse, including throwing stones at the blind; and, hindering their empowerment and self-worth. As devaluing as these treatment are, they are seen as socially acceptable and rationalized because of the believed assumptions of what blindness is and how people acquire it.

One way to understand why and how blind individuals are marginalized in society is through the deviance-liminality-stigma model (see Figure 1). This model explains that a person with a disability will encounter three stages of social responses to their impairment. In the first stage, a blind individual begins to acquire his or her social identity as a 'deviant' because he/she is labeled as disabled or different. Within a Ugandan context, the disabled person is viewed as a moral failure for past sins or the sins of parents; hence, disability is a punishment from god. The blind individual is, thus, no longer seen as a 'normal' person, but abnormal. This perception of people with disabilities hinders their social status and place in society. Consequently, their deviant status places them in a liminal state, where they are no longer seen as a fully functioning citizen of society, but as a dysfunctional, helpless individual. They are given multiple, poorly defined corporal and social inscriptions. No longer being seen as whole persons, the disabled are stigmatized in society and presented with negative reactions in their 
social setting (Reid-Cunningham 2009:105). Disabled individuals have "often been isolated, made invisible, seen as contaminated, avoided, without status, and economically marginalized" (Shuttleworth 2004:365).

In Uganda, the blind face a complexity in finding their social place in society; they are not included in its workings, yet are not fully removed either. Focus group participant Amanda explains the social situation for the blind: "the blind are not allowed to be active in society; they are not believed to be a part of the rest of the community, so they are never included in activities like everyone else." The way society deals with individuals who are seen as different is in terms of their perceived social position, and because the blind are in a liminal state, they are not seen as a member of the collective community. "Liminal people as the word denotes, are at a threshold. They are marginal to society--poised perhaps to enter, but still outside its boundaries" (Murphy et al. 1988:237).

While many anthropologists and academics (Murphy 1990; Turner 1967; ReidCunningham 2009; Devlieger 1999; Ingstad and Whyte 1995; Striker 1999; Goffman 1963) refer to liminality in terms of a change in status that occurs during a period of time, I refer to liminality as a permanent state an individual can take on from birth. A liminal period is "one of ambiguity and paradox" and creates a "confusion of all the customary categories" (Turner 1967:97). In this period, a liminal person loses his/her social classification and is not given a new one (ibid:96). While feelings of ambiguity and confusion do still exist, being in a perpetual state of liminality is the result of a lack of acceptance by others (Murphy et al. 1998:237). Moreover, Murphy et al. (1998:241) 
argue, "disability is not a thing, it is a juncture within a process-an arrestment in life history that is dramatized in a rite of passage frozen in its liminal stage.

Since liminal people are not clearly categorized and do not have a definite social place in society they are not given normal social reactions. Their liminal state and lack of social classification makes them seen by the community as dangerous people (Nicolaisen 1995:40). Focus group participant Derrick further explains, "If you see a blind person selling charcoal on the side of the road, you can just walk right past them. People fear to buy from the blind and will not support their business. They are not sure how to handle a blind person so they just stay away from them."

The countless "taboos that apply to the liminal person limit their social interactions and maintain their structural invisibility," making them socially oppressed and marginal in the workings of society (Willett and Deegan 2001:140). Moreover, this fixed liminal state creates a "social space that is no longer betwixt and between in a journey ending in a new social position" (ibid). Their disability, which places them in this permanent liminal status, restricts their full participation in society because they are not seen as valuable and contributing members. Turner compares states of being an outsider to the betwixt and between statuses of liminality, explaining that members of each of these states exist at the margins of society--occupying its lowest social positions (1969:125). Individuals who experience unending liminality take on a "permanent outsider status" (Willett and Deegan 2001:144). The social perceptions of blind individuals in Uganda have played a significant role in their marginalization in society, schools, and even in their own families. The following section will examine the integration of blind individuals within each context: society, schools, and families. 


\section{INTEgRaTion OF BLIND PERSONS IN UGANDA}

\section{SOCIAL INTEGRATION}

As evidenced in the preceding section, the blind are socially marginalized in society and are not fully integrated. Many of the negative treatment and understandings about blindness work as a hindrance in integrating blind individuals into society and limit social interactions with blind people. Their lack of integration, in part, shapes their disability. The blind are struggling "for integration into society in terms of economics, equal rights and equal opportunity" (Peters 2010:592). Focus group participant Derrick explains, "They feel isolated, discriminated; they feel lonely. Wherever they go, people will not accept them. Society ignores them." Disabled individuals, who are the least integrated within society, are also the least likely to partake in organizations for the disabled, let alone take on leadership positions (Yeo 2001:25).

Study participants felt the barriers that existed with respect to integrating the blind into society were amongst negative perceptions from community members, in addition to lack of access to mobility devices. Community members' negative perceptions toward blind people contribute to their isolation from society and negatively affects their selfesteem, confidence, and life quality. Life-story participant Bashir explained one situation where he attempted to integrate himself with fellow community members on a bus:

When I was on a bus, they were discussing something and I felt like answering and adding to their conversation, but they all got quiet. You wonder why this is, what kind of negativity do they have? They feel as though you contributing to them or talking to them is shameful and not normal. And yet, if it was anyone else there wouldn't be a problem. (Bashir 05/08/2011)

Negative feelings toward blind individuals keep them marginal from society and its workings. One major contributor in the social treatment toward the blind comes from 
the core of family life. The following section examines the integration of blind individuals within their families.

\section{FAMILY ROLE IN INTEGRATION}

Families play a critical role in the integration and socialization of their children in society. Their attitudes and interactions have significant impacts on a blind child's lifequality and ideas of self-worth. In a relevant study conducted on social sources of adjustment for the blind, it was found that the incorporation of a blind individual within a family is associated with potential social independence. Blind individuals "who are involved in family decisions also tend to be more independent" (Lukoff and Whiteman 1973:159). Moreover, positive family interactions for a blind youth and child, beginning at an early age, help in establishing "the social-role patterns for the blind person in the larger social context" (ibid).

With the difficulties and anxieties associated with youthhood--in terms of formalizing an identity, establishing peer relations and progressing towards independence - family tensions toward blindness intensify already difficult situations for blind youth. Study participant Wilfred communicated the importance of optimistic family attitudes on a youth's positive development in society, and on their social relationships with external community members:

If the family is not supporting the child, most community members will think: why should I help support the child when their own family is not helping them? Discrimination begins at the core of family life. Family members are ignorant to the potentials of a blind child. They have so many channels of things they can do, but they are unaware of the policies and options open to them. (Wilfred 16/07/2011).

As important as familial support can be to a blind child, in most instances children are neglected by his or her parents due to embarrassment from a loss in social status and 
social stigma. In parts of Africa, a child is the main source of a family's pride; therefore, a disabled child is one to be ashamed of, and so they are not taken to school or included in society (Abosi 2007:198).

Parents played a significant role in deciding and forming the futures of blind study participants who were born or became blind at an early age. In most cases, the schooling of a child is often determined by their parents. This can be problematic in situations where parents do not believe there are any benefits in educating a blind child. Parents who did not believe education would enhance the life-quality of their child, or that they would ever see long-term or even short-term benefits from it, are unwilling to make personal and financial sacrifices to promote the education of their blind child. While a blind child's prospective is enhanced through education, many traditional and negative beliefs and feelings from parents toward their blind child, as well as public stigma toward the parents, will cause a blind child to remain at home and prevent him or her from being taken to school. This has major impacts on their lives, as they miss opportunities to not only empower themselves through their education, but also to socialize with others in the peer group. This exposure to society has significant benefits for blind children and their peers, as they learn to work harmoniously in a shared setting. These opportunities are diminished if a family is unwilling to invest in their blind child, or if a negative perception towards disability consumes them with far too much shame to bring their blind child into society. Primary school teacher Frank ${ }^{15}$ explains the position many parents of blind children have towards sending them to school:

Most parents do not want to take blind children to school because they feel it is useless. They think... why waste money on a blind child, what will they do after all? If it is a girl, I expect her to get married, but who will

\footnotetext{
${ }^{15}$ Frank is a blind teacher of a primary school in Uganda. He is also a board member of NUDIPU.
} 
marry a blind girl. I expect my child to find a good career when they are finished with school and pay me back, but how will a blind person find work? So why pay for such a child? These are most of the questions parents raise, and for this reason blind students stay at home and live destitute and meaningless lives. (Frank 29/09/2011)

Clearly, the life opportunities and integration of a blind child are heavily

influenced by the family. However, due to the social stigma that is associated with having a blind child in Uganda, families feel it necessary to keep their child at home and away from the rest of society. In some cases, families will hide their disabled child due to the extent of shame that comes with having such a child (Alamillo and Diaz 2012:92). In other cases, they may even deny the existence of such a child if asked by fellow community members (Yeo 2001:7). A relevant study conducted in Uganda on disabled children and their caregivers found that children who come from homes with parents who believe their disability is shameful and should be hidden from society are often more affected with loneliness, isolation, and peer abuse (Hartley et al. 2004:174)

Notably, in most cases amongst my informants, disability was seen to occur through the mother, either by the woman not prescribing to traditional customs or by passing on disability to her child from her past sins. Therefore, the burdens that disabled children in Uganda face are believed to fall on the shoulders of the mother, and she is often held responsible for bringing 'the curse' to the family (Lwanga-Ntale 2003:13). It is not unusual for a man in Uganda to leave his wife soon after producing a blind child with the rationalization that he will find another woman who is not associated with sin, and will not produce disabled children. In situations such as these where familial tensions arise, feelings of resentment toward a child's disability are common (Hartley et al. 2004:178). 
The negative understandings of how individuals become blind, in addition to the social pressures of maintaining a respectable status, amongst other things, including poverty, can keep a blind child hidden at home. When they remain at home they "often get last access to food and other basic resources," which are prioritized for their siblings, and when they become ill, "they are often not given treatment but left to the "hand of God"' (Yeo 2004:9). In these instances, their difficulties are intensified, contributing to a lowered sense of self-worth. Study participant Wilfred explains the problems of keeping blind children at home:

To be sincere, the blind are not given food, and if they are given food they are given very little. Because the family thinks they cannot dig, they cannot fetch water, they cannot clean, and they cannot cook, not knowing if they can do it very well. But they do not give them the opportunity, and since they do not let them contribute to household work or go to school, they barely feed them. These people are ignorant about the lives of the blind and their abilities. (Wilfred 16/07/2011)

Isolation and negligence brought on by disability can be attributed to a lack of acceptance and understanding on the part of the family, hindering the social development of a blind child. This study reveals that the nuclear and even the extended family have considerable impact on the socialization, integration, independence, self-worth, life course, and life quality of a blind child.

The following section examines the integration of blind students within educational settings by examining areas that were described as barriers in offering a comparable quality of education to that of sighted students.

\section{INTEGRATION WITHIN EDUCATIONAL SETTINGS}

Education is a significant component in improving the life and status of blind individuals by opening up potential opportunities for them in the future, socializing them 
to the greater community and creating a sense of self-worth and empowerment amongst them. However, the problem that exists in Uganda today is that inclusive education for the disabled is still a work in process; although it has been established, it is not fully functional in most aspects. This has caused much distress in the lives of blind students, who wish to receive an equal level of education and treatment while attending educational institutions. Blind students communicated two areas that formed a barrier for their successful integration in school. The first is based on material aspects, as many of the integrated schools lack the proper resources necessary to properly educate the blind; and, the second is based on social aspects, primarily involving negative attitudes from teachers and peers.

Stress over a lack of resources to complete assignments was a common concern raised by blind students. Of all resources, there is a great need for Braille papers. Study participant, Frank, explains these difficulties:

Schools are yearning for Braille papers. Children will sit in class and learn from only listening without typing and reading notes. Not all schools can afford Perkins braillers and most of them are donated by NGOs. The last time the government bought these machines or supplied papers was in 2006; really... it has been a drop in the ocean. (Frank 29/09/2011)

Sometimes blind students will attend lectures without taking notes. Unable to study for their exams by reviewing their notes, they are forced to take exams without proper preparation. In another study conducted in Uganda within inclusive schools, there was a "lack of sufficient educational materials; lack of sufficient numbers of teachers trained in special needs education; high pupil-teacher ratios; and long distances between home and school for some learners" (Kristensen et al. 2006:140). Additionally, when it comes to library facilities, blind students do not benefit because the textbooks that are necessary 
are in print and not available in Braille. Blind students will request the assistance of sighted classmates to come and read to them from the textbook while they take notes. This, in itself, comes with its own challenges, as often times the sighted classmate will be unreliable and fail to make meeting times that may be critical for the blind student to catch up. This creates a relationship of dependency between blind and sighted students, which, without the efforts of others, makes their education unattainable.

Another area that is in dire need of resource development is mathematics. In Uganda, the country requires that disabled students have two years of mathematics. Unfortunately, this is the most difficult subject for them to follow as it includes many visual references. Teachers will often draw diagrams on the chalkboard, carelessly avoiding proper descriptions so the blind students are unable to follow. Frank explains the problems of mathematics for the blind:

There are no teachers who are qualified to teach blind students. In most cases you find a teacher gambling to teach or blind students gambling to learn. Most blind students get lower than 50\% in mathematics, which is a complete failure. But in most cases, it is not them to blame; the equipment to teach the blind is not there. How do you expect them to do well and understand when you are not providing them with the right educational tools? (Frank 29/09/2011)

Blind students explain that most of the problems can be addressed by schools investing in mathematics cubes that fulfill a tactile function, such as printing drawings and diagrams on braille paper, and through greater sensitization from teachers. Science is another issue; there are absolutely no resources available to educate blind students in any of the science fields, including biology, chemistry and physics. These subjects are not offered to the visually impaired and are completely left out of their curriculum. Consequently, the lack of resources needed for the education and empowerment of blind students is a severe 
obstacle that hinders their chances of achieving the same possibilities as their able-bodied counterparts. There is a significant need in Uganda to develop learning materials specifically books, charts, and audio and visual aids to enhance the education of disabled students, as many teachers feel that they are not properly resourced to handle the needs of all disabled children (Michael 2006:11).

Although the lack of resources has caused problems for blind students, the majority of them agreed that their greatest source of frustration comes from teachers and sighted peers. Extensive research conducted by Dei et al. (2006) on inclusive schooling within difference in Africa discusses how schools function as a mirror image to the rest of society; in doing so they usually reflect the "discriminatory, exclusionary, and stereotypical acts and attitudes that society exerts on individuals with disabilities" (Dei et al. 2006:211). The discriminatory attitudes and actions, which exist in a school environment, can harshly limit the educational aspirations and performance of students with disabilities, significantly limiting their right to equal access, educational opportunities and life-chances.

The attitude and behavior of teachers working with disabled students is a major concern in many parts of Africa; many continue to carry negative attitudes about fully integrating disabled children into regular classrooms. In a relevant study conducted on integrating disabled children in inclusive classrooms in Zimbabwe, 200 teachers were asked whether children with a range of physical disabilities should be in regular classrooms and if the teachers would teach in that class. The study revealed that $40 \%$ of the teachers interviewed, who were willing to integrate physically disabled children 
within their classrooms, would ignore the disabled child and do nothing differently to assist them (Barnartt and Kabzems 1992:140).

Sentumbwe (1995) gives an explanation as to why teachers have negative attitudes toward disabled individuals; she argues it to be due to teachers' ignorance and lack of knowledge about issues. For the most part, teachers remain conservative when it comes to dealing and associating with disabled students; they "prefer to keep children with disabilities at arm's length and pay lip service to their needs" (Abosi 2007:198). Study participant Wilfred explained how this takes place in classrooms in Uganda,

Even educated people still have negative attitudes toward the blind. Most schools you go to in Uganda, you will not be surprised to hear teachers telling disabled students they are a waste of time. "I have a 100 inside, you are only 1; I cannot waste my time with you." You, as a teacher, should have the patience to help the children. If a teacher asks a disabled student whether or not they understood the material from the lesson, and they say no, they will be caned for not paying attention. So, sometimes, you will even hear them tell teachers they understand the lessons when they do not have any idea. (Wilfred 16/07/2011)

It is not only negative attitudes from teachers that hinder the integration of blind students in the classroom; there is also a critical need for more special-needs teachers in the country who are familiar with Braille and working in inclusive settings. Wilfred explained that last year in the whole northern region of Uganda--which includes the major cities of Gulu, Kitgum, Lira, Arua, amongst other smaller towns, nearing a combined population of 8 million--only 2 individuals graduated with a degree in special needs. Study participant Odon explains this issue further:

There is a lack of teachers that are working with the blind students to help them in remedial assignments to make sure they are understanding or to sit with them and make sure that they are grasping the material. The work I am doing is far more than what I am getting paid for. Exams are not processed in time; while other students are receiving papers...the blind students have to wait. The blind students will take their exams sometimes not even 
knowing if they will ever receive them back. I have to transcribe the papers and give them to the teachers to grade. We are only two people that have the same amount of work as the other teachers; how are we supposed to manage this alone? But the school will not pay or invest in other specialneeds teachers, and mostly it's because there are not very many [teachers for blind people]. (Odon 21/09/2011)

If differently-abled students are to be fully included and integrated within educational settings, it is necessary for government and education authorities to be more responsive to their special needs. Funds should be allocated to develop the resources necessary in the education of differently-abled students, specifically Braille books and audio aids. Most importantly, attention should be given to training and developing the capabilities of those staff and teachers directly working with disabled students. Additional qualified teachers, who are specialized in counseling and emotional support, are also critical in the empowerment of blind students facing oppression and marginalization in society. Through these support mechanisms, a channel of communication must be kept open between visually impaired students and the support staff so that students can speak freely about their difficulties and challenges (Dei et al. 2006:224). If the development of these resources is not given the attention it deserves, no systemic transformative objective can be achieved. As study participant Wilfred explained, "Inclusive education is still a dream in Uganda; it has not yet fully taken place."

The difficulties blind individuals face when it comes to integration within their schools, families, communities, and society is further intensified for blind females, as they are already viewed as an inferior category in society. The following section examines issues of gender for disabled individuals in Uganda by presenting voices of study participants. 


\section{GENDER}

A salient topic that came up as focus groups and interviews progressed was the issue of gender when it came to disabilities. All individuals shared the view that the difficulties for the blind in the country are intensified for women. Study participant Wilfred referred to this happening as "double discrimination" for the reason that women are firstly discriminated against in society on the basis of their gender because they are considered to be secondary to men in all aspects of life, and secondly, based on their disability, which further extends social stigma against them.

Women have gender inferiority. Society thinks... "She is a woman, she is not worthy like a man," and then if you add blindness it is much worse. These are two very different problems and they are huge issues when you bring them on the table. Men facilitate all group meetings; only if a woman makes serious noise will they finally say okay now you can talk. Women are always the last option. The voices of women are not being heard, especially blind women. (Wilfred 21/09/2011)

The focus group held with workers of blind people explained that when it comes to disability rights and opportunities, in all cases, the individuals who benefitted from governmental programs were men. The primary reason was that groups created by the blind themselves, as a strategy to mobilize themselves and push for change, were run by men. They believed that the voices of women, especially blind women, would not be taken as seriously. On the rare occasion that the government did choose to sponsor an individual from the group by giving them chickens to raise and sell, or by sponsoring one of their children in school, it was always for the group leader, which meant that it was always a man who was chosen.

Interviews with blind youth and the focus group with friends and family members also detailed the perceived problematic issue of romantic relations for blind women. 
Study participants acknowledged the fact that blind women are greatly taken advantage of in society, especially by sighted men to fulfill sexual desires. Study participant Komogum describes this:

If you are blind and you are a woman, be careful, be wise. They call them a dumping ground. Men do and get what they want, and when they are finished they run away; it is more risky for girls. People consider you as someone to fulfill what they want but not mindful of staying with you or helping you. (Komogum 14/08/2011)

Sighted men willing to have sexual relations with blind women are almost always opposed to taking a blind woman as their spouse or publicly showcasing their relationship. Sentumbwe (1995:167) found a similar problem in Uganda while conducting a study on the romantic opportunities available to blind women. Her findings were that even if a blind woman had received some form of education in order to improve her social status, she still had reduced marital options. In other words, although a blind female may be seen as sexually desirable, making her a valid sexual partner, she "will normally not be socially acceptable as a potential housewife." A life story participant Othello explains this further:

For a blind girl to marry a sighted boy... it is not there and you will never see it. The community would say: There are many beautiful sighted girls out there, why would you go with a blind girl? Are you mad? They would just insult you. If a sighted boy goes with a blind girl it is only for sex, but they never marry them or take them as girlfriends. (Othello 09/09/2011)

The four blind females who participated in interviews admitted that they had encountered 'disturbances' from sighted boys and men to partake in sexual relationships. Referring back to the problem of double discrimination existing for blind women, men see blind women as a vulnerable group easy to take advantage of. This is partially influenced by blind women's lack of confidence due to continuous neglect and negative 
treatment in society. Life story participant Angel described with frustration that the sighted men in her life had always abandoned her. She explained that in the beginning, these men pretended to care about her, and she often believed that they genuinely loved her, but soon after she quickly realized that they were only with her to fulfill their sexual desires; they had no intention to commit to her in a prolonged relationship. The three occasions that she became impregnated by separate sighted men, each immediately disappeared from her life.

In comparison, Komogum explains the potential for romantic relations for blind men in relation to blind women.

It is easier for a blind man to get a wife than a blind woman to get a husband. Maybe you can even dig very well; maybe you can do everything very well except ride a bicycle. So those [sighted] women think his head must work. He has a room, he has everything, he can do anything, his mind works well, he talks well, and he dresses well so by that you can get a [sighted] woman. It will depend on how you conduct yourself. But for a [sighted] man to get a blind woman who has not been in school is very rare. (Komogum 15/08/2011)

This was a common theme that was expressed in interviews; blind men have the ability to take a sighted wife if they build a degree of credibility in society. This could happen through various means, including education; learning a craft that will provide an income; or finding small work that will supply enough money to sustain a family. However, the same is not true for women, primarily because what society defines as womanhood is contradicted for a blind woman but is not so for men. Masculinity and manhood are seen in relation of being self-sustaining, independent, and to be a provider; therefore, a blind man who is able to meet these standards is still believed to be somewhat of a viable partner or spouse. Womanhood, on the other hand, is associated with cooking, cleaning, and bearing and raising children. Blind women are believed to be 
incapable of fulfilling these roles, specifically raising children; literally 'looking' after them is thought of as impossible. Disabled women "face open or indirect suggestions that they are not really women" in most cases (Fisher and Galler 1998:177). A blind woman clearly does not have the same viable prospects as her blind male counterpart when it comes to having prolonged romantic relations with a sighted partner.

A common concern voiced by blind participants was the importance of developing the psychological and emotional traits of blind female youth in order to improve their confidence and sense of self-worth. In doing so, many expressed that the most common problems amongst female blind youth can be avoided: problems such as dropping out or being pulled out of school because of teenage pregnancy, or being taken advantage of by men seeking to fulfill their own sexual needs.

This chapter focused on outlining the social context of blindness in Uganda, notably how social perceptions and beliefs about blindness and blind people have contributed to their marginalization and lack of integration within society, the family, and educational institutions. Through interviews and focus groups with study participants on various topics concerning these issues, it became clear that many of the challenges and barriers blind individuals are facing in Uganda are more influenced by society than their blindness itself. In the following section, I discuss how blindness is a social construction which creates barriers for blind people in society.

Discussion: The Social Construction OF DisAbility AND its EFfEcts

Many anthropologists have identified disability as a socially constructed category (Armstrong \& Maureen 1996; Holzer et al.1999; Ingstad \& Whyte 1995; Susman 1994; McDermott \& Herve 1995). Social understandings of blindness and blind people in 
Uganda have contributed to the way in which blind individuals are integrated into society, how community members choose to associate with them, and the language they use when referring to blind people. The loss of sight itself is not as much of a hindrance to the visually impaired in Uganda as the "defined societal standards for normative bodies, behaviors, and role of fulfillment" (Reid-Cunningham 2009:107). Most of the difficulties disabled individuals encounter in society are not caused by their impairment; rather, they are brought on by "physical, social, economic, and attitudinal barriers that result in inequality" (Dunn et al. 2006:2). If society "treats a person as having a disability, the person has one" (Charlton 1998:8). Disability can thus be understood as a socially constructed category because the ideas, perceptions and understandings a society has of disabilities, and disabled individuals will differ from place to place depending on values given to certain bodily functions; therefore, accounts of experience from disabled individuals will also differ cross-culturally (Kasnitz and Shuttleworth 2001:20).

The standards that society sets for its members create problems of social exclusion, oppression and marginalization, which contribute to poor life quality for the blind. Thus, "disability has very little to do with any physical, mental, or sensory impairments, but it is a social definition of who is and is not valued" (Willett and Deegan 2001). The negative feelings and attitudes that community members hold for the blind are not innate, but are learned through "culturally prescribed notions about blindness shared by large sectors of the community" (Lukoff 1960:24). So individuals' tendency to react negatively towards the blind communicates much about the values of the society they live in and the normalized social reactions that are considered appropriate to have towards the blind. The negative treatment people practice towards the blind are socially acceptable 
and will take place in public spaces. The often cruel treatment community members practice are rationalized by the social understandings they have of the blind.

The social factors that set the stage for how individuals should feel toward blindness and blind people are created and learned over time by subsequent generations. Scott states:

The disability of blindness is a learned social role. The varied attitudes and patterns of behavior that characterize people who are blind are not inherent in their condition but, rather, are acquired through ordinary processes of social learning. Thus, there is nothing inherent in the condition of blindness that requires a person to be docile, dependent, melancholy, or helpless. (1969:14)

In Uganda, social behaviors and attitudes toward blind individuals have been in practice for several generations and are, thus, heavily ingrained in society and social thinking.

Consequently, the experiences of the blind are heavily shaped by social factors. An individual's self-perception and personal identity are "at the heart of his experience as a socialized human being" (Scott 1969:15). In other words, a person is not born with a specified identity; rather, his/her identity is created through various experiences as he is socialized in society. The essence of an individual's self-concept of himself/herself "largely consists of his perceptions of the evaluations that others make of him and particularly those others whose opinions he values most highly" (ibid). A blind person's self-perception, attitudes, beliefs, and feelings about who he/she is and his/her place in society are shaped through his/her experiences in society, through a process of socialization. Therefore, being aware of the social context of disability is fundamental in understanding individuals' personal experiences with blindness, an issue which is further explored in the following chapter. 


\section{CHAPTER FOUR: LIFE STORIES AND THEMATIC ANALYSIS}

\section{INTRODUCTION}

There is limited literature that outlines the personal stories and first-hand experiences of disabled individuals within an African context, much less specifically on blind youth in Uganda. The fact that these narratives are mostly overlooked in most academic research makes evident that these voices are rarely being considered or listened to as they should be. The stories included in this chapter present an interesting perspective of the struggles and difficulties of four blind youth and two blind adults, who have grown up in Uganda as members of a blind minority group that is stigmatized in society. Although I had the opportunity to speak with and/or interview ten blind youth and six blind adults, I chose to include these six individuals based on specific factors. The reason for my choices included these individuals' unique and various perspectives and experiences with blindness as a youth and/or during their youthhood; I took into consideration gendered perspectives, social upbringing, level of completed education, their current situations, and the cause of their blindness. Additionally, the amount of time I was able to spend with each of these individuals, and the amount of information they were willing to share with me about their personal situations, also influenced which life stories I chose to include.

The stories of these life-story participants are all significant and worth sharing, as they allow the voices of socially suppressed individuals to express their personal views, and, for most of them, to speak for the first time about how Ugandan society has, in different ways, disregarded them as valued members in society. The stories of these six life-story participants were significant to this study because of the amount of information 
they shared about very personal details from their upbringing and experiences as a blind person, while other blind individuals I spoke to were more apprehensive to talk about such intimate information. Bashir's perspective presents a narrative of an individual who had been blind since almost birth, while Malcolm presents a narrative of an individual who become blind during youthhood; significantly, both Bashir and Malcolm were faced with family barriers after becoming blind, while only receiving emotional support from their mothers. Othello's story was important to this study as it presented a narrative of an individual who became blind from the years of war and political upheaval that took place in northern Uganda; his story is one of reintegration as a blind individual after years of absence from school and society. Albert's story was important to this study because his narrative introduced a perspective of someone who had spent the greater portion of his life blind, went through formal schooling, graduated, and later became employed at Meba High School, where he once attended. Moreover, unlike most others, Albert's family was quite supportive of him throughout his life, following his blindness; his story highlights the benefits that come with education, and the importance of familial support for blind individuals. Angel's story was important to this study as it presented the perspective of a female, who had been blind since birth, who had unsupportive family members, and who was unable to finish formal schooling. Lastly, like Angel, Evette's narrative was important to this study as it also presents the perspective of a blind female and the difficulties that accompany it. However, contradictory to Angel's story, Evette's narrative is of a blind female who has had the ability to go through formal schooling, and is almost finished. 
During interviews, my primary research objectives were to understand: who these individuals are and what relationship exists between their blindness and personal identity; how they see themselves, and how they believe society sees them; and, how they cope with negative social situations. During interviews with the two adult participants, Albert and Angel, I further inquired into experiences from their youth and the impacts it has had on them today. The information gathered from life stories reveals numerous problems within Uganda when it comes to the integration of blind individuals in schools and society. Certain reoccurring themes and topics emerge in many of the interviews that were held with blind individuals. These themes, which include stigma, communitas, education, and ideas of personhood/selfhood, are examined in further detail below in the thematic analysis section.

As mentioned earlier, this study was carried out in Northern Uganda, in the town of Gulu. Therefore, all participants interviewed and included in focus groups were living in Gulu during the summer of 2011. Additionally, these six life-story participants, in one way or another, have a relationship with Meba High School. Bashir, Malcolm, and Othello were attending MHS; Albert had attended MHS, went on to university, and then was employed at MHS; Evette attended MHS for four years, and then went on to teacher's college; and Angel was a prospective student of MHS after completing her primary education at Meba Primary; however, due to her inability to pay her school fees, she was never able to go. The following section provides a description of Gulu town, and Meba High School, in order to provide more information about the local space in which some of these individuals have spent a great portion of their lives. 


\section{Gulu Town ANd Meba High School}

Gulu, Uganda, where this study takes place, is located in Northern Uganda, which is primarily populated by the Acholi ethnic group. Gulu has one main university campus, Gulu University, which is not equipped with the necessary resources to provide education to blind high school graduates or other categories of disabled persons. Therefore, blind students finishing their high school education in Gulu usually attend Makerere University or Kyambogo University, both in the capital city of Kampala. The main town, which is surrounded by smaller villages, has three main hospitals: St. Mary's Lacor Hospital, Gulu (Regional) Hospital, and Gulu Independent. There are seven main secondary schools in Gulu; of these, Meba High School is the only high school that has the resources to accept blind students. Meba High School, a Protestant-based boarding school in Gulu (see Map 1), has a little over 1,200 students enrolled on their campus. There are 11 blind male students, and one partially-blind female student, making a total of 12 blind students enrolled at MHS.

Since February 2010, the non-profit organization, Invisible Children, has taken considerable interest in rebuilding MHS, because of damages to the property from the civil war (discussed in Chapter 2). Invisible Children has also assisted with improving the capabilities of teachers. During my field study, there were three Invisible Children volunteers working on the campus, one of which had been placed in the school's blind annex ${ }^{16}$ to provide extra assistance to the annex's supervisor.

\footnotetext{
${ }^{16}$ The annex is a resource room for blind students on the MHS grounds. Blind students are able to complete school assignments and prepare for their classes on their Perkins Braille machines here.
} 
Tuition for one whole school year at MHS costs a family the equivalent of 180 Canadian dollars. ${ }^{17}$ Most of the blind students in the annex were sponsored through external contributions from various NGOs and independent sources. Of the 12 blind students attending, there was only one whose tuition was paid for by his parents. The annex was equipped with one Perkin's brailler for each student, a shelf of reading materials, novels, and textbooks that had been transcribed into braille or donated from various NGOs, and a separate office for the annex teachers. The two teachers in charge of the annex had access to one computer, a scanner, and a Braille printer, which was located in the interior of the office. Beside the shelf the computer and devices sat on, there was one small table where the two teachers could sit and transcribe student materials into Braille (see Figures 2 and 3). In the main room of the annex, there were eight desks, so a couple of students were forced to share the space. The annex was a designated area for the blind students to come and study, and where they completed their class assignments using their braillers (see Figures 4-6).

Meba High School was first founded in 1914, but it did not start accepting blind students until the mid-1970s. It is one of six functioning secondary schools in the country that has the resources and capabilities to provide placement for blind students. It offers lessons from years one to four in O-level (Ordinary level) and years five and six for Alevel (Advanced level). Students who complete their O-level education with good grades move on to A-level training. Students enrolled for their A-level primarily intend on attending a post-secondary institution or university. Others may choose to go on directly

\footnotetext{
${ }^{17} 180 \mathrm{CAD}$ is equivalent to 460,000 Ugandan shillings. The average salary of a teacher in Uganda for one month of work is around 500,000 shillings. For families that are not employed within a formal sector, this amount is very difficult to pay.
} 
to a teacher's college upon completing their O-levels. Of the 12 blind students at MHS, there were six students in their O-level and six in their A-level.

Female students uninterested in going on to their A-level after completing their Olevel education had the option of attending a teacher's college. There was one teacher's college in Gulu, Christ the King, which did not have adequate resources to fully integrate blind students. However, they continued to accept blind students on their campus; at the time there were two blind female students enrolled.

While this school profile provides a necessary backdrop for better understanding the situation of blind students in Gulu, Uganda, the following section of blind youths' narratives and their lived experiences contributes to a more expansive and holistic knowledge of the current challenges the blind are facing in the country.

\section{Life NARRATIVES}

This section is a compilation of narratives that present stories of six different individuals' personal experiences as a blind individual in their communities, family, schools, and in general society. Their unique stories and experiences shed light on some of the challenges facing blind people in Uganda today. To begin the life narratives, in the following section I present study participant, Bashir's personal story.

\section{BASHIR}

Bashir was 17 years old at the time I met him; he was the first born son to his parents, who later divorced with his father choosing to remarry. Bashir explained that his father and mother began dating very young and his mother gave birth to him while his father was still a student in university. Having complications with his sight since birth, when Bashir was struck with measles at the age of four, he was left permanently blind. 
Since he was still fairly young when he became blind, he had no recollection of sight. He could not explain what colors looked like, nor did he have any memory of his family members' faces.

He explained how difficult it was for his mother to bear a child, who, at such a young age, lost his sight. Bashir's loss of sight brought along social stigma to his family, but affected him and his mother the most. While Bashir's father's situation was seen with disappointment, in the inability of his wife to bear a son that would be able to make his family proud, his father was not tied to Bashir's blindness in the same way. It is not unusual in Uganda, to hear of a father leaving his family and blind child, because he believes that blindness does not run in his own family and is solely brought on by the mother of the child. Community members looked at his father's situation with sympathy, and his mother's with apprehension and judgment. Bashir told of his paternal uncles often going to his father to persuade him to leave his mother in order to find himself a woman that could give him healthy children, and one who did not carry the burden of a social stain, such as blindness.

Bashir talked about his blindness as a defining feature in his life and identity, not something he saw as separate or disconnected from who he was. Bashir told me that around the age of five or six, he began to understand who he was. At such a young age, Bashir's ideas of his selfhood began to form around his experiences and treatment by others. When describing his situation of growing up in Uganda as a blind child, Bashir told me,

My childhood was not good. Children were mean, someone who wants to tease you will come with a cane and beat you and run away. So I was not happy when I was a child. In most cases, my fellow classmates would lead 
me to the bush and think it would be funny to see how I would make it back.

Children in Uganda who are not in school spend most of their time doing housework or farm work. Most families who are poor or struggling financially rely on the household contributions their children can make by working for them. Bashir, unable to perform laborious farm work like most other boys his age, was deemed useless by family and friends, and was excluded and isolated from other boys in his age group. Bashir explained this by shedding light on reoccurring events of his childhood, noting that, "When people would go for farm work, they would lock me inside and tell me to remain there. I could not help anyone in any way. I knew I was useless to everyone. All I thought was that I was born to live for a short time and die soon after."

Most of Bashir's negative treatment in society was brought on by the perceptions that community members had of his blindness, which primarily was believed to be a punishment from God. He explained this in his own words.

Most of the time I find that people understand my blindness as a form of punishment or a curse brought on by mother, not something that just happened by chance. Many believe that I have a sealed fate... what I mean is that when someone bears a blind child, it cannot be understood as happening from a loose reason. It is always understood as a form of punishment brought on by something you did to someone, or to a group of people, and, because of this reason, people fear you, and they treat my mother and me differently because of it. (Bashir 05/08/2011)

Bashir spoke of people, whom he considered to be friends, who would avoid walking with him in public areas because they feared ruining their own social positions. This type of societal thinking heavily contributes to a blind individual's experiences in the social world. 
Societal understandings and actions towards the blind greatly influence many factors of blind people's lives and life chances. Bashir's parents, who were young, had community members come to them to question repeatedly what use Bashir could be to their family. Although very difficult for them, they chose to overlook outside advice and decided to put Bashir into school for the first time ever when he was eight years old. Being able to attend school for the first time was a highlight in Bashir's life and by far his most valued personal experience. "That's when I saw a future for myself. Older blind students, in higher grades, would come and talk to us, give us confidence, and tell us not to see ourselves as helpless. They told us when we study hard, and read hard, we can be very important people. I began to rejoice, it was the first time I had ever really been happy." Bashir valued the opportunity to be enrolled in an educational institution, as he knew many other blind youth in the country were not as fortunate as he was; yet, he still felt as though much needed to be improved within the country in order for him and other blind youth to be more successful.

Bashir explained that even though he was in school, his problems still remained. Friends of his parents came to inquire about how he was managing in school. "I always just sit back and wonder why this is happening and I ended up drawing a conclusion. Other people are tall like me, other people are black like me, why do I appear different from others? So, I started to believe people relate everything to my blindness, because I am the same as others in every other way." Of all his critics, he explained that his stepmother was the worst of all. She continuously told him that he is useless to the family, he is nothing and never could be, and she wondered aloud why his father "wastes money on [him]." Bashir is in a position where he constantly has to prove himself to 
others, that he is a valuable person and that he has much to offer to society once he finishes his education.

It is not just family and outside community members that focus on Bashir's blindness, but it was something that is always on his mind as well. He explained this feeling by saying, "I always think to myself: I am Bashir, I am blind, so I should excel and make this blindness appear whiter and whiter so people in society, everywhere, even at my parents' place, will not think of me as less. I always work hard to appear a bit different." Bashir attempts to 'lighten' the burden and social stain brought to his family and himself caused by his blindness. By excelling in academics, he is proving his value and worth to the rest of society who may question it, and thus he is bringing his abilities to the forefront of his character, so that his blindness is in the background.

However, certain occurrences at school make it very difficult for Bashir to do well. He told me about the thoughtlessness of his teachers in the classroom, who often used the chalkboard to give explanations, while he sat in class for an hour unable to understand anything the teacher was discussing, as he or she pointed to diagrams drawn on the board. If seeking help outside of class, teachers made it clear that he was a waste of time, and any effort they put in assisting him would be a waste of theirs. So he relied heavily on the assistance of his sighted friends to assist him on course materials, but this was a challenge in itself.

Bashir's story is significant as it reveals the effects of social stigma on the life of a blind youth. It describes how notions of devalued personhood -- by defining an individual in terms of their blindness -- impacts their own self-perceptions and ideas about their selfhood. His story further highlights that education is not only valuable to blind youth in 
raising their morale and confidence; it also works as a socializing agent. Through education, blind youth are able to give each other mutual support, form bonds with one another and even with their sighted counterparts. Like Bashir, Malcolm also narrates the benefits of education in terms of self-development for the future and peer support from other blind students.

\section{MaLCOLM}

Malcolm was the second born of four children. At the age of 12, Malcolm contracted meningitis, which caused him to go into a coma for nearly two weeks. Once he awoke, he realized that he had permanently lost his vision. "Let me explain it in the situation of a book" he said:

I had to close one chapter and open another. So, I opened another chapter which I had to transform a lot of things, and adjust to a lot of things. I had to even think different. I had to change everything in my life at that point. I lost myself. I could not know where to go or where to start. Everything I had prepared had to be put aside and I had to start building a new life because I had already built my life up to that point, now I had to start to build this one. (Malcolm 13/09/2011)

Malcolm detailed the heavy toll his blindness has taken on his emotional and psychological health. Nearing the age of 13, and going through a transitional period where he is no longer seen as a child, but rather a young man, his blindness brought great disorganization into an already challenging time in his life, causing him to question his own identity, self-worth, and potential opportunities for the future. I asked him what seemed to have been the most difficult aspect for him during this phase in his life. He admitted that having to relearn everything was difficult, and the negative perceptions from society members were unbearable, at times. However, without hesitation he responded, "the hardest part was the lack of love from my father...it was not there. After 
I became blind, my father's love became less and less - this is when I began experiencing psychological torture. Remember, I was young, I could not handle this situation." Once Malcolm became blind, his father stopped speaking with him, explaining that his father does not believe a blind person can do anything in life.

The perceptions Malcolm's father had of him contributed to Malcolm's selfloathing, "I hated myself so much at that time; the only thing I wanted was to die." Although, his father was the most vocal about his negative feelings towards Malcolm, he knew there was a loss of hope and respect from the other members in his family. Once he became blind, which was in 2002 , he was pulled from school and remained at home for four years. Unable to contribute to housework any longer, he described an excruciating boredom that included him sitting for hours on end, with no human interaction at all. One particular problem Malcolm identified was that family members would do everything for him, never giving him the opportunity to learn to be independent. "What I wanted most, was to be guided, I wanted to be supported. I did not want people to 'help' me, or do everything for me, so I would not be able to stand up on my own." He explained that some individuals may have good intentions, but because of their accustomed belief that a blind person is unable to care for him or herself, they would attempt to do all his tasks for him.

"My mother was the only person in my life that tried to understand me, and because of her I'm still here struggling, [as] much as I am still facing many challenges, a lot of criticism, a lot of rejection. She struggled for me, so I have to also struggle for myself." Malcolm recounted how he manages difficult situations and the continuous challenge of proving his abilities to others. 
The people around me who meet me always believe I cannot do things. That's why I'm so quiet. You see Arianna...if you have realized it by now I am a quiet man. Most of the times when I talk people do not take what I say as something real or serious. But I am not a quiet person, I like talking, I like sharing ideas. But whenever I talk, people criticize me. People do not take what I say as something important. People do not believe in me but I now believe in myself, and that is why I am facing so many challenges. The world is trying to convince me I am not important. (Malcolm 13/09/2011)

He added that it was not as imperative for him to find people who would believe in him, rather, he only wishes for people to try to understand him. However, he explained that people have no desire or intention to try to understand him as a person. Additionally, upon meeting him, Malcolm feels that community members begin to formulate their own negative opinions and stereotypes about him, which makes it difficult for him to overcome.

Like Bashir, Malcolm was most happy when he was in school; a monumental time in Malcolm's life was when he returned to school as a blind student. He told me that until he returned to school, he never believed that he would have the opportunity again. He was unaware of the fact that blind people could be educated and could advance to university under the right conditions. I asked him about his first encounters with other blind students; he told me that for the first time in four years he began to really see hope for a positive future.

Although happy to be in school, Malcolm had much to say about the difficulties blind students are facing. He explained that the ways things are handled and carried out within the school are rooted in negative perceptions of blind people by staff and teachers. He stated that the teachers in the school do not believe blind students can ever be at the same level as their sighted counterparts. "There is no cooperation; people are not working 
together. There is a lot of selfishness in this school, and the origin of it is in the staff...that's the worst part of it." He explained that even when teachers take time to help him, it is never with good intentions. "There is one teacher who is worst of all...he does not teach me to help me [to be] understood; he teaches wanting to show people around that I do not know anything. He always pressures me; he does not give knowledge, which is what I am here for." He felt as though this negativity from the staff was, ultimately, harming his and the other blind students' futures, explaining that as long as this treatment continue, they are the ones who suffer. "We are still trying to build our futures... which are being spoiled by the teachers." He identified this as a major problem not only for himself, but within the whole country.

Malcolm explained that unless the conditions of integrative schooling in the country are improved, blind students will continue to suffer and be underrepresented amongst the student population. Although unhappy with the current situation, he explained how vital education is to the lives of blind people, especially youth, in order to instill a higher sense of self-worth. "The only thing I have going for me is my education. I have to rely on my books, on my education, which as you can see is not going well on my side." He voiced strong feelings towards improving conditions for blind students in order for them to be able to make positive changes in their own life, and for a stronger, more united, Uganda.

Othello, whose life story follows, also describes education as a contributing factor in improving the social status of a blind individual in the future, and like Malcolm and Bashir, he admits that it is an opportunity for blind youth to meet and assist one another. However, Othello's story is rather unique compared to others, as he returned to education 
at a later age in his life, after his experience as a child soldier in northern Uganda's war. The following section encapsulates the onset of Othello's blindness and its life impacts.

\section{OTHELLO}

Othello was the last born of five children in his family. Like Malcolm, he was born sighted and did not become blind until he was 11 years of age, around 1997. It was the way in which he became blind, and his life afterwards, which makes his story so unique and necessary to tell. In the late 1990s, Othello was captured by the Lord's Resistance Army as a child soldier. ${ }^{18}$ On one particular evening while traveling with them in the district of Amoro, ${ }^{19}$ the LRA had settled to prepare food when they were attacked by government soldiers. The government fired guns at the LRA rebels, and hit Othello in his right temple. "The bullet did not pull out, but remained in my head under the right side of my eye. It was very unfortunate; I was left on the field, a dead body. The government came and removed everything but they left my body there. The [LRA] rebels came back again and they found my dead body; I was naked, but still breathing at that time." The commander forced the rebels to carry Othello's body with them until he died.

They took him deep into the bush where they treated patients. "I stayed for almost a month, without knowing if I was injured. I did not know who I am, I felt like I was dreaming. I started waking up by crying and yelling 'I'm injured come and help me!" A month after his injury, Othello's wounds had healed, however, the bullet remained lodged in his head, causing permanent blindness and years of unbearable head pains. Unable to fight for the LRA any longer, the commander forced Othello and a few others who were injured to be taken to southern Sudan, a journey that takes a week to walk, but they

\footnotetext{
${ }^{18}$ A deeper explanation of the LRA and the Ugandan war is given in Chapter 2.

${ }^{19}$ Amoro is located directly west of Gulu, sharing a district border.
} 
managed to complete it in less than three days by walking day and night without food or rest. Othello was guided by the hand of another child, and since he had only just become blind, the journey was quite difficult for him. "The whole time I was thinking to myself...I only want to die. I am now blind, what use will I have now?" Othello remained in southern Sudan for the following nine years of his life, between the ages of 11 and 20, with other wounded children who were unable to be taken to battle.

After dreaming of escaping for many years while held captive, Othello finally managed to do so after those nine years. "I ran alone, without anyone holding my hand, without anyone guiding me, from 11 a.m. to 6 p.m., I ran the whole time without stopping. I did not even know the position I was going. When I would stop I would sleep with my face towards the direction I was going so that I wouldn't go the wrong way when I would wake up." After days of running alone, Othello came across others who had escaped and had recognized him. They began to move together in hiding. "At this point we were eating leaves. Any leaf that could not kill you, we would eat. We used a hose to hit wood, and we were eating termites." It was not long before the LRA found them and began firing bullets towards them, which caused Othello to again run away on his own again, with no clear knowledge of where he was going or what would happen to him. "I already knew my life was over, but I wondered what would kill me."

He was discovered by guards on the Nile River. After telling them his story, they offered to return him to his family in Gulu.

I told them if they have the interest to take me back to Uganda, then they can just kill me. The reason why I said this to them, Arianna, is because I was abducted while I was still young; when I was home everyone trusted me so much. People loved me so much. How would I return after so many years? And to return in the condition I was in? I only wanted to die then. (Othello 08/09/2011) 
However, the guards refused to kill Othello, and instead took him to World Vision ${ }^{20}$ in Gulu. After spending one month at World Vision, news of Othello's story had reached home. The organization took him back to Gulu to see his family for the first time in nine years. He described the overwhelming feeling that came with reuniting with his family after such a long period of absence.

Once living at home again, it was difficult for Othello to take part in activities, because the bullet that remained in his head affected his mental clarity. It was finally in 2007, that a woman who was volunteering at World Vision became aware of Othello's story and became so affected by it that she flew him to Mobile, Alabama where doctors performed a nine hour surgery to remove the bullet from his head.

After returning back to Gulu, Othello was determined to force himself to relearn everything and not to allow his blindness to prevent him in achieving a good life in the future. However, in doing so, it has been a long and hard road for Othello:

When I first became blind I hated myself, that's why I wanted to commit suicide. I tried to kill myself three different times. Being a blind is not easy here. Even if you have problems in America, it's not like we do here. It's too painful, you see, even in the community people will even fear to greet you. These people here, we are even from the same tribe, and they do not even want to greet me. They even fear if they come greet me maybe they will become blind. They think to themselves 'Is there no other people to greet? Why should I waste my time greeting a blind person? (Othello 09/09/2011)

He explained that when people first meet him, the first thing on their mind is his blindness; they relate his identity and personal characteristics back to his blindness - as if they solely influenced it. "Even if you are doing many good things, they will always focus on the blindness." This alone has been very discouraging for Othello, as he only

\footnotetext{
${ }^{20}$ World Vision is an NGO that works with child soldiers who have returned from the bush. They counsel them, help make sense of their experiences, and assist in reintegrating them back into society.
} 
wishes that people value him as a contributing member to society. "Even if we do good things, they cannot appreciate us. Are we not a human being? Is that not for us also?"

Othello explained that most of the time his sighted counterparts do not care if he hurts himself or fails. He told me of one instance when he had been walking and suddenly fell on a fire, because none of the sighted individuals he was with cared to warn him. "Usually they do not care if you live or die; it makes no difference to them. They already see you as a cursed person, so they will treat you that way." However, the other blind students in the annex, especially his dearest friend Komogum, have been a positive support system in his life. They have assisted in helping him make sense and cope with his past experiences, and especially in pushing him to remain optimistic about the future. Othello described the significance the other blind annex students have played in his life and by improving feelings about his self-worth.

Othello found it important to challenge dominant thinking towards the blind. He believed that by studying hard, he could "open [society's] eyes" to the potential of blind people. However, he explained that it is difficult for blind students because teachers will talk to them as if they are "stupid and sinful people." He explained that sometimes when teachers walk into the classroom, they say to the female students, "Do not sit with the blind; do not talk with the blind. If you talk to them they will try to have sex with you." But Othello realizes that this is something he must deal with in order to create the life he wants for himself. It is important for him to have a job in the future that is able to provide for his wife and children, and, therefore, he is committed to establishing his independence, knowing that his parents will not always be around to help him. "My blindness is too painful, by the way, but it cannot stop me." 
Similar to Bashir and Othello, Evette discusses her blindness as a defining feature in her social relationships with community members and her social identity. Like Malcolm, Evette too has chosen not to allow her blindness to act as a barrier in working towards improving her future opportunities. Moreover, like all prior life-narrative participants, Evette highlights the importance of education and the need for further improvements within it. Again, another unique perspective is presented below, as Evette presents the voice of a blind female youth, her story follows.

\section{EVETTE}

Evette was born on December 23, 1989 as a sighted child, and only became blind at the age of five after being affected with measles. She explained that she grew up without a father because he was a soldier, and so she only had a mother. However, due to the mother's neglectful and negative treatment towards Evette, her uncle removed her from her mother's care and took her into his home where she remained for the following ten years of her life, not once seeing her mother during that time. She explained that when she was a young child, the community members who were exposed to her feared her greatly, and kept their distance from her. They wouldn't approach her and limited their association with her to the bare minimum. These behaviors from others left Evette feeling very isolated and alone from the outside world. "Most people just looked at me and felt sorry for me; they never saw me as their equal, so they tried not to come to close." Community members were influenced by their perception that Evette's condition was brought on from witchcraft. "When people think you have been bewitched, they will never want you to come close to them, or come into their home, or play with their children. They will tell stories about you that are not true and can be very mean." 
She explained that "the biggest challenge for young blind people in both the society and community is the challenge of education. First off, most people are ignorant. They do not know blind children should be educated. Secondly, they do not know how to handle blind children. They think we are helpless to them and they do not want to waste their time helping them succeed." However, Evette made it clear that this is a problem that exists within the whole country; blind people are seen as useless bodies with little purpose. For this reason, Evette's struggles are many, not only because she is trying to create a life of independence for herself through her education, but also because she continuously has to prove her ability and worth to others: "It is impossible for most people to look past blindness, because it is the first thing they see about you, and everything else you do or say is related to your blindness." She pointed out that one of the root problems of how blind people are perceived comes from the language that is being used to talk about them. People refer to her as a disabled or handicap individual, while Evette very much believes herself to have plenty of abilities, while lacking others.

There are some people who are able to play football very well, while there are those who cannot. There are some people, who can do hair, and there are those who cannot; and, those who cannot do these are not seen as disabled. Then, why am I for not being able to do some things like everyone else? I can read Braille, when most people cannot. Everyone has different abilities. (Evette 19/09/2011)

Evette then described the issue of gender within disability. She explained how the difficulties of being blind become far more intensified for women because men find it easy to take advantage of them. "When I return home from school, the sighted boys always try to disturb me, they will yell things, and even some have tried to take me to bed forcefully but I always try to stop them because I do not want to become pregnant, I want to continue my education." Evette explained that sighted men who have pursued her in 
the past, have done so with the intention of wanting only a sexual relationship with her; she has yet to have had a sighted male pursue her for a relationship that could possibly lead to marriage. "[Sighted men] do not want a blind woman as their wife, only for sex, and they will leave her as soon as she becomes pregnant. They look at [a] blind woman and think how they will manage a household and children; they look at them as a liability."

Evette acknowledges the highly disproportionate numbers of blind males in school compared to blind females, attributing it to two main reasons: the first is pregnancy, and the second is general discrimination against women. She explained how difficult it is for people to see the advantages of educating a disabled person, let alone the advantages of educating a woman. This makes her situation a continuous battle of having to prove herself to teachers, friends, family, and the general community.

She mentioned lack of sensitization from teachers and staff members as being another barrier to her success. Unable to empathize with her situation, teachers are careless in attempting to make sure she is not having troubles completing her assignments. The teacher's training college that Evette is attending does not even have a single teacher that is trained about special needs students, or any teacher that is able to read Braille. Therefore, all assignments that Evette and her one other blind classmate complete are sent to Meba High School, ${ }^{21}$ where they are transcribed. However, even when the assignments are transcribed and given to teachers to grade, there is still a lack of urgency that Evette described when dealing with the blind students: "If you try to ask them about your scripts they will tell you they did not receive your papers or that they

21 Transcriptions are primarily done by Albert; however, if necessary, Odon will also transcribe documents. 
need more time to grade your work, even when they have had your assignments sitting on their desk for over a month. This only happens to the blind students, none of the other students face the same challenges we do." She told of the difficulties of lacking resources, and how this poses the biggest challenge in being able to complete school lessons. When I asked her how she works through her difficult situations she responded by saying, "I manage, because this is the lifestyle I am used to. Whether you like it or not, you have to push yourself to survive your situation like that: There is no one to help you; you must only help yourself."

Even after seeing her living conditions at the school, it seemed as though Evette and the only other blind girl at the school were the worst off. The two were separated from the other girls, and had their own small room that barely fit their two beds and their belongings. Their room had leaks and was in terrible condition compared to others I had seen. The only aspect of 'inclusive' that held true to the workings of the institution was that the girls were able to sit in the same lectures as their sighted counterparts, however, they lived in separate facilities, and were unable to partake in sporting activities, which comprised much of the social aspect of the school.

Despite such challenges, Evette hopes to complete her education and become a primary school teacher, establish a degree of independence for herself, and create a future with better living conditions for the blind. "My message to the world is that here, in Uganda, the blind are not being supported, they are not being supported in education, and they are not being supported emotionally. The blind are not seen as valuable and most of them are kept at home, hidden from society. This needs to change and there needs to be more people to help make this change." 
Similar to Evette, Albert too has faced many barriers in his life, including social stigma and negative stereotypes towards his character. Moreover, like all life-story participants above, Albert too attended Meba High School, however, his account presents the perspective of an individual who then went on to university and even graduated. Albert's story highlights similar themes to those in the narratives above, while exemplifying how education during youthhood does have the ability to enhance the life opportunities of a blind individual.

\section{ALBERT}

Albert was born in 1983 and was the only blind child of seven children. The onset of his blindness began at an early age. His parents recognized that he was having trouble using his left eye, so they immediately sought medical attention for him. However, the surgery that was performed on his eye in an attempt to save his vision was carried out so poorly, that Albert was left blind in the one eye, and subsequently remained partially blind until he reached age nine. While Albert was nine, the vision in his right eye began to slowly diminish until it was completely gone. However, because Albert had one functioning eye until he was nine, he does recall being able to see. He explained that he still remembers what his family members look like, specifics of the area and home he grew up in, and what general items, land features, and colors look like when people are talking about them. He is able to put a visual image to their descriptions.

Albert described his feelings after becoming fully blind: "It was a difficult time in my life because of my age, I was not so young to not understand my blindness, but I was not old enough to fully comprehend it." Albert identified his parents as a major support system in his life, explaining that because of them he was able to survive the 
following 21 years of his life. What made Albert's parents such an integral part of his perseverance to continue living, and to carry on with his education, was the fact that they spent much time with him, trying to understand him and giving him encouragement to pursue his dreams. His stepmother was the one person Albert mentioned that had been a burden in his life, and someone from whom he had received much negativity. Albert correlated his stepmother's negative treatment toward him with her lack of knowledge and understanding of blindness, as well as her strong traditional upbringing that influenced her perception of blind people. Additionally, he pointed out that his father's care and attention towards him prompted jealously from his stepmother, because she could not grasp why his father supported Albert as much as he did, and why finances were being spent on him, when she believed they could be spent on better causes, rather than being 'wasted' on Albert.

Our discussion about Albert's stepmother prompted him to begin to talk about what he believed to be some of his other greatest challenges he has faced in his life. The first area he identified was mobility, explaining how difficult it has been for him to independently move from one city to another, let alone one area of his village to another point. He contributed his mobility problems, which he explained are similar amongst the majority of blind people in the country, to a few various causes. Although Albert, unlike many other blind individuals, has a white cane to assist him in walking around town, he explained that the uneven pavements make it quite difficult to walk alone, even with the cane to assist him. "If the government would level our roads, it would not only benefit the blind, so they would not trip and fall as often from the hilly and uneven roads, but 
even people with physical disabilities in wheelchairs could move more easily through the town.

Aside from the poorly kept roads, Albert showed great concern and unhappiness towards the way individuals treat the blind when they are moving through town alone with their white canes. Rather than assisting the blind when they realize the cane is a necessary walking device, people will make it more difficult for them to move through town, by purposefully throwing objects in front of them, on the path they are walking, or by tripping or pushing them. Albert recalled many occasions where he attended events and set his white cane to the side or back of his chair, only to realize that someone had taken it when he was not paying attention, and moved it to the other side of the room, so that they could watch him scramble to find his necessary walking device. "People do not realize how important the white cane is for us to move, it is our eyes, and because they do not understand, they find it too funny to watch us suffer while we try to find it." In an attempt to lessen the occurrences of this from happening, Albert always makes sure to place his white cane on his lap while seated, to make sure no one takes it from under his nose.

Similar to others interviewed, Albert identified education as another one of his challenges, not only in accessing education, but the quality of education given to blind students. "There is a lack of urgency and care; these teachers could not care less to see a blind student succeed. They see them as a waste of time, especially a waste of their time." He described occasions when other children would come and spit on him or throw garbage over his head, and he informed the teachers who did nothing, and had no concern for what was happening to their blind students. Since teachers wouldn't do anything, 
Albert told me that he took matters into his own hands; he learned to adopt a stronger personality, to stand up for himself, and to prevent other students from taking advantage of him. He explained that on one specific occasion, after being spat on by another student, he picked up a rock by his foot and threw it at the boy's head, and from that time on the other students left him alone. Albert explained that the treatment by others were dependent on the way he conducted himself; if he confidently became vulgar when necessary with others when they were vulgar with him in school, they would usually leave him be.

As the only individual I interviewed who completed his university education as a "blind student," Albert has an extensive knowledge of education when it comes to students with disabilities. Even at the university level, Albert found many areas to be very difficult. He admitted that while a student at Meba High School, he was only taught how to use a Braille machine, and not a typewriter. Therefore, when he arrived to Makerere University, his first year was extremely difficult, as he was unable to complete his assignments in the form his teachers could read and grade it. He explained that this problem is the result of the poor quality of education given to the blind, in addition to the lack of skill and knowledge of teachers in special needs areas.

Upon completing his education in history at Makerere University, Albert sought employment. He acknowledged this as being another one of his greatest challenges faced, explaining that receiving his education seemed easy compared to his search for a job. Albert had applied to work at many different high schools and was continuously turned down. "There is no market; there is no vacancy when it comes to positions for the blind. There are those jobs that you will apply to that they will tell you that there is no position 
available when you know there are such positions. Then there are jobs that will tell you to go wait and they will call you, and you wait for so long and they never call you. I applied to about five or six schools that never even contacted me back." When I asked Albert if he ever thought it was his qualifications that prevented him from acquiring those positions, he immediately responded by saying 'no,' and that he knew the only reason that those positions were not given to him was because he was blind. Establishing his independence and finding a steady source of income was a priority for Albert.

Albert was finally able to get a position at MHS, as an assistant in their annex, transcribing the work of the blind students from Braille to print, and teaching history to second-year students. Albert expressed his frustration with the overwhelming amount of work he is left to transcribe, since there are no other teachers who can read Braille, he must make all of the blind students' work readable to teachers. With a little over ten students in the annex, each of whom are taking multiple subjects, with multiple assignments, his work load can be unbearable at times, but the school is unwilling to invest in hiring additional special needs teachers. Albert explained that the annex should be run with a total of five to six full time staff, as of now, there are only two. Not only was the lack of special needs teachers burdening Albert, but also the negative attitudes from sighted students and staff members. Albert had only been working at MHS for five months at the time we spoke, and he had told me of the first day he walked into his classroom to teach second-year students a history lesson. "On that day, most of them ran out the classroom; they never wanted to attend the class again. They were thinking, how can a blind man come and teach this class. Initially they did not know me or understand me they thought it was too strange to stay in my class." He explained that over the next 
following weeks, the students began to start coming to his lectures, and began to enjoy the material he taught them, and it was no longer a problem.

Aside from this initial negative treatment from students, which slowly lessened over time, Albert acknowledged negativity from his co-workers at the high school, which was confirmed by my own observations. He did not talk extensively of his relationships with other staff members, but he did mention that he had only a few individuals at the school he would consider to be friends. From my own observations, I found it to be far more extreme than even Albert may have realized. During meal times on the school grounds, the teachers congregated in the staff room to share breakfast and lunch with one another. They sat close to one another, had discussions and even shared jokes. However, I noticed that Albert almost always sat alone to eat his meal, rarely having anyone pay any attention to him. On the rare occasion, one person came to greet him in the mornings but there was a definite intentional lack of association with Albert. Once he finished his meals, he would head immediately back to the blind annex office, rather than lingering in the staff room like his co-workers. Having lived 21 years as a blind person, Albert might have been used to this lack of contact from others, and this might account for him overlooking it when we spoke.

Our conversation ended with Albert's own perceptions of his blindness. "I definitely see my blindness as a medical condition, but if you look around society, you will notice that no one else sees blindness the same way. Culture will say one thing about my blindness, religion will say another, and yet science will have its own explanation." With many varied explanations as to the cause of Albert's blindness from community members, Albert chooses to overlook their opinions, and adopt his own understanding of 
his blindness. He believes that much of the way people associate and treat him is directly related to their understandings and knowledge of blindness. If a sighted person believes Albert's blindness is a punishment from god, then that person will limit his or her contact with him. The negative perceptions people have of blind individuals affected him far more when he was younger than they do today. Albert has learned over the years, that most of people's intolerance toward his disability is due to their lack of awareness rather than seeing it as being something he has control over.

Although Albert still encounters negative experiences based on his blindness from society members, his current situation is far better than most blind adults in the country. Albert has his own home, where he resides with his sister, who does most of the cooking and cleaning. His salary from working at the high school has enabled him to provide food for himself and his sister, and a relatively comfortable home. Albert and NUDIPU board member, Frank, were the only two blind individuals I was exposed to who were relatively independent; the only significant commonality between these two individuals is that they had both graduated from a university. Albert's story is significant in that it shows how the education of blind youth is critical in self-development, improvement in life-quality for the future, and in achieving personal independence. Albert's presence at MHS, as a blind individual with an education, and who has a career, was a positive display to the blind students in terms of the benefits of education on their futures.

Albert exemplifies how the life opportunities of a blind individual are enhanced when investment is put towards their education during youthhood. However, unlike Albert, Angel whose study follows, did not go to university, nor was she even able to attend secondary school; her education was halted after primary school. The following 
section details Angel's story - it serves as an example of how lack of investment in the education of blind youth has dire consequences on future life-quality and sense of selfworth.

ANGEL

Angel's perspective is unique among individuals interviewed because she is a woman, she is no longer in school, and she did not finish her education. Angel was born sighted in 1975 in Gulu; however, when she turned five she was struck with measles, which eventually contributed to her sudden and complete blindness. This was the beginning of what she explained to be an internally and externally painful life brought on by community members, and even more so by her family. Her family's immense negative attitude towards her was the most difficult of all to bear. They treated her as a complete liability, as someone who was cursed and who had brought a curse to the whole family: "They would always hide me from people in one of the rooms in our home. Whenever my brother's girlfriend would come to our house to visit, he would make sure that I was locked away so no one would find out that he had a blind sister." Her family feared the shame that would come along with having a blind person in the family. If the girlfriend ever found out about her, she would have left Angel's brother proclaiming that she could never stay in the same home as a blind person, nor could she marry a man with a blind sister. So, for years, Angel remained a secret from many in her community.

Besides her one brother, Angel had two sets of twins in her family. On one occasion the government sent her a few clothing items; however, every single item was taken forcefully by her sisters, who she said would verbally abuse her. They rationalized their harshness towards her by saying that a blind person is undeserving of nice clothing, 
which they are unable to see. But out of everyone in Angel's life, she explained her damaged self-worth to be caused by her mother. "My mother really hated me, and I cannot even begin to define the extent of that hatred she had for me. She hated me completely, with every part of her body." Her father was the only person in her life, at that time, who showed her love, made her feel valued, who gave her hope for living, and who made her believe that she could go on with life.

Angel explained the feelings she had during this period, "how can a human being be degraded so that even your family members chose to hide you? They do not love you they do not have mutual understandings of you, or want to support you? If your own family cannot even do that, what makes you think society will?" Over time Angel found strategies to deal with her oppression and neglected social status. She explained that she would spend much of her time praying. She prayed for the health of her father, to be able to remain in her life; she prayed for strength; and, she prayed for the forgiveness of those who were not able to fully understand the impact of their negative actions towards her.

After finishing primary school, Angel was supposed to go on to Meba High School to continue her studies; however, she was forced to remain at home because no one would pay her school fees. While at home, within less than a year after she stopped schooling, she became pregnant. In the following six years of her life, Angel became pregnant three times with three different sexual partners, all of whom abandoned her. She explained that they only used her to fulfill their sexual desires and, once they discovered she was pregnant, they quickly disappeared. This forced Angel to attempt to find work in order to support her children, at the age of 22 . She explained that there had been many 
wealthy Sudanese refugees that migrated to Northern Uganda during the time, and so she made a small living by washing their clothes.

Angel remained alone for a few years, until she met a man who was willing to remain in her life. The two were married and produced four children together over the following few years. The man she married was also socially shunned from society; he was constrained to a wheelchair from having paralyzed legs. Angel explained that once they were married, it was only then that the two of them began to figure out life together. They worked mutually and supported one another, however, life became a huge challenge once her partner died from HIV in 2009; Angel was 34 at the time. This left Angel alone with an HIV positive status requiring ARV medications to live, and seven children with no one to support her.

Angel described a future that she feels very pessimistic about; she explained that in Uganda, education is everything. "When a boy is not educated he may end up as a robber or a thief, and for girls she may become pregnant at an early age." Most of her children are at home, and she does not see a good future for them. She explained that if they were in school they may be able to find some work but as of now they have nothing. She does not even have any land of her own. Her family owned a huge chunk of land in the village, but her brothers and sisters divided it amongst themselves, and did not allow her to take any of it. To this day, they do not allow her anywhere near the grounds.

Access and control over resources is completely impossible for a blind person. At least if you have another disability and you are sighted they can say that you can see your land, but if you are not sighted they will say what will [you] use the land for? If you go and look for work they will respond with how will you dig? If you try to find work in a bakery they will say 'how will you know when that bread will be ready?' They always look at us like we are nothing. (Angel 24/08/2011) 
She explained that when she travels to the main market in town, there are occasional occurrences when she bumps into another individual accidently. Upon this happening, she is always met with extreme verbal abuse and hatred from community members. Even when she attends social gatherings or Sunday church services, she is ignored by others. People do not attempt to help her find seating nor do they greet her. Moreover, Angel's stigmatized social status is not only confined to herself, but passed down to her children. She explained that when her children attempt to go looking for work to wash clothes or clean stores, most often they are chased away. "People will say to them, 'Stupid kids, we do not want you to bring those stuff to this place' and they only say these things because they know I am their mother."

Angel believes that people define her by her blindness. People do not usually mention her name when speaking to or about her; she is known as the "blind woman."

Blindness is everything. It is the most outstanding thing in an individual, and everything else is just a background to it. In today's world, especially in Africa, they only focus on a person's disability. They look at you as you are the disability, not as a human being. Whatever they do to you or what they do to you is according to your disability. They look at the disability, not the person. They look at my blindness, not me as a human. Whatever they do for me will be based on my blindness, nothing else. (Angel 24/08/2011)

Currently, Angel lives alone with a few of her youngest children, while her first three children have moved out. As of now, she is being supported by small contributions from her children, but explained that sometimes it is very difficult to put food on the table, as "money is very little." She explained that she tries to make her own money when possible from washing clothes, but her positive HIV status has made her significantly weaker over the years and unable to work as much or as frequently. Although Angel was a bit older than the other life-story participants, I thought it was necessary to include at 
least one story of an individual who had been blind since birth, and was not given the opportunity to complete her education, which is the situation for the majority of the blind population in Uganda. In the case of Angel, almost immediately after being unable to attend Meba High School, she was impregnated on three different occasions. Her lack of support, marginalized social status, and lack of education, further disempowered and disintegrated her from society. This is the reality of blind adults in Uganda who are not given the initial opportunity for education during their childhood and youth. Angel's narrative is significant as it highlights many important components of disability inquiry: stigma, devalued personhood, and the role of education, which are further examined in the thematic analysis section below.

\section{Thematic ANALYsis}

The life stories included above reveal a great number of commonalities amongst study participants. In this section, those themes will be further explored, including their significance within their contexts. Common themes that were salient throughout interviews included topics such as stigma, communitas, education, and personhood/selfhood. In the first section, I examine a common feature within blind individuals' social relationships: stigma. The second theme discussed is communitas, it examines the way blind individuals cope with their marginalization through solidarity and the support of one another. The third section outlines the theme of education in terms of the psychological and emotional impacts it has on their lives. Lastly, I discuss the theme of personhood within interviews, focusing on how blind individuals' social identities are constructed through the influence of negative perceptions of disabled people 
in society. Additionally, I examine how personhood is related to feelings of selfhood within blind individuals.

\section{STIGMA}

Through multiple interviews with blind individuals, it became apparent that most of their social relationships had been affected in one way or another from their blindness. These relationships were with community members, peers, classmates, teachers, potential partners, and family members. Social beliefs of blindness influenced the ways in which community members dealt with, managed, and chose to interact with blind individuals and, because of negative perceptions of blind people, people would limit their dealings with blind individuals to a minimum, and in some instances fear to get too close to them.

Society establishes ideas of normalcy for community members, and those who fall outside of these categories are reduced from a usual or whole person, to a tainted or discounted one (Goffman 1963:3). This negative association given to individuals because of their blindness can be understood as a social stigma, which has the ability to affect their relationships with others and the way in which people will choose to associate with the blind. In his classic work Stigma, Goffman explains that it is not the impairment itself that brings the greatest struggles for the stigmatized individual; rather it is society's responses to it. My position is similar to that of Goffman's, as the individuals I spoke to did not express direct frustration about their lack of sight, but rather with the consequences that their lack of sight brought on, one of those primarily being negative social responses to them. These negative perceptions people have of blind individuals influence the way they choose to interact with them. Study participant, Othello, explained this by saying: 
People usually see blindness as a curse. Most people naturally fear a blind person, and will never come near you. You can try to change the way people think, and maybe they will come talk to you but they will always have that fear. The fear is hard to remove, sensitization will help to minimize the problem and help in all corners with the problem. However, when a blind person is walking with a sighted person they will become ashamed; they are not interested in walking with a blind person. You may be nice and smart, [but] instead of guiding you and being near you, they will stand very far from you rather than guiding you close. They will stand too far from you; I never understand...it only hurts me. (Othello 09/09/2011)

Stigma towards disabled individuals is not the same amongst different categories of disabilities. The degree of stigma society places on individuals can vary, "depending on the different cultural values that are transgressed" (Shuttleworth 2004:365). It can also depend on how a "particular social context calls for the use of some culturally defined abilities and invokes some values but not others" (Herskovits and Mitteness 1994). In Uganda, since eyesight is believed to be the most important sense, and the most vital in order to carry out daily activities, the blind face higher levels of stigma than other disabled groups in society.

Some of the worst stories I was exposed to, in regard to negative treatment towards the blind, was not always from community members, but many were from the blind individuals' family members. Since children are seen as an extension of their parents, some families regard a disabled child as a stain on their social status, and this has much to do with the fact that disabled children are often hidden away from the rest of society (Abosi 2007:198). In Uganda, the terms kateyamba and agoro are used by the Buganda and Acholi ethnic groups to categorize the physically disabled; kateyamba means unable to help oneself and agoro relates to a frail or helpless person (Sentumbwe 1995:162). The perception of disabled individuals as being 'useless' in society 
contributes to negative attitudes towards blind individuals about their ability to be selfreliant; it is both disempowering and demoralizing.

Frequently, I was exposed to stories from the blind themselves about reoccurring instances where they would be locked in closets for days so family members could prevent others from finding out that they have a blind relative. One participant explains this by describing a childhood experience when she says, "Whenever any visitors would come to our home I would have to stay indoors so I would never meet any of the visitors and bring shame to the family. Even when it came to eating, I was supposed to wait for things to be given, I was not supposed to touch anything and wait until everyone else had finished their meals" (Florence 21/09/2011).

Goffman explains that the negative treatment towards the stigmatized individual are in ways rationalized due to the belief that they are not quite human, or do not necessarily fit within that human category completely. Therefore, these various discriminatory acts are exercised towards the individual, often mindlessly, effectively reducing their life chances (1963:5). Goffman's theory of stigma can be used to make sense of the negative treatment towards the blind in Uganda, due to the belief many have in witchcraft, superstition, and divine punishment. Because of these traditional beliefs, many disabled children and students are neglected and mistreated by their families and teachers, making them unable to reach their full potential in society and in the classroom. Furthermore, of all the disabilities, blindness in Uganda is considered to be the most problematic in carrying out normal social interaction. Loss of sight is believed to be completely incapacitating and, therefore, the worst of all physical disabilities. One participant described the way in which society members treat and refer to her. 
If people are coming to my place, even though they know my name they will refer to me as the blind woman, and will say they are going to the blind woman's home, and even when my children are playing they will say this is the child of the blind lady. They relate everything $I$ do and every mistake I make to my blindness; they think I'm a worthless person because of it. (Florence 20/09/2011)

Goffman clarifies the basis of these behaviors by explaining that society tends to attribute "a wide range of imperfections on the basis of the original one" (1963:5). Therefore, having the inability to carry out an unrelated task, is immediately associated to the blindness, regardless of its relevance or not. This is especially the case in Ugandan society where masculine admiration is influenced by the capability to be independent, to perform manual labor, and to provide for a family, and womanhood is associated with fulfilling household obligations, raising children, and meeting the sexual needs of your husband. Blindness is seen as a condition whose effects are multitudinous in the ways in which they contribute to individual ability to perform and carry out each of these requisites. Nayinda Sentumbwe (1995) makes reference to this occurrence, calling it a phenomenon known as spread. She defines 'spread' as multiple functional limitations brought on by the loss of one physical function (1995:163). Spread may help in understanding why blindness is such a defining characteristic within individuals, as blindness is perceived as an all-encompassing condition, which affects multiple areas of life and performance. As indicated in the life stories, above, many study participants believed that society defines them by their blindness. Additionally, most of them felt that their blindness was not seen as separate from them, that is, they are not an individual who has many other characteristics but happens to be blind, rather, they are always blind first and foremost. 


\section{COMMUNITAS}

Blind study-participants accounted for many community members and peers in school that had harassed them on one occasion or another, or even feared nearing them. For this reason, many blind students explained that their social circle of friends was limited to other blind community members and students. They expressed a certain feeling of ease that only existed with other blind individuals. Bashir spoke about these relationships: "I am so happy and free with [the other blind students]; we can make jokes and laugh together. But then, when you are with a sighted person, you are never really sure how they feel being with you, you are always worried you will upset them. It is very different."

Murphy et al. (1988:240) explain that when two individuals discover they are both outsiders in a society, a connection or bond between them can develop and may even be extended to other liminal people. As discussed in Chapter Three, being in a permanent liminal state can be socially discrediting for anyone. As a response to this, in some cases, a small group or community might form between individuals experiencing similar social stigmas that marginalize and oppress them. The formation of this unique social interaction between individuals is known as communitas; it is an unstructured community, which includes discredited and liminal individuals in society. In the creation of such a group, individuals are able to create social equality amongst themselves, which they are not able to experience in the larger community. Victor Turner $(1985: 124)$ describes communitas as "relatedness among individuals without judgementality." Since they all share a similar social position, they are "in the same boat" together. In communitas there is "full, unmediated communication, even communion" between 
members. (Turner 1992:58) I found this to be taking place in the lives of blind study participants; they articulated finding much comfort and solace in their friendships with one another. It was a unique type of relationship in their lives, as it was not based on superiority and inferiority complexes, but rather on mutual acceptance and understanding of their common situations. Similar to Turner, I suggest that in these situations blind individuals are able to leave the liminal status they receive in society.

For the blind, finding comfort and solace in their friendships with one another is a critical system of support in order to accomplish their ambitions and to deal with social marginalization. Similarly, Carol Goldin (1984), in her research amongst the blind and visually impaired, identified various elements of communitas that had formed between groups of individuals. She explains that identification of membership within such a community is based on:

[A] blind person's sense of belonging to a group, including the feeling of a positive bond with other blind persons, and the sense of being excluded from social relationships with the sighted. It provides individuals with a sense of purpose and a safe social environment, but in the blind community it requires recognition of one's stigmatization by the larger society. Those who identify primarily with the community perceive their blindness as a defining feature of their social status. (Goldin 1984:123)

Furthermore, members who create a community or communitas amongst

themselves are brought together by their shared experiences of their socially stigmatized status (Willett and Deegan 2001; Goldin 1984:124). Goldin (1984:124) further explains another feature of blind communities:

My informants reported similar individual experiences with insensitive "normal" persons, and common experiences of stigmatization fostered by custodial blindness institutions. Prevocationally, blind persons share similar life histories. Each individual can recount embarrassing incidents, inappropriate offers of assistance, and meddlesome comments by sighted strangers, classmates, colleagues, and acquaintances. 
In this study, I, too, found that blind study participants shared many similar life-changing experiences, which made it possible to easily relate to one another. A past-time activity of MHS blind students included artistic expression through collective musical performances, which communicated their shared feelings of social experience. In one of their songs, they communicate to society about living with a disability:

Fellow countrymen, disability is not a curse nor a blessing. It's a concern for everyone, for no one wishes for this kind of life.

By taking part in activities with one another, "this community of the blind represents the power of communitas to generate new meanings of blindness" (Willett and Deegan 2001). Blind individuals are able to challenge negative social thinking about their blindness and redefine it in positive and meaningful ways together. Participation in these groups improves health, reduces stigma, and increases acceptance of disability (Willett and Deegan 2001; Wasserman and Danforth 1988; Gitterman and Shulman 1986). It also helps individuals build constructive self-perceptions that are different from those given by society.

The relationships amongst individuals who share communitas can be related to Martin Buber's (1958) concept of I-Thou relations. In his work, Buber, seeks to understand the way individuals relate to each other as human beings. He explains that when fostering I-Thou relations, we view the other as an equal to us, whereas, an I-It relation "objectifies other human beings in relational encounters" (Mumba 2009:257). In Uganda, the existent social perception toward blind individuals objectifies them, making them lesser people or citizens in the community's eyes. However, communitas amongst 
the blind fosters support, placing individuals in an equal social category. Communitas is not only a response to negative attitudes from society; it is a necessary coping mechanism employed by blind individuals in order to deal with their discredited social status. It helps to strengthen their morale and gives them hope for the future.

\section{EDUCATION}

All blind individuals placed high value on education in order to benefit their future. Although blind students interviewed were unhappy with the quality of education they were receiving, they saw the advantages of being in an educational institution, regardless of how positive or negative their experiences had been up to that point. They voiced their opinion that a benefit of education was that it had the potential to improve their social status in society. A blind individual may receive greater acceptance from society once they have attained a higher level of education, but will oftentimes face numerous negative attitudes from community members, family, and even friends in the process. One study participant expressed his belief in investing in education by saying,

If you are not taken to school, you will be neglected forever because you will not be able to make any contributions to your country. If you are blind and you do not try to do anything and push yourself, then people will always think of you as useless. If you want value in yourself and your family you must push yourself for your education. (Komogum $15 / 08 / 2011)$

Unfortunately, stigma from family members and the rest of society may prevent a blind individual from being able to continue his/her education, as revealed in the life story of Angel.

When enrolled in an educational institution, blind individuals often face discrimination from peers, classmates, and teachers, which affects the quality of their education; this was expressed by all life-story participants. They believed the negative 
perception teachers and school administrators have of disabilities is a primary factor in preventing positive learning experiences in the classroom. Even though most teachers have a higher level of education compared to the rest of society, many of them still accept traditional explanations for blindness, and therefore treat blind students in a negative manner.

The problem is that the inhumane and discriminatory perceptions of disabilities that exist in society are translated into parallel actions and treatment in the classroom. Evette states that it is necessary that "a specialty teacher should have the initial interest to help the blind students or else the blind students will suffer at their hands." Although negative perceptions from teachers, peers, and classmates was a major concern vocalized by blind students, all of them shared the consensus that they preferred being in integrated classrooms with sighted students, as opposed to separate educational institutions for only blind students. Othello expressed this while discussing St. Frances school for the blind, the only all blind school in Uganda:

Isolation is not good because, when it comes to getting a job; will you work somewhere that only has blind people? Are you going to share an office with the blind only? They need to get used to us, and we need to get used to them. We need social skills to be with them; we need to share leadership together. (Othello 09/09 2011)

Study participant, Komogum, shares a similar perspective, but attempts to see some benefits that exist in separate educational settings:

Sometimes I can see the advantage of being in an annex school only because there won't be any disturbances from the sighted students; we wouldn't receive any insults. All people are the same, and they are equal. But one problem is you will never learn to be very social with sighted people like making joke with them. You will not learn how to live in the real world. Going to a separate school is not living in the real world. An inclusive school prepares you for being in the work place and teaching you 
to live amongst others. You can share knowledge with sighted students and they can become sensitized to the blind. (Komogum 16/08/2011).

The most significant advantage in integrating blind individuals within inclusive classroom settings is its socializing quality, which has the potential to enable blind students to interact with sighted students. These socializing practices are believed to provide "a positive means for boosting the morale, confidence, and sense of self-reliance, independence, and growth in differently abled students" (Dei et al. 2006:211).

Additionally, sighted students are given the opportunity to interact with blind students, which gives them the ability to learn about their lives and become conditioned to them at an early age. In most cases, individuals who are exposed and familiarized with the blind at an early age are far more accepting towards them later in life, in comparison to those with little or no contact with the blind. One of the many benefits of creating inclusive environments is that sighted individuals are exposed to the culture, lives, and hardships of the blind, and consequently, are given the ability "to interrogate the various negative, cultural and traditional, stereotypes surrounding disability issues and identities" (ibid).

As expressed by all blind students participating in this study, education is a very critical aspect in the lives of the blind, and, in turn, can provide an important space for socializing them into the world in which they live. It has the potential to educate future communities of learners and students to have a positive approach to issues concerning disability, in addition to improving the lives and statuses of the blind within the community. Komogum provides a suggestion for sensitizing and exposing community members to the blind:

Educated blinds should be taken to society to talk to people, so community members can say, "Wow this blind person is educated, is speaking very well," meaning the child that is left home in the village should also be 
taken to school because they also have a potential. Once they can see an example, they may have more faith, because most people in the village have never seen it happen, so they do not believe a blind person can do greater things like studying or doing official or clerical things. $(15 / 08 / 2011)$

Although many of these activities have the potential of bringing greater benefits to society and especially to the lives of the blind, one critical factor which was emphasized by life-story participants was the need for initial interest and good will from community members. Without these important components, teachers will continue to ignore and neglect the needs of blind students in the classroom; peers and classmates will remain hindrances in integrating blind students within educational environments; and, society at large will continue to lack faith in the benefits of educating the blind.

\section{Personhood/Selfhood}

Interviews with life-story participants revealed the notion of having an identity constructed and shaped by community members. Blind individuals' perceived identity in society is influenced by the relationship of their disability to their personhood.

Personhood can be understood as the individual self as a social entity, which society imposes, and is different from selfhood, which is the substance of the self that includes self-awareness (Cohen 1994:57). Selfhood is inward-looking, introspective and a withdrawal from society, while personhood is individual development through the proper performance of social roles (Celtel 2005:65). Theories which conceptualize personhood attempt to comprehend how persons are understood and seen in relation to structures in society, religion, and biology. Whyte states an important research question to ask is how an incurable impairment might affect the future possibilities an individual will have, in addition to his/her validity as a person in society $(1995: 267)$. 
Luborsky (1994:239) talks about disability as the "loss" and "erosion of full adult personhood," explaining that some impairments limit an individual's ability to carry out necessary daily tasks and to take "part in valued personal and social life through holding a job and leisure activities." When an individual is unable to perform certain valued activities in society, he or she is met with social devaluation. "One of the cultural consequences of having disabilities is that an individual's identity, as a complete person, comes into question." A disabled person's inability "to fully perform normatively valued activities and roles in the workplace, home, and community, challenges an individual's core identity as a full adult person" (ibid).

A "person" can be found in all cultural groups and societies; however, constructed individual identities and capacities are culturally specific, and should be examined within their own socio-cultural contexts (Luborsky 1994:239; Geertz 1984; Shweder and Bourne 1984). Society gives individuals their personhood when they are witnessed to achieve or maintain their specific social roles. Luborsky (1994:240) further explains that personhood "is not an intrinsic property of the individual;" while the "term 'individual' is used to refer to the concrete biological organism," personhood, on the other hand, "is not an automatic or intrinsic property of the individual nor can it be gained by personal claim - it must be socially legitimated."

For the blind in Uganda, their inability to perform tasks in society is compared to other community members' ability to function and contribute. Therefore, the identity of the blind as being 'useless' is formulated in reference to others. Similarly, in another locality in Africa, Comaroff and Comaroff $(2001: 268)$ found that Tswana ${ }^{22}$ personhood was socially constructed because of two reasons: "nobody existed or could be known

\footnotetext{
${ }^{22}$ The Tswana are an ethnic group in Botswana and South Africa.
} 
except in relation and with reference to, even as part of, a wide array of significant others and, second, the identity of each and every one was forged, cumulatively, by an infinite, ongoing series of practical activities." Individuals who are unable to prove they can perform in society, like others, are not granted full adult status.

Interviews revealed that community members associated blind individuals with a variety of different stereotypes, and because these verbal associations were so overused, they had become a common perception amongst individuals about the way blind people are. These constructed associations made towards blind individuals and their personhood had great implications in multiple areas of their lives. Not only did negative perceptions of disabilities affect individuals' self-perceptions, but it also affected their social relationships, their opportunities for employment, their options in finding a spouse, their ability to mobilize themselves, and their goals and ambitions.

Common assumptions made about blind individuals were that they were useless members in society, incapable of making important contributions; that educating the blind was worthless because it would never amount to any real future benefits; that a blind person is a greater liability in need of constant attention, rather than someone that has the potential to be an independently working member in society; and, that marrying a blind person would amount to having a social stain on the spouse's status. Moreover, since there is a heavy emphasis in Ugandan society on the ability of rear and care for offspring, blind individuals are perceived as being incapable of providing and caring for their families, therefore, they are unable to reach full adult personhood under those terms. In Ugandan society full personhood is earned after proving oneself to be a responsible, contributing member of society, in combination with marriage, or by 
establishing a legitimate family. Marriages can secure and strengthen social ties with community members, and bring a higher position of power amongst couples. "Through marriage, individuals [are able to] develop important components of their personhood" (Udvardy and Cattell 1992:280). Life-story participant, Albert, talked about the importance of marriage within notions of full adulthood/personhood in Uganda by saying a boy will only be able to transition into a man upon taking a wife and creating a family. Before he reaches that point, he is still perceived of as a boy, and although Albert is 29 years old and has his own home and job, he struggles with societal pressures and perceptions of his inability to reach full manhood.

These negative associations formed and reiterated in society, about the way blind people are, have detrimental effects on the development of blind youths' selfhood and self-perceptions, which expand into ideas they have of their own worth and the potential contributions they can make in society. Individual consciousness continues to form through experience, and much of the experiences of the blind have been demeaning and belittling. Anthony P. Cohen (1994) argues that selfhood is formed through its assimilation of personhood, which is affected by it, but not subordinate to it. In other words, subjectivity and ideas of the self are formed through society's perceptions and constructions of the individual. Cohen's argument manifests itself in the narratives of the blind, as many of them expressed separate notions of their self-perceptions from societal ones. Although most of the blind youth that participated in this study rejected constructions made about their character, worth, or ability, their narratives revealed that they had been affected by them in different ways.

Actually, it was not easy for me to accept the condition of being a blind person. Being blind led to losing many friends and even relatives; they 
saw me as useless, especially those who live in the village and are uneducated. Even though I did not think I was useless, they kept telling me so much I almost believed it. People really believe that [for] a blind - person to go to school is a waste of time and money. (Komogum $15 / 08 / 2011$ )

Negative conceptions of personhood that inhibit a blind individual from full participation and integration into social life are shaped in dynamic response to the specific features and context of a society (Nicolaisen 1995:49). Within Ugandan society, there is a great need for the development of resources that can better integrate blind and other disabled individuals in society. The structures that exist are not easily accessible to the blind, and exclude them from fully participating in society; hence, they are viewed as being 'useless.'

The study of personhood and the impact of social constructions of disability on identity have been useful in anthropological works detailing individual lived experiences. In order to fully understand a person's experiences within a society, it is important to consider "the implications of disabilities at the cultural level of personhood" (Luborsky 1994:241). Comaroff and Comaroff (2001:276) explain that although personhood may be culturally formulated, it "is always a social creation."

Chapter Three explored the social context of disability in Uganda, while communicating to the reader that blindness is a social construct that has the ability to influence individual experience in the social world. This chapter outlined these experiences through the presentation of life narratives of blind individuals, focusing on how the family and the social world have constituted their own self-perceptions and ideas about their selfhood. Chapter Five, which follows, broadens the understanding of the reader by stepping back from micro-level occurrences to consider macro-level issues. It 
analyzes Ugandan institutional structures and how their functions contribute to social disempowerment, marginalization, and many of the negative experiences described by blind Ugandans in Chapter Four. 


\section{CHAPTER FIVE: ECONOMICS, Politics, ANd DisAbILITY}

\section{Poverty AND DEPENDENCY}

In northern parts of Uganda today, disabled individuals are experiencing

"shattered livelihoods and entrenched poverty" (Muyinda and Whyte 2011:119). The 20

years of war that took place in the north, which is described in Chapter Two, caused the displacement of almost $90 \%$ of the Acholi population who were living in internally displaced camps (IDPs). The difficult situations that many Acholi people experienced during this time were intensified for individuals with mobility disabilities, specifically those who are "unable to move around easily because of impairments to their legs or eyes" (ibid). The reason for this being that a "mobility impairment increases poverty while poverty prevents the social arrangements (including assistive devices) that might improve mobility" (ibid). Study participant Wilfred explains this by stating, "The blind do not have access to canes. Without white canes, they are forced to be dependent on others; they are not independent. They are depending on their families for assistance."

Muyinda and Whyte (2011:120) explain that the changes that accompanied the war and displacement in the mid to late part of the first decade of the $2000 \mathrm{~s}$,

constituted a multifaceted jeopardy in the form of entrenched poverty and affected people with disabilities in different ways. Most were unable to access mobility devices and have been unable to develop their livelihoods because it is difficult for them to invest in learning appropriate skills and education and to effectively participate in activities needed to reduce poverty.

Furthermore, these burdens are extended to disabled individuals' family members "who are forced to divert household expenditure to non-productive expenses such as food purchase, healthcare and extra needs for their family members with disabilities" (Muyinda and Whyte 2011:120). When a family has limited resources, "it may be seen as 
economically irresponsible to give an equal share to a disabled child who is perceived as unlikely to be able to provide for the family in the future" (Yeo and Moore 2003:573). Therefore, an "early lack of investment in disabled children is not just a reflection of ignorance. In situations of poverty this is a desperate but rational decision" for some families (Ashton 1999:1). It was estimated that the probability of poverty for Ugandan urban dwellers, who lived in the same household as a disabled person, were $60 \%$ higher than for those who do not live in a household with a disabled person (Hoogeveen 2003:618). Approaches to disability that solely focus on attitudinal changes may be inadequate, as they "alone cannot lead to equality" (Yeo and Moore 2003:573).

Often times, disabled children will get last access to food and other basic resources. Moreover, when "disabled children become ill they are often not given any treatment. In households or communities already living in poverty, this exclusion is frequently a life or death situation. Early and preventable death is the most extreme symptom of poverty; thus, disability must be a central concern of those committed to poverty reduction" (Yeo and Moore 2003:573).

Poverty reduction is often accompanied by serious inequalities with negative implication for disabled individuals. There are many political pressures to reduce the head counts of people living in poverty as quickly as possible and to document these in statistics, which means there is a greater focus on lifting individuals out of poverty who are closer to the poverty line (Grech 2009:775). This means, that the majority of disabled individuals, who are mostly living in chronic poverty, are "often bypassed because these require extended time, resources and fundamental organizational changes and are, hence, less politically attractive targets" (ibid). There are a few identifying features of chronic 
poverty that differ from other forms of poverty, which is discussed in this section in relation to the current situation of the blind in Uganda, focusing on how poverty and disability are inextricably linked with one another.

The main notable feature of chronic poverty is the length and duration of time an individual will spend being poor. In other words, people who are considered to be chronically poor will spend most of their lives in chronic poverty, and may even pass their poverty on to their children and subsequent generations (Hulme and Shepherd 2003:405). This is evidenced in the case of life story participant, Angel; she has not only passed the social burden of her blindness on to her children, but also the inescapable poverty she has faced as well. Chronic poverty, affecting the lives of the blind, can be explained by three types of exclusionary models: economic, social, and political.

In terms of economic involvement, access to financial resources in the country is practically impossible for blind individuals. Most disabled people in Uganda are denied credit facilities in most of the financial institutions primarily because managers do not believe they have the ability to pay back loans (Lwanga-Ntale 2006:9). Blind individuals' lack of economic access to improve their financial situation keeps them in a constant state of deprivation and need. Consequently, the blind are unable to afford radios, a major component in obtaining critical public information and taking involvement in the country's political affairs, and they cannot buy or read newspapers. Additionally, without money, the blind are not able to afford transportation to reach town if they are living in remote villages. Therefore, empowering blind individuals "through legal and policy reforms is perhaps idiosyncratic, if poor people cannot even afford transport to reach a 
government office and seek redress" (Grech 2009:778). In most cases, blind individuals living in the village are confined to their homes, thus causing lost opportunities for them. As for political involvement, disabled individuals in certain localities in Uganda "are rarely invited to community meetings, and on a few occasions when they are invited, their views are not taken into consideration" (Lwanga-Ntale 2003:9). This was a common concern of study participants. They felt voiceless, as though their most urgent needs were being ignored by community members, local leaders, and even government officials. All of them had the desire to mobilize themselves, to change their social status, and to improve their lives, however, none of them felt as though they had the ability to access resources, information, and assistance necessary to do so. Furthermore, their state of financial deprivation, in addition to their marginalized statuses, prevented them from even knowing where to begin or what potential opportunities existed for them. Their lack of access to public information is one of the many barriers to their full integration within society.

The effects of poverty on the lives of the blind were also a repercussion of their social exclusion from society. Although there are a handful of blind children enrolled in educational institutions, the majority of them remain at home; hence, they have limited socialization opportunities from an early age onward. Social exclusion for the blind ranges from missed opportunities in attending school to being secluded from community gatherings and activities. This causes them to miss out on vital information about health, political issues, and life skills, which further marginalizes their status and participation in societal activities. Moreover, blind individuals' social exclusion contributes to their missed educational opportunities. In combination with negative perceptions from society 
about disabilities, restricted job opportunities causes blind people, and those with other disabilities, to have significantly lower income levels than the able-bodied population.

Another pressing issue for the blind, who are living in chronic poverty in Uganda, is that intergenerational poverty is almost guaranteed for children of blind parents, primarily due to social and cultural perceptions of disability. A blind individual who is believed to have acquired their blindness as a result of witchcraft, being cursed, or through divine punishment is socially stigmatized by society, which affects the social status of their entire family. Therefore, children of the blind in Uganda are often identified in society by a parent's impairment. It is not uncommon to hear a child being referred to as the 'child of the blind woman/man,' and stigmatized by that characteristic as their identifying feature. Social stigma from having a disability is transferred from one generation to another, and the poverty that affects blind people also affects their offspring.

Blind individuals who have children are usually unable to find the means to provide all of their basic needs. Social stigma, which affects their job opportunities and options, places them in a situation where they are unable to make an income.

Consequently, many of the blind participants in this study admitted to being unable to put their children through any kind of schooling or formal education. As Angel noted, "I have four children who are not doing anything, because I do not have the money to provide.

They are just sitting at home now." Hoogeveen (2003:605) explains:

The likelihood that disabled people experience poverty is greater than that for the population at large. There are many reasons for this. Exclusion and discrimination, unequal access to food, health care and education and reduced capabilities for work, all contribute to [fewer] opportunities for disabled people and reduced income generating capabilities. 
It would be of great benefit to Ugandan development planners to track and analyze the life experiences of individuals who suffer from a disability and chronic poverty in order to better address this national crisis.

One primary indicator of the high rates of poverty amongst the blind is their lack of access to resources and opportunities that can empower them and promote their integration within society. The following section examines blind individuals' opportunities to access information, education, employment, and health services in Uganda.

\section{ACCESS AND OPPORTUNITIES FOR BLIND PERSONS}

\section{ACCESS TO INFORMATION}

In 1997, Human Rights International stated that "the most powerful weapon in the human rights arsenal is information" (Ng'ang'a 2004:130). However, today in Uganda lack of access to information is a major hindrance for blind individuals wishing to mobilize themselves, improve their situations, and take charge of their rights as citizens. Life-story participant Malcolm explains:

The majority - about $95 \%$ of blind people in Uganda do not know their rights. It is so important for a blind person to familiarize themselves with the rights available to them. You see, in Uganda, if anyone knocks you while you are holding a white cane, you can arrest them, but many blind [individuals] do not know this. A blind person could have a lot of opportunities, but they do not know what to do or where to start. (Malcolm 14/09/2011)

Since most blind individuals do not have proper access to information about "the scope and content of their rights to health, housing or work, [they] are unable to determine whether their rights are being respected" (ADC 2007:18). Furthermore, in order for a disabled individual "to adequately meet their needs or carry out any plans or goals in life" 
and "to effectively exercise and protect their rights, they need access to information" (Mathiesen 2008:2).

When information is made accessible to them, blind individuals are able to stand up for themselves, their rights, and they are further "able to participate effectively in the national development of [their] country" (Ng'ang'a 2004:130). However, the reality of the situation, as study participant Florence explains, is that, "The blind are unaware of their rights and what programs and opportunities are open to them. They are mostly ignorant; they are unaware that their voices can actually be useful if they come out and speak up about their rights."

The ability to access information is not only a critical aspect in creating economic opportunities for the blind, but it also contributes to protecting "necessary personal support" (Percival and Hanson 2006:57). Study participant Wilfred explains, however, that the problem is that "The blind do not have knowledge or ability. They do not know their options, so they are unable to participate in [these] social, economic, and political activities."

Blind individuals are unaware of where they can access important Brailed information, such as Government documents, newspapers, and other valuable publications. Consequently, this impacts their access to other avenues of selfdevelopment and support; this includes education, employment, housing, health services, government programs, their rights as citizens, and channels of emotional and psychological support. The following subsection further examines blind individuals' access to one of these areas: education. 


\section{ACCESS to EDUCATION}

Education is a critical component in empowering blind individuals as it establishes a foundation that makes other avenues of opportunities more attainable in the future. Blind individuals who are educated are able to improve their social status and lessen the degree of stigma and discrimination from community members. Moreover, disabled individuals, who are not given the opportunity to access educational institutions, are not only adversely impacted by their lack of qualifications and experience, but also through low levels of confidence and self-esteem (Yeo 2001:15). Therefore, uneducated disabled individuals have restricted employment opportunities (ibid).

Currently in Uganda, one significant barrier that exists in educating the blind is that only primary education is considered free and universal. However, even though free universal primary education (UPE) is stated in the constitution, only second-rate primary educational institutions are free. If a family wants to invest in quality primary education for their child, they will enroll him or her in a private institution equipped with higher skilled educators, better facilities, and enhanced resources, which in most cases is necessary for blind students to reach their full educational potential. Without the correct learning tools, a blind student will not obtain an adequate learning experience.

Additionally, beyond primary education, secondary schools and high schools all require school fees; this means a family will end up spending a significant amount of their household income in order to put their child through years of education.

Since education, unlike manual labor, does not show immediate benefits to parents, for some, making such an investment in their child is difficult; however, the difficulty of this decision is significantly intensified for parents contemplating whether or 
not they should invest in the education of their blind child. Life-story participant, Evette, talks about this issue by stating, "Sometimes, even the real parents of a child will hold negative attitudes towards them. They won't push them for their education because they will never believe in his abilities to make use of his education." Since a blind child will not participate in manual labor for his/her family, their main window of opportunity and a future potential of financial stability lies in education. Although, for many families who lack knowledge of arenas of opportunity for the blind and potential contributions that blind individuals can make within society, or even prospective employment options open to them, many families fail to make the initial investment in the education of their blind child.

The chances of a blind child being put through primary school are far less than their sighted counterparts. An unconfirmed estimate given from life-story participant, Albert, was that only one-tenth of blind students in primary school go on to secondary school, and as the years progress the numbers continue to decrease, making the number of blind high school graduates in the country a small handful. Study participant and primary school teacher, Frank, gave an example in regards to the school he works at in Kampala: "[This] primary school began in 1999. Of the many blind students that have attended this primary school, only four have made it to university, all boys, no girls."

The International Disability and Development Consortium estimate that $98 \%$ of disabled children in developing countries are denied any formal education (IDDC 1999:7). In Uganda, there are significant regional differences in attendance of disabled individuals within schools. NUDIPU's baseline report reveals that the highest attendance rates of disabled individuals in schools are in the Eastern districts of Uganda and the 
lowest are in the Northern districts. ${ }^{23}$ The survey indicates that more than half $(51 \%)$ of children with disabilities are not going to school in the Acholi sub-region (NUDIPU 2010:13). In Gulu's bordering districts of Kitgum, Pader, and Amuru, which do not even have one school with facilities and resources to integrate any disabled individual, children and youth are forced to "join mainstream schools, yet such schools lack basic facilities for teaching them. This has contributed greatly to the high dropout rates of children with disabilities in [Gulu, Kitgum, Pader, and Amuru]" (ibid:14).

Barriers in access to education for persons with disabilities, including blind youth, are: (1) lack of support and assistance from their families; (2) stigma and discrimination; (3) lack of special needs teachers trained to cater to their needs; and, (4) lack of nearby schools. Lack of support from families and stigma were both attributed to lack of knowledge. The lack of "training and recruitment of special needs teachers did not receive high priority" due to the 20 years of war in northern Uganda (NUDIPU 2010:15). NUDIPU's survey revealed that the challenges in access primarily originate from "lack of government prioritization of education for children with disabilities" (ibid). Greater government attention and support in the education of the blind is not only necessary but fundamental in assisting the blind to enhance their quality of life.

When a blind child is not given the opportunity to access education, his or her ability to secure employment in the future becomes far more difficult. The following section examines access to employment opportunities in Uganda.

\section{ACCESS TO EMPLOYMENT}

There is a strong correlation between poverty and disability; the blind, as well as other disabled citizens in Uganda, are amongst the poorest category in the country.

\footnotetext{
${ }^{23}$ The Northern districts include: Gulu, Pader, Kitgum, and Amuru.
} 
Discrimination and marginalization brought on by having a disability prevents disabled individuals from accessing equal opportunities for development (Okidi and Mugambe 2002:6). One of the greatest components in the high rates of poverty amongst the disabled is discrimination in both the formal and informal employment sectors, which often contributes to significant barriers in personal empowerment and independence (Mont 2004:5).

In recent years, the government of Uganda has created policies in favor of employing disabled individuals in the labor market in an attempt to eradicate poverty amongst them (Mpagi 2002:94). However, employers are careless about these standards, and almost always favor non-disabled individuals, even if they have lower credentials. In the Persons with Disabilities Act of 2006, Section 12 prohibits discrimination within employment on the basis of disability. It states that "A person shall not discriminate against a qualified person on the ground of that person's disability in regard to any job application procedures, hiring, promotion, employee compensation, job training, and other terms, conditions and privileges of employment." It goes on to say that these discriminatory acts include: "favoring a non disabled employee over a qualified employee with disabilities;" "providing less payment, remuneration or fringe benefits, to a qualified employee with disabilities, than the amount paid to a non-disabled performing the same work;" or, "using qualification standards, employment tests or other selection criteria that screen out or tend to screen out persons with disabilities."

A baseline report conducted by the National Union of Disabled People in Uganda (NUDIPU), surveyed 979 disabled individuals to see what they believed was the cause of their unemployment. The responses given included: lack of employable skills (no formal 
education or vocational training) $(25.1 \%)$, negative attitudes from employers $(22.9 \%)$, immobility (15.8\%), lack of support to enable a PWD to work (i.e. a guide) (15.3\%), frailty (10.5\%), and inaccessible work environments (10.4\%). Disabled individuals in Uganda felt that failure in obtaining education in their earlier years, was the main contributing factor that prevented them from building the skills necessary to obtain formal employment opportunities, which in turn "condemned them to perpetual income poverty" (Lwanga-Ntale 2003:6). Lack of education also contributes to feelings of disempowerment amongst blind Ugandan adults, additionally many blind children who are not given the opportunity for education "lack self-esteem and confidence which, in later adult years, contributes to high unemployment figures" (ibid). Many disabled Ugandans surveyed by NUDIPU expressed that even if they did possess the necessary qualifications for a specific position advertized, they did not always apply because they believe they "would be discriminated against" (NUDIPU 2010:18).

Interviews with blind youth enrolled in educational institutions revealed that the majority of them felt positively about completing their education and securing employment in the future in order to better their lives and the lives of future generations of blind children and youth. However, interviews conducted with older blind community members who were mostly uneducated, revealed feelings of disempowerment and pessimism towards the labor market. This is because many of them had attempted to find work in the past, and were repeatedly turned away. Wilfred explained his views on employment for the blind by stating:

These people are never given the same opportunities as a normal person. We need to admit it to ourselves. What employment opportunities are open to the blind? Someone who is lame or deaf at least has their sight and they can engage in work of making shoes and repairing them on the 
side of the road. But for a blind person, they are only left with the ear. Their most important sense organ is gone. So finding employment is very difficult. The only [formal] employment opportunity for the blind is for them to work in a school. (Wilfred 16/07/2011)

Blind community members, who were generating an income for themselves, were doing it through independent initiatives, such as: knitting sweaters, selling small items on roadsides, or washing community members' laundry. Of the many blind individuals I met in Uganda, only two had positions in the formal employment sector: MHS teacher, Albert, and NUDIPU board member and primary school teacher, Frank. The commonality between these two individuals is that they have both attended and completed post-secondary education, which enhanced their opportunities for employment.

In the same survey by NUDIPU, mentioned above, employers were interviewed on their perception of hiring individuals with disabilities. The majority of employers stated that the "preferred categories of persons with disabilities to be employed were the physically disabled and the deaf" because "they can easily read and write and are energetic" (NUDIPU 2010:18). Their "least preferred category was the blind and the deaf blind" (ibid). The blind encounter extreme difficulty when it comes to securing employment, as most members of society perceive blindness as the most 'disabling' of all impairments. Evette talks on the issue of employment for the blind by stating:

It is very difficult for a blind person to find employment, more than anyone else. You have to face serious challenges when finding employment. When you move around with your certificate, the first question employers will ask you is "how will you manage?" You will always be considered last. If they are not able to find anyone else, then you will be considered. (Evette 19/09/2011) 
A blind community member, Kevin, ${ }^{24}$ explains his experience in looking for employment:

I went to be a gate attendant, and when I went for the interview they asked "and what are you seeing now?" When I took a minute to answer they said to me "You see we knew you could not do this job." The job was only for opening a gate and giving visitors a book to sign-in, I could easily manage but the employer refused me. I am still looking for work; it has been very long. (Kevin 28/08/2011)

Discriminatory behaviors practiced towards blind individuals have created disproportionately high unemployment rates amongst them compared to the rest of society. In the late 1990s, the unemployment rate among disabled adults, age $20-64$, was 80 percent higher than for individuals without disabilities in developing countries (Mont 2004:7). Employers and community members tend to discriminate against disabled individuals on the basis that they are non-productive members of society (Lwanga-Ntale and McLean 2003:13). Moreover, "prospective employers are suspicious [and] uninformed about the capability of a person with a disability to perform productively on a job; hence, they opt to play it safe and exclude such a person without even trying him or her" (Ndawi 2002:103). Although education does enhance potential employment security for the blind, it does not guarantee it; this is because blind individuals with a "good academic background" are still facing "severe discrimination in the employment market" (Katsui \& Kumpuvuori 2012:233).

Blind primary school teacher and a board member of NUDIPU, Frank, explains, "Persons with disabilities are the poorest of the poor, because people do not want to give us the jobs; employers do not want to hire us so you see educated blind people begging

\footnotetext{
${ }^{24}$ Kevin is the uncle of focus group participant, Derrick, mentioned in Chapter Three. I met him through the monthly gathering for the blind at St. Joseph's Orphanage/Primary School. He is approximately in his mid-40s. He was a participant in the Semi-Structured interviews.
} 
on the street." Notes compiled from discussions with three study participants (Kevin, Wilfred, and Frank) revealed four areas of recommendations on employment for the blind: (1) allowing the blind to have access to microfinance credit so they can establish their own enterprises and individual initiatives; (2) developing sensitization amongst employers and the community; (3) promoting vocational training workshops in various crafts for blind individuals who never went through formal schooling; and, (4) informing parents about the benefits of investing in the education of their blind child early on so these blind individuals will have increased access to employment in the future.

It is important that efforts made to improve the working and educational situations for the blind are open, inclusionary, and made in a unified effort (by community members, working professionals of the blind, the government, and the blind themselves). The four suggestions mentioned above really stem from one primary issue: a lack of understanding and sensitization of blindness from the general society. Therefore, it would be in the greatest interest of blind individuals if focus and attention is brought to informing the community of the capabilities, value, and potentials a blind person can offer and make in society. In an interview with study participant, Komogum, he mentions in a quote (used on page 114-115), that it would be beneficial if an educated blind person was brought into these types of gatherings in order to display to community members that educating a blind person is not a wasteful investment. By focusing on enhancing community understanding of blindness, in order to have greater numbers of educated blind people in society, other current and pressing issues in the country for the blind will also improve, including employment. 


\section{ACCesS TO Health SERVICES}

The occurrence of illness and disease are most common amongst vulnerable populations in society, and disabled individuals are considered one of the world's most vulnerable populations (Groce 2005:215). In Uganda, the exclusion of persons with disabilities from healthcare and health services is a problem in nearly all districts of the country. Lwanga-Ntale (2003:12) found that blind individuals in one health facility in Iganga, ${ }^{25}$ Uganda, were being skipped over "because they had not come with proper guides."

Interviews revealed that the two main barriers in accessing health services for the blind were: stigma from health care providers and lack of transportation and mobility. Eighty percent of persons with disabilities in Uganda live more than one kilometer away from a hospital; therefore, this presents a problem to blind individuals who do not have mobility canes, caretakers, or money for boda transportation. ${ }^{26}$ of that $80 \%, 56 \%$ live more than three kilometers away, making it significantly difficult for a blind person to access health facilities (NUDIPU 2010:6). Furthermore, "the high poverty levels among persons with disabilities aggravates the situation," because transportation fees increase in relation to the distance being traveled. When disabled individuals manage to turn up at health facilities, it is not uncommon for them to be "automatically referred to bigger hospitals" because staff members are "unsure how to handle [them]" (Lwanga-Ntale 2003:12). Focus group participant Samson explains, "I have met blind people that were only partially blind but, because of lack of healthcare, they are now completely blind."

\footnotetext{
${ }^{25}$ Iganga is district in eastern Uganda with a population of around 55,000 .

${ }^{26}$ Boda bodas or more commonly known as bodas, are motorcycle or bicycle taxis. They charge negotiable fees to deliver individuals to their place of destination.
} 
Today, one primary concern for the blind population in Uganda is high rates of HIV infection. One factor contributing to this is that "women with [disabilities] are up to three times more likely to be raped than non-disabled women; boys and men with disability may face equal risk of rape and sexual abuse as these disabled women" (Groce 2005:218). Mulindwa (2003:49) conducted a study on HIV/AIDS infection amongst disabled individuals in Uganda; she found that $37 \%$ of disabled individuals felt that rape is the biggest problem in HIV/AIDS contraction. Moreover, sexual violence is a greater concern in northern Uganda than other parts of the country. A baseline report from NUDIPU states:

As a result of war, gender violence and sexual violence has intensified in the Acholi sub-region, both arising from the direct acts of rebels, but also within the communities and families. This has had a great effect of worsening the spread of HIV/AIDS and the infection rates are among the highest in Uganda. (NUDIPU 2010:9)

The survey revealed that only $61.5 \%$ of persons with disabilities had received HIV/AIDS services (ibid). This is primarily due to the fact that persons with disabilities "are not reached with HIV/AIDS messages; [they] are unaware of the symptoms of HIV/AIDS, and do not understand the implications of these symptoms, should they appear" (Groce 2005:221).

One of the key reasons the blind are facing barriers in accessing various opportunities in the country is primarily a result of the ineffective functioning of governmental structures for disabled people, and poor leadership of district heads in combination with negative social perceptions of blindness and blind people. The following section analyzes the role of the Ugandan government and local leaders in the functioning of blind persons in society. 


\section{UGANDAN GOVERNMENT, LOCAL LEADERS, AND THE BLIND}

As a marginalized group in Uganda, the most urgent needs of the blind and visually impaired are ignored and unanswered. Negative social perceptions towards the blind have contributed to them being a voiceless category in society. Therefore, they are unable to represent themselves and communicate their positions and feelings on community initiatives or governmental workings. As mentioned before, they are often uninformed about development opportunities and left out or uninvited to community gatherings, and during rare occasions when they are present, they are overlooked by their able-bodied counterparts. It is understood that most disabled individuals "have neither representation nor voice in decision-making, including regarding matters that affect their well-being" (Lwanga-Ntale and McLean 2003:13).

Since the blind are marginalized from participating in decision-making on matters that could potentially benefit their lives and current conditions, they have local councillors (LCs), district leaders, or organizational heads that represent them in society, or speak on their behalf. However, the large numbers of representatives that have worked on behalf of disabled people have had little or no effect on their livelihoods (LwangaNtale 2003:19). Many of these representatives fail "to visit, consult or feed information back to their constituents" (Lwanga-Ntale and McLean 2003:13). They are rarely in touch with disabled persons to keep them informed on matters regarding issues relevant to their lives. Life-story participant, Angel, explained during an interview that she had gone to visit the district leader of Gulu to discuss financial assistance she had been promised; however, once she arrived, she was lied to and turned away. She explains:

As a blind person, you depend on your hearing to identify individuals...people's voices become their faces, and it becomes natural 
for you to identify someone by hearing them. When I went to visit the district officer of Gulu to ask him about the funds I was promised and never received, I heard his voice. He was telling the secretary 'Make that blind woman leave, tell her I'm not around.' They view us as a burden but they enjoy benefiting from us. (Angel 25/08/2011)

A current and pressing issue for blind individuals, which many study participants voiced during interviews, was the misuse of funding for the blind by local and regional leaders. Study participant and NUDIPU board member, Frank, explains, "The misuse of funds is across the board, it is everywhere: at the government level, at the district level, and in the institutions, including the schools." In most cases, local representatives of the blind will outline and propose agendas and development schemes, which they state could benefit the lives of the blind if implemented with the necessary funding. These proposals are then submitted to the government and internal and external NGOs. If the projects are approved, the district and local leaders, representing the blind, are able to secure significant amounts of funding. However, once local and district leaders are awarded funds, the majority of the money is withheld by them, and only a small portion of the money is given to the blind. Angel explained that on a separate occasion she was sponsored by the government to complete six months of vocational training. Yet, after only being enrolled in the program for a month and a half, her funding had stopped and she was unable to continue. She explained that she had attempted to inquire about the issue and look for funding from other sources; however, she was unsuccessful. She spoke of the issue during an interview:

The local leaders did not allow me to finish the course. When [the local leaders] submit their budget to the government, the government will submit money back to them to carry out activities. Then [the local leaders] will decide to only send us to attend training for a small time and then they use the rest of the money for themselves. (Angel 25/08/2011) 
Many of the blind community members interviewed explained this to be a fundamental problem and barrier they were experiencing. Rather than the government and organizations sending money directly into the hands of the blind, it passes through individuals who withdraw large portions of funding that have originally been allocated to develop projects to empower the blind. Study participant Wilfred explains, "[Local leaders] know very well that [the blind] cannot do anything, that they are powerless, and cannot take it to the authority above them. So they abuse them the most."

According to study participants, when reports are written on the status of projects, they usually state that they have accomplished their goals and the projects have been successfully implemented. However, if follow-ups are conducted, which they rarely are, in almost all cases, no benefits can be seen. Wilfred talks on this issue:

[The blind] do not have a voice. We call them the voiceless. The chairperson for Gulu district is the person that is supposed to represent their views accurately, but they always lie and tell the government that people have achieved their goals and are doing something with the funds given to them. But if follow-ups are carried out they realize not one thing has been accomplished. (Wilfred 21/09/2011)

It should be noted, that although many of the political and structural issues that exist in the country present barriers for the blind: "The disability rights movement in Uganda has achieved a great deal, including forming a unified voice of people with disabilities, the National Union of Disabled Persons of Uganda (NUDIPU)" (Aniyamuzaala 2012:283). Due to the inception of this organization, people with disabilities are now able to vote on individuals to represent them in parliament; out of the 215 Constituency Representatives, there are five seats allocated to PWDs in Uganda's parliament. However, Aniyamuzaala (2012:285), who currently works in Uganda as the 
President of the Steering Committee of the African Youth with Disability Network, describes the problem of parliament members who represent PWDs:

There is always interference by some government officials in the election of the members of parliament. Consequently, [PWDs in parliament] end up representing the interests of the government more than the interests of people with disabilities. Sometimes the government supports the election of representatives of persons with disabilities who do not fully understand the needs of the disability movement. Any disability rights activist who opposes [the government's] interference (which is against the law) is considered to be against the government and those members of parliament elected by people with disabilities who have been corrupted. This has affected the disability movement of Uganda - as the working relationship between disability rights activists and representatives of people with disabilities in parliament has loosened. And the disability movement in Uganda has been weakened. It is very important for the disability movement in Uganda, and in East Africa more widely, to separate politics from the real business of advocating for their rights and improving the lives of people with disabilities.

As voiced through interviews by study participants, there is a dire need for

changes to happen within the social, political and economic structures currently existing in Uganda. Unless this takes place, no future improvements for the lives of the blind or any other category of disabled persons will be possible. The following section provides an anthropological perspective on how structures and institutions can prevent individuals from acquiring their most basic needs, hence causing them to experience social suffering.

\section{DiSCUSSION: STRUCTURAL VIOLENCE AND SOCIAL SUFFERING}

Structural violence can be understood as "social arrangements that put individuals and populations in harm's way. The arrangements are structural because they are embedded in the political and economic organization of our social world; they are violent because they cause injury to people (typically, not those responsible for perpetuating such inequalities)" (Farmer et al. 2006:1686). Anthropological work on structural violence examines how states use violence, in the form of social and 
institutional powers and structures in order to silence resistance, manipulate certain groups in society, and to work for their own benefit. This area of study has proven useful for anthropologists interested in a critical medical anthropology (CMA) approach when it comes to analyzing social oppression, marginalization, illness, and suffering.

Unlike CMA, medical anthropology has "tended to be narrowly focused on the micro level and involved explaining health-related beliefs and behaviors at the local level in terms of specific ecological conditions, cultural configurations, or psychological factors" (Singer 2004:24). Critical understandings are often influenced by political economy and seek to address macro-level issues. It is a distinctive approach "not simply because of its scope and concern with the macro-level, but more importantly by its commitment to embedding contexts" (Singer 2004:25, Morsy 1996). By applying a CMA approach when examining social suffering, anthropologists, and researchers alike are able to understand "that the physical, material and social organization of our society promotes inequalities, and withholds rights and resources to some groups" (Davis 2010:196). This is evident in the case of the blind in Uganda, who are denied access to the most basic needs of full citizenship.

As explained by Kleinman, Das, and Lock (1996:xi), social suffering "results from what political, economic, and institutional power does to people, and, reciprocally, from how these forms of power themselves influence responses to social problems." As witnessed in the three sections above, addressing topics of access, poverty, and governmental workings, it is evident that there are multiple forms of disablement in Uganda for the blind. The ability to access different avenues of empowerment, including information, education, employment, and health services, is a critical component of 
inclusion, social acceptance, and an aspect of self-development. However, when denied these opportunities, disabled individuals become socially oppressed and marginal in society, and, as a result, they suffer from political injustice.

In their inability to access different services granted to their able-bodied counterparts, the blind lack knowledge and experience, making them a vulnerable category in society. Furthermore, not only is access to resources and services critical in empowerment, it is also a component of healthy living. Singer (2004:26) explains that "within CMA, health is defined as access to and control over the basic material and nonmaterial resources that sustain and promote life at a high level of satisfaction. Health is not some absolute state of being but an elastic concept that must be evaluated in a larger socio-cultural context." Moreover, in terms of health and prosperity, Farmer (1996:276) also found that the origin of "increased rates of morbidity and mortality" amongst South African blacks stem from their lack of access to resources. Farmer explains that this serious lack of resources has forced them into dire poverty, and "poverty remains the primary cause of the prevalence of many diseases and widespread hunger and malnutrition among black South Africans" (ibid).

Without access to information and education, the blind in Uganda are denied full participation in their communities, and are ignorant of how to mobilize themselves and improve their lives. Denial of employment has created high rates of poverty amongst disabled persons, making them one of the most impoverished categories in society. A lack of money to pay for transportation in order to reach distant medical facilities, negative attitudes from community members and health practitioners, and malnutrition from lack of care by caregivers, all contribute to potential health problems amongst 
disabled persons. Furthermore, the problem of chronic poverty amongst the disabled places them in situation where they are more susceptible to illness and death. In his work, On Suffering and Structural Violence: A View from Below (1990), Farmer explains that:

The World Health Organization now acknowledges that poverty is the world's greatest killer: "Poverty wields its destructive influence at every stage of human life, from the moment of conception to the grave. It conspires with the most deadly and painful diseases to bring a wretched existence to all those who suffer from it." As the twentieth century draws to a close, the world's poor are the chief victims of structural violence. (1996:279-280)

Bourgois and Scheper-Hughes (2004:318) suggest that is necessary for critical

anthropologists to "disentangle the causes, meanings, experiences, and consequences of structural violence and show how it operates in real lives." Moreover, Bourgois and

Scheper-Hughes support where anthropological work can be useful:

'Violence' is a slippery concept that goes beyond physicality to include assaults on self-respect and personhood. The social and cultural dimensions of violence are what give it its force and meaning. Farmer's model of structural violence is a vivid reminder that most violent acts are not deviant. They are defined as moral in the service of conventional norms and material interests. As ethnographers we can best contribute by rendering visible these erased and unexpected linkages between violence, suffering, and power. (2004:318)

These instruments of oppression, suffering, and 'disablement' are both politically and socially rooted, and should be examined within their own contexts. By identifying the factors that encourage suffering and oppression amongst the disabled, we stand a chance to stop them. 


\section{CHAPTER SIX: CONCLUSION}

\section{General OVERVIEW}

This thesis explored the lived experiences of blind individuals in society through their life story narratives, ideas about their selfhood, and coping mechanisms employed when dealing with social neglect. The focus of this study was narratives during blind persons' youthhood, and the geographical context was northern Uganda, specifically Gulu.

In order to fully understand the experiences of blind study participants, Chapter Three explored the role and influence of external forces, specifically the family and the social world on individual lives and personal identities. However, as stated in this thesis, the social contexts of disability are dependent on historical processes. The history of disability in Uganda and of the Acholi people, detailed in Chapter Two was, therefore, critical in establishing a background to understand the current social behaviors towards the blind. Furthermore, in Chapter Five this thesis considered the role of Ugandan structures and institutions on life experiences of the blind. It explored how the functioning of these institutions has further disintegrated and disempowered blind individuals in schools and society through various means, specifically in forming barriers to access education, employment, information, and health services, and creating an environment of inescapable poverty for the blind.

This chapter provides an overview of the main study findings and their implications. This study also allowed for blind participants to discuss their thoughts on improvements they believed were necessary to promote blind individuals' integration, empowerment, and positive experiences in schools and society. These and other practical 
suggestions are discussed in this chapter, followed by a reexamination of collaborative work between anthropology and disability studies. Lastly, this study discusses areas in need of future research for disabled persons in Uganda.

\section{SUMmary OF MAIN Findings ANd SUggestions}

Three key points that surfaced after data collection were: (1) the conceptualization of a disability is dependent on the way the larger society defines it - in Uganda meanings attached to disabilities are demoralizing and erosive to blind individuals' personhood and social identity; (2) the social environment and functions of governmental structures and institutions, in terms of their allowance to access different services, work as barriers and further marginalize and disempower the blind; (3) lastly, blind individuals' experiences, self-perceptions, and ideas about their selfhood and self-worth are heavily shaped by the social and political contexts in which they exist.

This study further identified four interconnected thematic categories amongst lifestory participants: stigma, ideas of personhood/selfhood, communitas, and education. These themes, explored in Chapter Four, examine from the perspective of blind youth the various factors that inhibit and promote integration and empowerment for the blind, and their subsequent life effects. Since the key points of this thesis are deeply interrelated with the thematic categories identified in life narratives, the following discussion on main study findings will encompass these different points and categories simultaneously.

The first of the thematic categories, stigma, can be acknowledged as a marginalizing and disempowering social force. This study found that stigmatized feelings and perceptions held by the larger Ugandan society towards the blind, contributes to blind people's marginalization and oppression in social, political, and economic life. Although 
blind participants desired to improve their current situations and promoting positive change, their discredited social status was working as a barrier in achieving this. They identified themselves as voiceless; their most basic needs were unattainable and were generally overlooked by society, including community members, teachers, health care providers, local leaders, and the government. Moreover, marginalization, a loss of voice, and all other pressing issues affecting blind individuals in society were intensified for both women and youth. The difficulties these blind study participants are facing in Uganda, to a certain extent, are brought on by their impairment; however, to a large extent, they are brought on by social and cultural definitions attached to blindness.

The reason blind participants find greater difficulties in society than from their blindness is because what becomes a disability to a person is primarily determined by "social meanings [attached] to particular physical and mental impairments" (Albrecht and Levy 1981:14). These socially constructed definitions of blindness and blind people assist in fostering negative perceptions towards the blind, which stigmatize them in society and create attitudinal barriers for them. This brings us back to the first key point of this thesis - ideas about blindness and blind people are conditioned by Ugandan society; these social definitions have a great deal of power and influence on the subjective experiences and personal and social identities of blind individuals. This is because a person is not born with an identity; rather, his identity is created and influenced by society. The second of the thematic categories, ideas about selfhood/personhood, further explores this.

Personhood, or the individual self as a social entity, is imposed by society. In the context of Uganda, ideas towards blind individuals' personhood, like stigma, could also be categorized as a disempowering and disintegrating force. The notions created around 
individuals' social identities are assimilated into forming their own personal identity, self-perceptions, and ideas about their selfhood. Thus, study participants expressed that negative social discourse on blindness and blind people contribute to their feelings of social devaluation and lessened self-worth. Furthermore, in order to achieve full personhood in Uganda, an individual must prove himself or herself to be self-sufficient, and must be perceived to be a valuable, contributing member of society. This includes: securing employment, getting married, owning land and a home, having children, and providing for them. However, due to social, political, and economic barriers, the blind have difficulties in accessing education, which further prevents them from securing employment. They are denied land from their families, and they are viewed as being unsuitable spouses as they are perceived as unable to provide or care for their children. Due to these factors, blind individuals are prevented from achieving full adult personhood similar to that of the rest of society.

This speaks to the second key point made - the created social environment in Uganda works as a barrier in promoting full integration and empowerment for the blind. In order to improve these conditions, various suggestions given by study participants included: (1) Community sensitization - participants believed that if educated blind individuals were given the opportunity to speak with community members, the community would be able to see the benefits in promoting the education of blind persons and it would assist in further familiarizing the community to the lives of the blind. (2) Redistribution of power - participants voiced the opinion that the local leaders, who represented and spoke on behalf of the blind, had their own self-interests in mind; Ugandan local leaders were said to be working more for their own benefit than that of 
blind individuals they represent. Participants suggested placing more power in the hands of the blind by giving them greater voice in society so they are able to represent themselves, advocate their own rights, and spearhead problems most significant to their own lives and personal conditions. (3) Developing resources - study participants expressed that by developing resources available to them, blind individuals can have greater opportunity to take part in society and social matters. This includes enhancing mobility devices. In doing so, blind individuals would have improved access to information, healthcare facilities, community gatherings, and employment opportunities. In schools, this would mean providing all blind students with Braille paper, Braille machines, Braille textbooks, audio supplements, and by developing the capabilities of special needs teachers and those working with blind students.

The role of education was identified as a third thematic category. Unlike stigma, and notions against blind individuals' personhood, education helps in promoting the integration and empowerment of the blind. All study participants expressed the importance of education on the life-quality of a blind person. Since the blind are unable to take part in manual labor, their main avenue to independence rests in pursuing their education. Study participants identified various ways that education can improve the lives of the blind: (1) Education gives the blind the ability to work towards independence and self-reliance - participants believed that through education, blind individuals were more likely able to secure employment. In doing so, they would be able to earn an income and provide for themselves, rather than depend on the assistance of others, which comes with its own issues. (2) Education has the ability to empower the blind - participants explained that education can improve the self-confidence of a blind person and foster positive and 
optimistic feelings for the future. (3) Through integrative educational facilities, blind and sighted students can learn to work harmoniously - blind participants expressed that although some sighted students still hold negative feelings towards them, they would rather be in an inclusive school than in a separate school for the blind. One reason for this was that they could have early exposure to one another, so that both sighted and blind students would be able to learn more about each other's lives. Integrative educational settings were also said be beneficial in lessening social stigma towards blind individuals by sighted persons in the future.

This speaks to another key point in this thesis: blind individuals' experiences and self-perceptions are heavily dependent on the contexts in which they exist. By improving the conditions of blind individuals' social world, such as the quality of their education, accessibility to avenues of empowerment, community sensitization, enhancing resources, and promoting their integration in society, blind individuals will have better experiences in schools and society, and an improved life quality.

The last of the thematic categories, communitas, like education, promotes the empowerment of blind individuals. Communitas, a social community formed amongst individuals facing social stigma or liminality together, is constructive to improving ideas of self-worth amongst its members. Communitas is an instrument employed by blind individuals for support and to promote an environment of equality amongst themselves. Blind study participants, who identified themselves as part of a social group, were more positive and confident about the future. Communitas can be an example of the benefits of social groups and forums for marginalized persons in society. If specific forums were created to give blind individuals the opportunity to voice their opinions and be activists 
for their own rights, this would give them the ability to work together to mobilize themselves to improve their lives.

Through the use of methods described in Chapter One, study findings provided valuable thematic categories based on life narratives of blind youth and signalized areas in need of further attention in the future. The following section examines anthropological engagement with disability studies, followed by future directions of research.

\section{ANTHROPOLOGY AND DISABILITY}

Anthropology has the potential to make significant contributions to disability studies by bringing to surface life narratives of individuals who are being affected by impairments. This is because, currently, there is limited academic literature that includes the subjectivity and voices of disabled persons, especially in developing countries. Anthropology, therefore, has a significant place in future research within disability studies; anthropologists understand that disability cannot be fully examined through its medical context because it is "so complex, so variable, so contingent, and so situated. It sits at the intersection of biology and society and of agency and structure. Disability cannot be reduced to a singular identity: it is a multiplicity, a plurality (Shakespeare and Watson 2001:19).

Susan Reynolds Whyte (1995) suggests that anthropologists should pioneer new theoretical approaches to expand the anthropology of disability studies, while not losing sight of traditional ethnographic focuses on cause and cure. Reflecting on my own study, I found that focusing on life narratives was an important component in detailing information about an individual's personal experiences with a disability. Moreover, it also tells a great deal about the functions, views, and relations of power in a given 
society. I advocate anthropology's continued practice of collecting life narratives, in addition to other theoretical applications. One area that may make the greatest contributions to the lives of disabled persons would be through the application of a human rights perspective.

Human rights can be understood as "internationally agreed values, standards or rules regulating the conduct of states towards their own citizens and non-citizens" (Baehr 1999:1). In combination to the theory of personhood, discussed in Chapter Two, which is the status of being a person, which brings into question what makes a person in a given society, anthropologists are able to research the notions of personhood amongst disabled individuals and are then better able to conceptualize how their rights as citizens are being abused. When combining personhood and a human rights perspective, a further analysis can be drawn of social inequalities and power relations. Academic work within human rights could make significant and further contributions to the lives of disabled persons and would be an area of interest for myself in the future, which I further elaborate on in the next section.

\section{FUtURe DiRections}

Employing a human rights perspective within anthropological research on disabilities and disabled persons may further highlight ways to improve disabled individuals' life-quality. Although anthropologists have made past contributions within human rights, they have largely been uninvolved in its policy formulations (Messer 1993:221). Moreover, Karna (1999:5) states:

During the last couple of decades, extensive research has been conducted in developed societies regarding the social integration of disabled persons. In [India], too, the last few decades have witnessed a proliferation of studies and surveys concerning the problem of disability. What has not yet 
been attempted is a comprehensive and integrated study with a human rights perspective, covering multi-dimensional problems, confronting the disabled person(s) both as an individual and in groups.

Future research within disability studies, specifically in the developing country context, should focus on how they can promote human rights for disabled persons. Farmer (1999:1488) explains that anthropology allows for both human rights abuses and discourses to be placed together in their broader contexts. He further explains that anthropology permits researchers to "ground [their] understanding of human rights violations in broader analyses of power and social inequality; whereas a purely legal view of human rights tends to obscure the dynamics of human rights violations." Farmer (1999) encourages researchers and anthropologists to adopt an inclusive human rights perspective in order to better conceptualize pathologies of power. However, Shuttleworth (2004:366-367) explains that past work within the anthropological study of disability has minimally analyzed "relations of power." He further explains that detailed critiques of power relations which work against impaired individuals are of paramount importance in order to understand social exclusion and oppression in a given society (ibid:367).

This study conducted on the lived experiences of blind persons in Uganda is an important academic contribution because it brings to surface the voices of marginalized and socially oppressed individuals in society. However, further contributions can be made to their lives if these narratives are used to research broader contexts of human rights violations and, additionally, through the application of a critical interpretive approach in anthropology. Since a human rights perspective permits anthropologists to analyze social inequalities and power relations, a critical medical or critical interpretative approach in anthropology can, additionally, further seek to understand the impact of these 
political and economic power relations on the health conditions of disabled populations, and can also assist in improving the condition of this vulnerable group in society. Given that anthropologists are concerned with improving the lives, conditions, and situations of those they study through their research of often overlooked groups in society, this would be an important perspective to take on for further study within disability topics and issues. 


\section{FIGURES AND MAP ${ }^{27}$}

FIGURE 1- Deviance-Liminality-Stigma Model (Reid-Cunningham 2009:105)
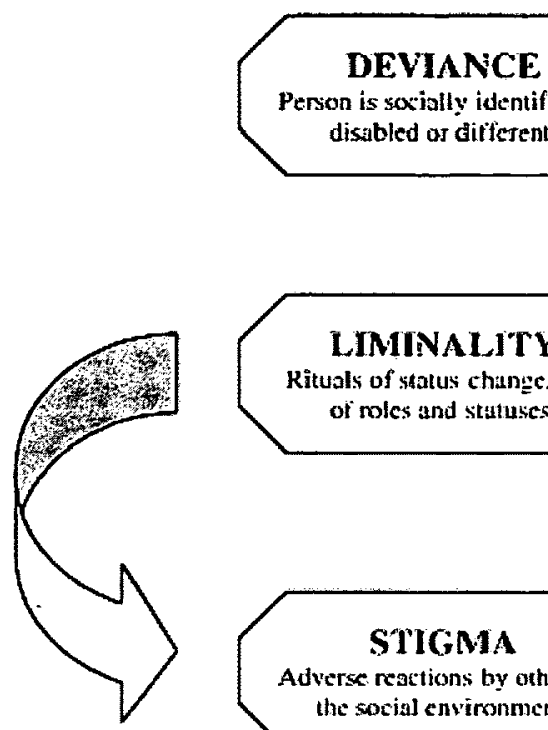

Person is soriblly identified as disabled or dititerent.

\section{STIGMA}

LIMINALITY

Kituals of utatus change. Jass oi moles and stumises.

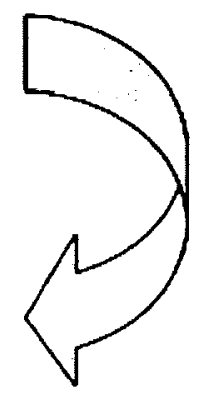

FIGURE 2 - MHS BLIND ANNEX OFFICE

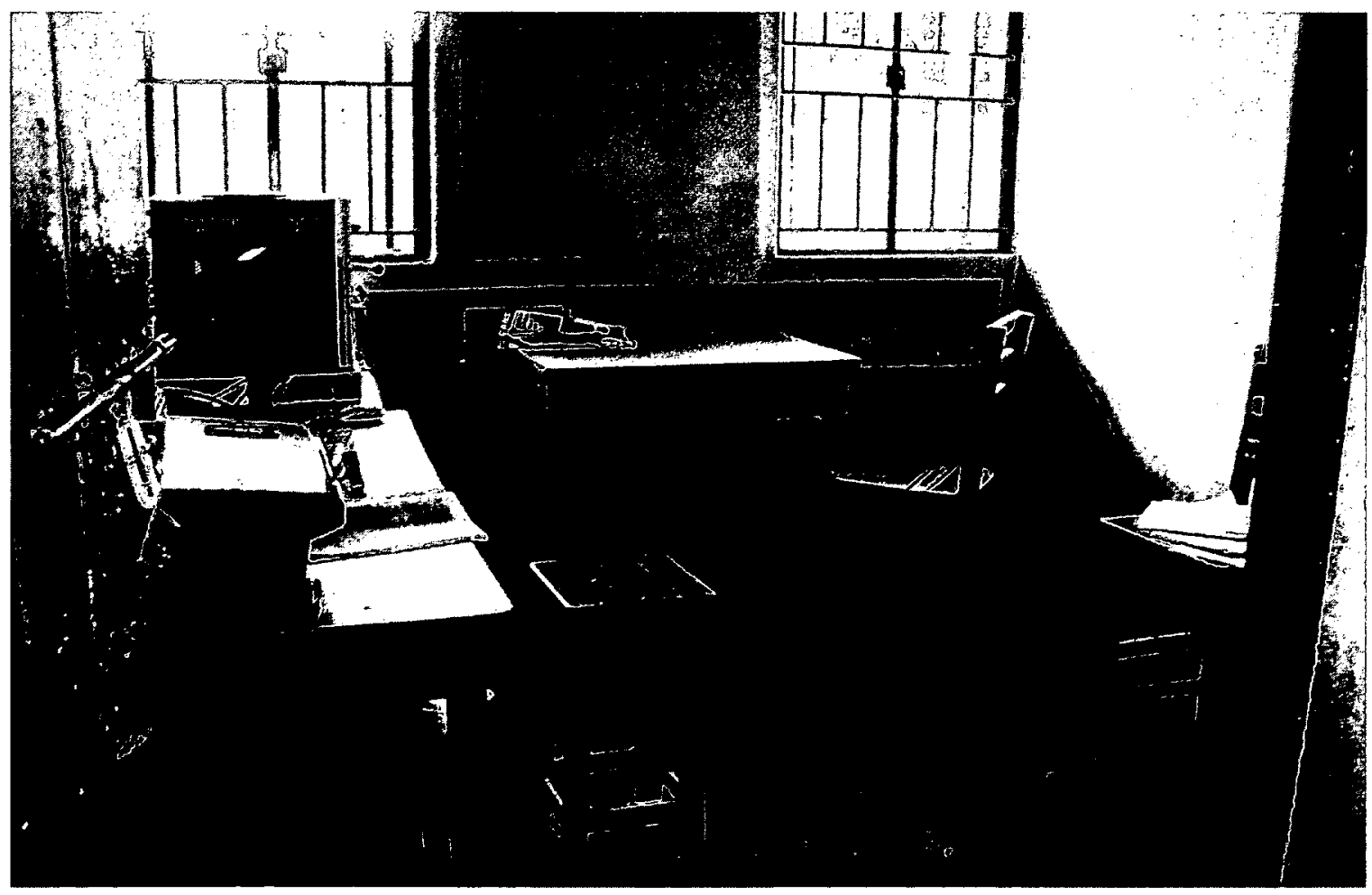

${ }^{27}$ Figures 2-6 are photographs taken by me while in Uganda during the summer of 2011. Map 1, which is a map of Uganda, was made by copying and pasting a screen shot from Google maps. 
FIGURE 3 - MHS ANNEX OFFICE EQUIPMENT

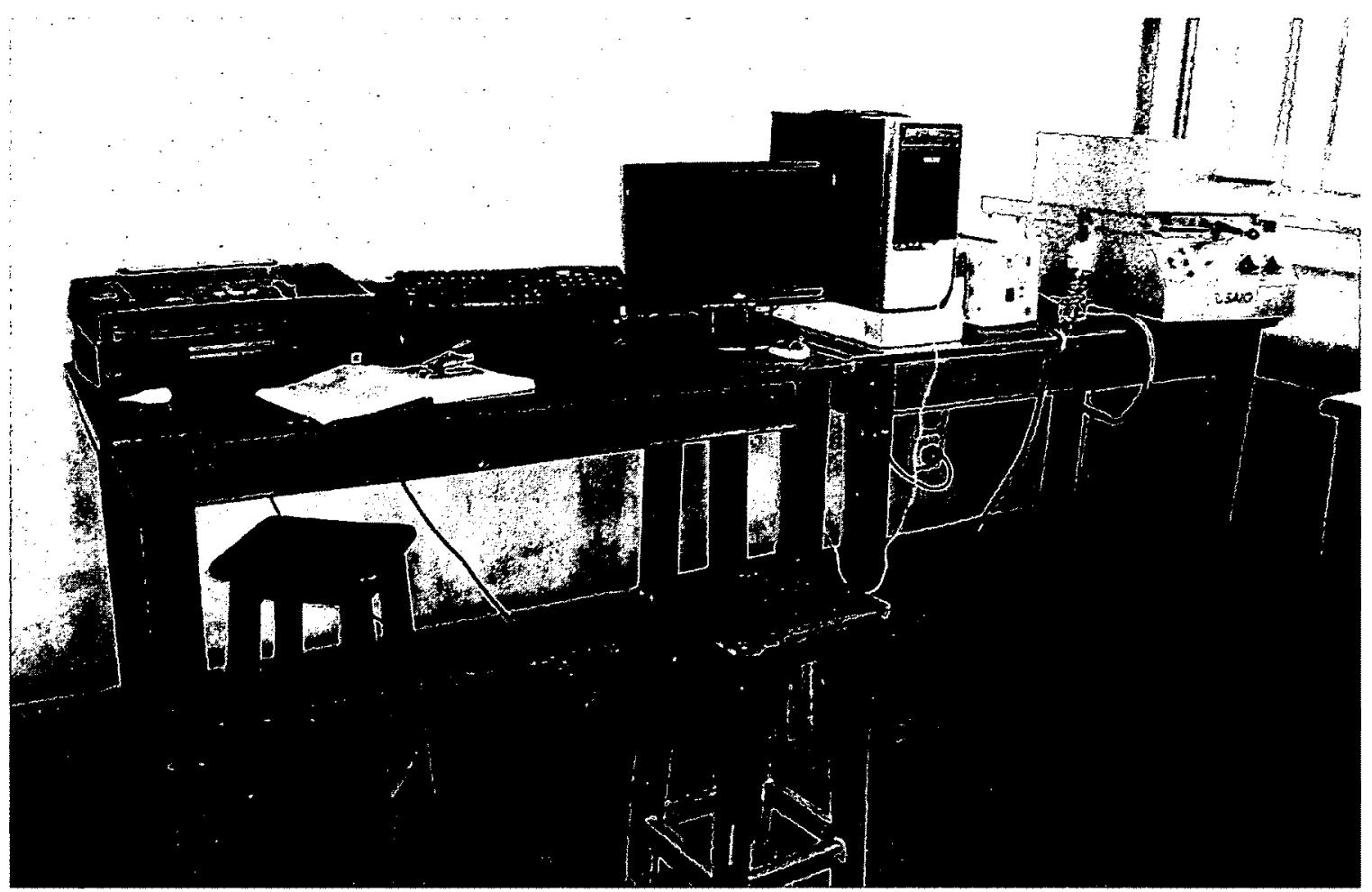

FIGURE 4 - MHS BLIND ANNEX ENTRANCE

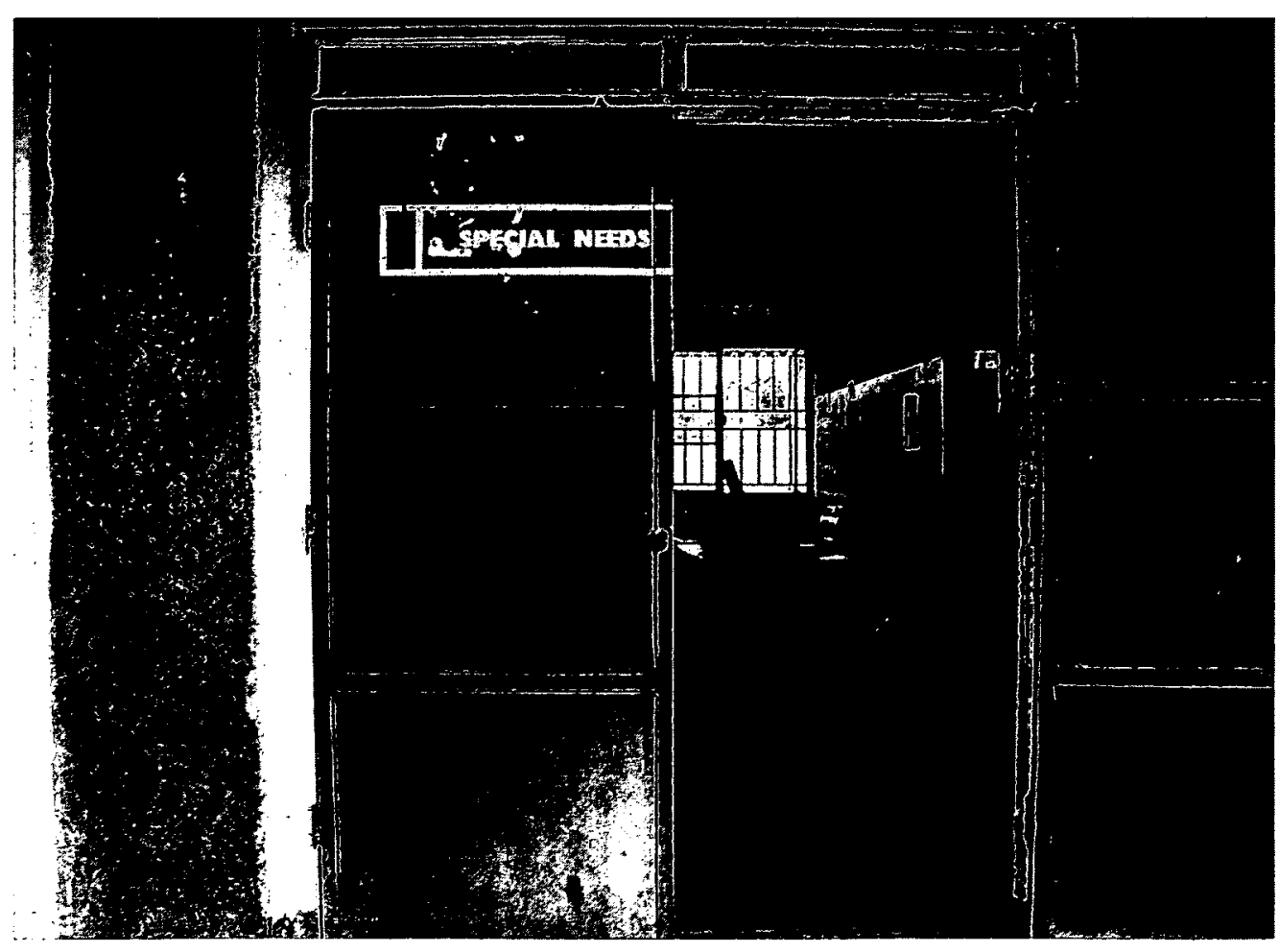


FIGURE 5 - MHS BLIND ANNEX MAIN ROOM (Right side of room)

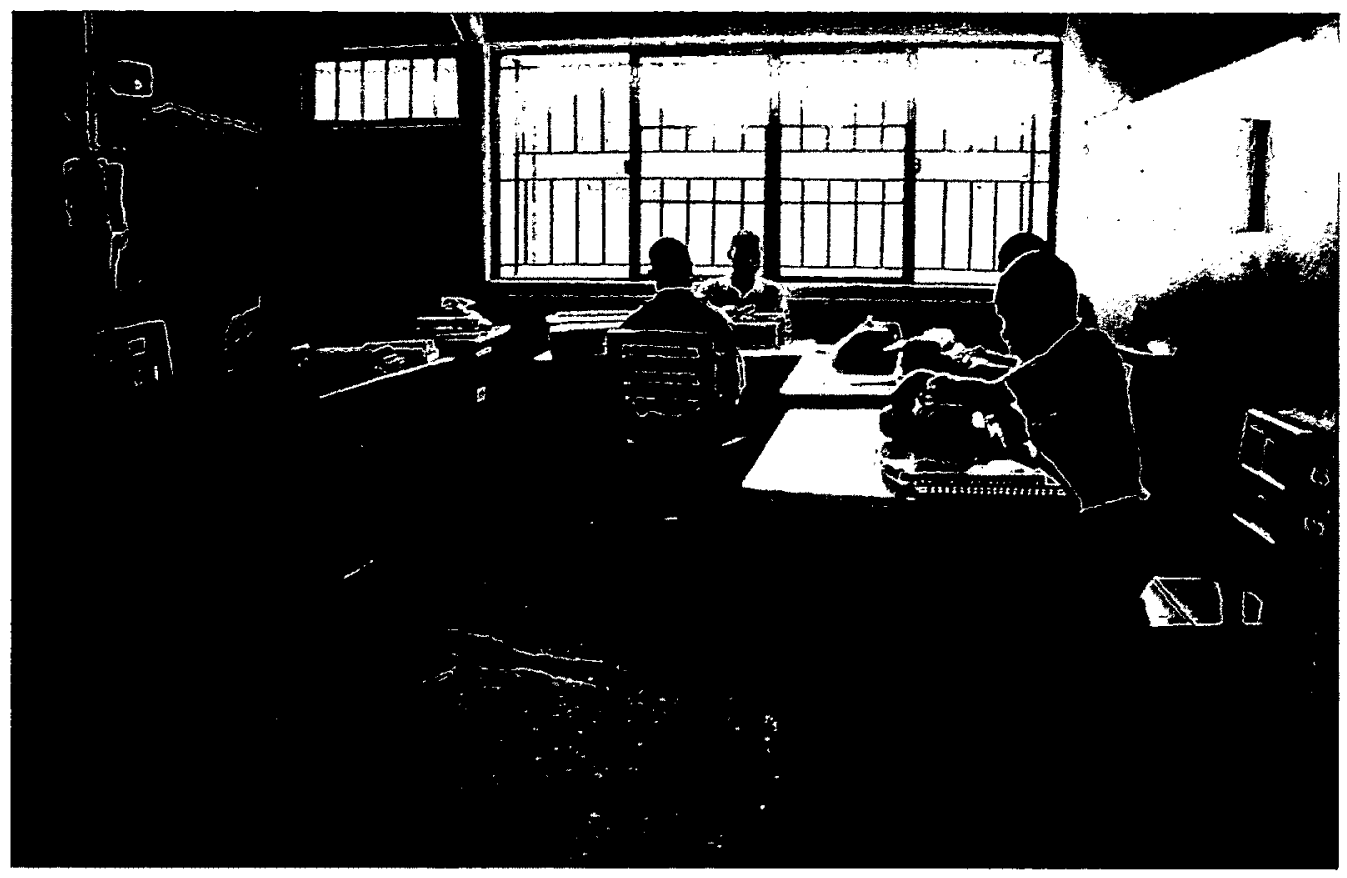

Figure 6 - MHS BLIND ANNEX MAIN ROOM (Left side of room)

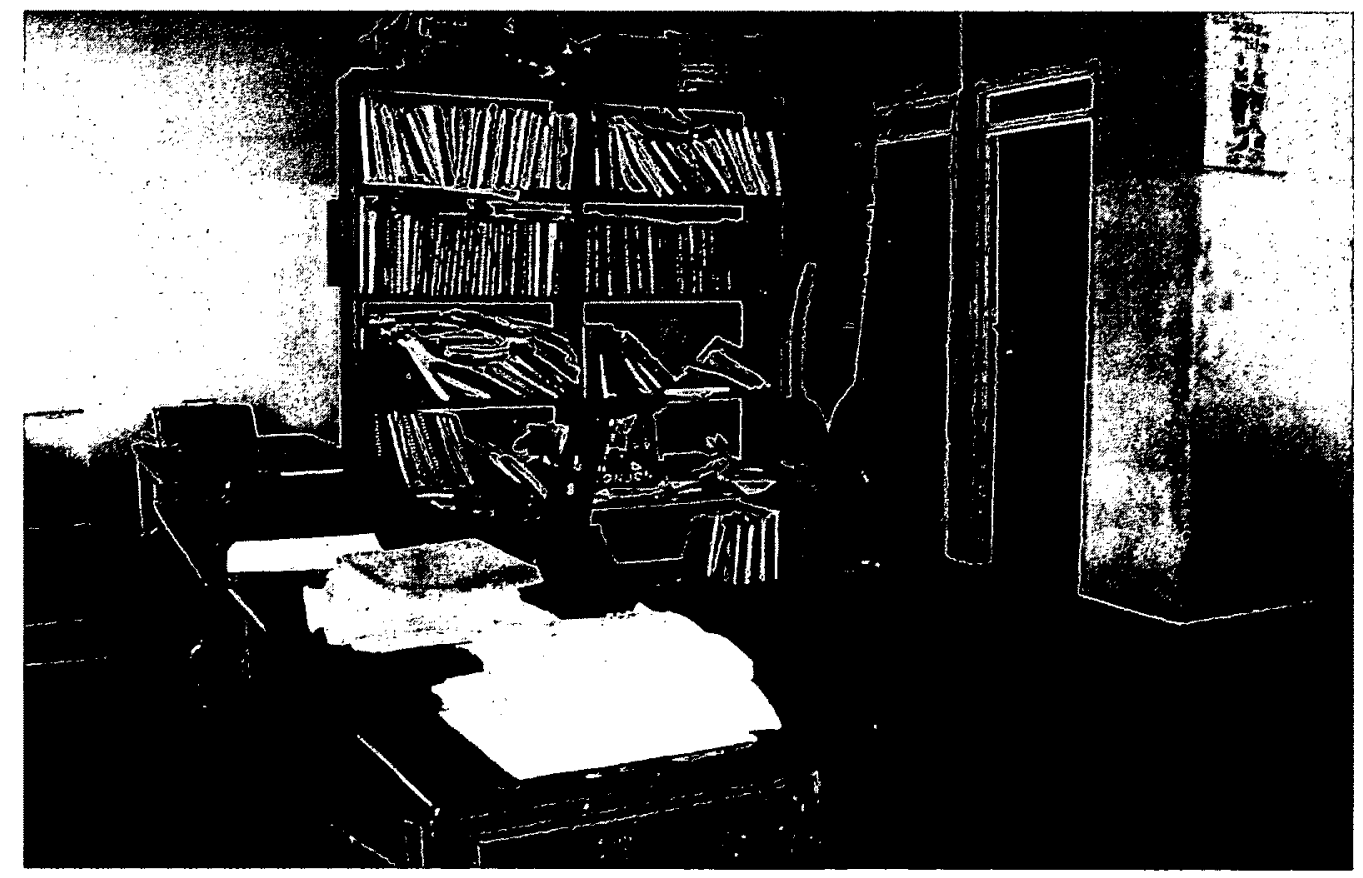


MAP 1 - MAP OF UGANDA (maps.google.com)

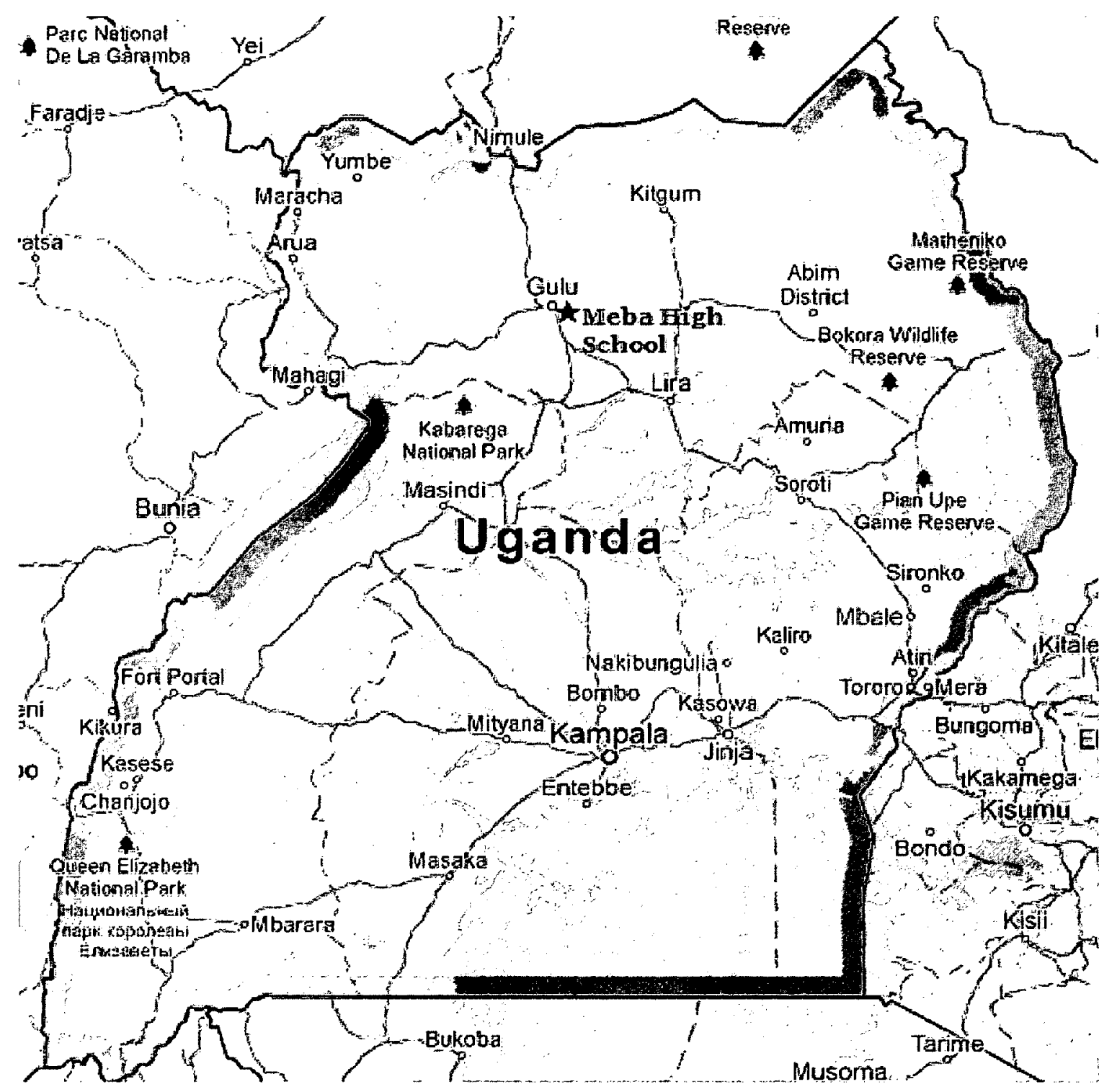




\section{APPENDiX A: SAMPLE QUeSTIONS For Life STORY}

\section{BACKGROUND INFORMATION}

- Tell me about yourself and your life here.

- Were you born blind? How did you become blind?

- If you became blind after birth how has it changed you? [probe: Has it changed your self-perception? Tell me about any life adjustments you have made.]

- Tell me about your childhood and growing up in Uganda.

- Tell me about your family.

a. What has been their role in your life?

b. What are their feelings towards your blindness?

c. Have they been supportive of you?

- Tell me about the difficulties you face at home, school, or in society?

- How do you deal with these difficulties?

- Tell me about any activities you are involved in. (e.g. sports, church, at home, or at school?)

- Tell me about some of your goals and ambitions for the future.

a. How do you plan to achieve them?

- Tell me about some of the greatest struggles you have faced in your life.

- Tell me about some of your greatest accomplishments. How did you achieve them?

- Tell me about any romantic relationships you have been in? Has your blindness affected your love life? If yes, how so?

\section{EXPERIENCES WITH BLINDNESS}

- Tell me about growing up as a blind youth in Uganda (if this is the case).

- Tell me about some of your experiences?

- Has your experiences with blindness in the past affected the person you are today? If yes, how so.

- Do you feel as though people attempt to judge your character based on your blindness. Elaborate.

- [If yes] Tell me about some of the impacts it has had on your life.

- As you've grown older, has your goals and aspirations changed. If yes, how so? Why have they changed?

- Can you recall any specific negative treatment you have received just for being blind? Tell me some details about this experience.

a. How did you deal with the situation?

- Tell me about some of your relationships with other blind individuals.

- Tell me about some of your relationships with sighted individuals.

- Tell me about some of the greatest difficulties you face on a day to day basis.

- Has being blind changed/influenced your relationships with other people in your life in any way? If so, please elaborate.

- Sighted people rely so much on sight in their daily activities; what do you rely upon to go about your affairs on a daily basis? 
- Using examples of blind athletes to introduce this topic - Has your blindness ever prevented you from doing things you desire? Has it ever been a barrier?

- What are the attitudes of people from your family, school, and community about blindness?

- Do you feel as though you are valued differently in society because you are blind? If yes, how so? Explain.

- Do people treat you different because you are blind? If so, how? Tell me about this.

- Do you think that you view yourself in the same way as others do?

- How do people explain blindness - do they see it as a medical condition? caused by spiritual forces? Genetic? Due to chance?

- How do you explain your blindness?

- Please share with me anything else you can think of about yourself and your experiences that I may have overlooked.

\section{EDUCATION/SCHOOLING}

- Let's talk about your situation in this school: Tell me about your experiences in the classroom. [probe: pros and cons of being integrated into regular classroom]

- Tell me about your relationships with other students.

- Tell me about our relationships with your teachers.

- Tell me about your level of communication with your teachers.

- Tell me about any negative experiences you have had in the classroom.

- Tell me about some positive experiences.

- Tell me about the accessibility to Braille printers and paper; and walking supports.

- Do you ever have troubles completely assignments due to lack of resources? Tell me about this.

- Tell me about your plans after you graduate from school?

- Do you feel as though your education has adequately prepared you?

- What improvements, if any, do you think are necessary to happen within your school for blind students to benefit even further?

- Please share with me anything that I have left out that may be useful to my knowledge of education and schooling for the blind.

\section{MODIFIED QUESTIONS FOR ANGEL ${ }^{28}$}

- Tell me about the direct impacts being withheld from continuing your education has had on your life.

- How did you feel at this time? Tell me about the various barriers that prevented you from attending school.

- How do you feel your life would be different if you were able to finish?

\footnotetext{
${ }^{28}$ Since Angel was withheld from continuing her education at MHS, the section on 'Education/Schooling' in the life narrative questions was not applicable to her. Rather, I created a list of modified question as a replacement for that section. These modified questions were only used during my interview with Angel.
} 
- What were some of your biggest challenges while you were younger? How did you deal with this?

- What role do you think society and family members play in determining the futures of blind youth? Tell me your thoughts on this.

- Has your blindness affected your children's lives? If yes, how so? Tell me about this.

- How are you supporting yourself and your children?

- Tell me about government programs or services that you know about. Have you seen any benefits from these? Why or why not?

\section{MODIFIED QUESTIONS FOR ALBERT ${ }^{29}$}

- Tell me the direct benefits you have seen in your life from completing your education.

- How would your life be different if you were not able to finish?

- What role do you think society and family members play in determining the futures of blind youth? Tell me your thoughts on this.

- Tell me about your experiences in looking for employment.

- Tell me about your experience working in the annex at MHS. Tell me about the positive and negative aspects.

- Tell me about some of your most significant challenges during your youth.

${ }^{29}$ Since Albert was no longer enrolled in school, but was rather teaching at Meba High School, the section on Education/Schooling' in the life narrative questions was not applicable to him either. I created this list of modified questions for my interviews with him only. 


\section{APPENDIX B: Sample Questions for Focus Group with Friends and Family}

Question 1: Tell me about your own personal perceptions of blindness. How do you believe your friend or family member became blind?

QUESTION 2: Tell me about how community members react to or treat blind individuals? Can you give an example? What effect does this have on the blind?

QUESTION 3: Tell me about how community members react or treat you for being in close association to a blind person? Can you give an example? How has this affected you?

QuEsTion 4: Tell me about some of the biggest challenges and barriers the blind are facing in Uganda today. What are some of your own challenges for being in close association to them?

QUESTION 5: Are there differences in experience for blind females than males? Explain these. 


\section{APPENDix C: SAMPle Questions for Focus Group WiTh WORKERS OF THE BLind}

Question 1: Tell me how you first became interested in working with blind individuals. How has your profession affected your life?

QUESTION 2: Tell me what you think the challenges and barriers are that the blind are facing in Uganda today? What are some of the causes of this?

QUESTION 3: In what areas of your profession do you feel needs improvement in order to help the blind reach their potential? What areas do you see to be positive?

QUESTION 4: Tell me about the structures and institutions that exist in the country for the blind. How do you feel about their workings? 


\section{APPENDIX D: SAMPLE QUESTIONS For SEMI-STRUCTURED INTERVIEWS WITH BLIND COMMUNITY MEMBERS}

\section{BACKGROUND INFORMATION}

- Were you born blind? How did you become blind? What life adjustments did you have to make? What challenges did you face at that time?

- What has been the role of your family in your life?

a. What are their feelings towards your blindness?

- Do you have children? If yes, how has their treatment been in society?

- How are you currently making a living?

- Tell me about any romantic relationships you have been in? Has your blindness affected your love life? If yes, how so?

- Did you attend school? At what point did you stop? How important is education for a blind person?

- Do you feel differently about your blindness today than you did when you were younger? If yes, how has it changed? Why?

- What did you find to be the greatest struggle during your youth?

\section{Social Context of BLindness}

- Tell me about romantic opportunities available to blind men or women? Are they affected negatively because of a lack of sight? Are romantic opportunities different for men than for women? If yes, how so?

- Does being blind change/influence people's social relationships? If so, please elaborate.

- How do people explain blindness - do they see it as a medical condition? caused by spiritual forces? Genetic? Due to chance? How do you explain your blindness?

- Does society see differences in people who are born blind from those who become blind when they are older?

\section{Political and EConomic Context of BLindness}

- Tell me about access to
a. Education
b. Employment
c. Information

- What are some of the barriers that prevent the blind from accessing these and improving their conditions?

- What are the causes of inaccessibility?

- What opportunities are open to blind individuals?

- Tell me about what the government is currently do for the blind today? Have you seen any benefits from any of their programs?

- Please share with me anything else you can think of that I have left out that may be useful to my study on blindness in Uganda. 


\section{APPENDIX E: SAMPLE QUESTIONS FOR SEMI-STRUCTUREd INTERVIEW WITH A NUDIPU BOARD MEMBER/PRIMARY SCHOOL TEACHER}

- Tell me about your worls at NUDIPU. What role does NUDIPU play in the functioning of blind individuals?

- In what areas of your profession do you feel needs improvement in order to help the blind reach their potential? What areas do you see to be positive

- Tell me about what the government is currently doing for the blind today? Have you seen any benefits from any of their programs?

- What are the differences in gender between blind males and females in terms of access and opportunities?

- What role does education play in the lives of blind youth? What are the major challenges for blind youth in society and within educational institutions?

- What are the chances that a blind person will be enrolled in an educational institution? What are the chances these individuals will graduate and go on to university?

- Tell me about your work as a teacher. What challenges have you had to face?

- Tell me about access to

a. Education

b. Employment

c. Information

- What are some of the barriers that prevent the blind from accessing these and improving their conditions?

- What are the causes of inaccessibility?

- What opportunities are open to blind individuals?

- Please share with me anything else you can think of that I have left out that may be useful to my study on blindness in Uganda. 


\section{BIBLIOGRAPHY}

Abosi, Okey

2007 Educating Children with Learning Disabilities in Africa. Learning Disabilities Research and Practice 22(3):196-201.

Acker, Frank Van

2004 Uganda and the Lord's Resistance Army: The New Order No One Ordered. African Affairs 103/412:335-357.

Albrecht, G. L. and Levy, J. A.

1981 Constructing disabilities as social problems. In Cross-national rehabilitation policies: A sociological perspective. G. L. Albrecht, (ed.) Beverly Hills: Sage. Pp. 11-32.

Aniyamuzaala, James R.

2012 Raising our Voices for an Inclusive Society: Challenges and Opportunities for the Disability Rights Movement in Uganda. Journal of Human Rights Practice 4(2):280-287.

Asociacion por los Derechos Civiles (ADC)

2007 Access to Information: An Instrumental Right for Empowerment. London: Article 19.

Armstrong, M. Jocelyn and Maureen H. Fitzgerald

1996 Culture and disability studies: An anthropological perspective. Rehabilitation Education 10(4):247-304.

Ashton, Beverly

1999 Promoting the Rights of Disabled Children Globally - Disabled Children Become Adults: Some Implications. Somerset: Action on Disability and Development (ADD).

Baker, Wairama G.

2001 Uganda: The Marginalization of Minorities. London: Minority Rights Group International.

Barnartt, Sharon N. and Venta Kabzems

1992 Zimbabwean Teachers' Attitudes Towards the Integration of Pupils with Disabilities into Regular Classrooms. Journal of Disability, Development, and Education 39(2):135-146.

Bourgois, Philippe and Nancy Scheper-Hughes

2004 Comments. In An Anthropology of Structural Violence by Paul Farmer. Reviewed Work(s). Current Anthropology 45(3):317-318. 
Buber, Martin

1958 I and Thou. New York: Collier Books.

Celtel, Andre

2005 Categories of the Self: Louis Dumont's Theory of the Individual. New York: Berghahn Books.

Charlton, James I.

1998 Nothing About Us Without Us: Disability Oppression and Empowerment. London: University of California Press.

Cheney, Kristen E.

2007 Pillars of the Nation: Child Citizens and the Ugandan National Development. Chicago: University of Chicago Press.

Cohen, Anthony

1994 Self consciousness: An alternative anthropology of identity. New York, NY: Routledge.

Comaroff, John L. and Jean Comaroff

2001 On Personhood: An Anthropological Perspective from Africa. Social Identities: Journal for the Study of Race, Nation, and Culture 7(2):267283.

Crapanzano, Vincent

1984 Life-Histories. American Anthropologist 86(4):953-960.

Davis, John M.

2010 Disability Studies as Ethnographic Research and Text: Research strategies and roles for promoting social change? Disability and Society 15(2):191206.

Dei, George J. Sefa, Alireza Asgharzadeh, Sharon Eblaghie Bahador, and Riyad Ahmed Shahjahan

2006 Schooling and Difference in Africa: Democratic Challenges in a Contemporary Context. Toronto: University of Toronto Press.

Devlieger, Patrick

1999 Developing local concepts of disability. In Disability in different cultures: Reflections on local concepts. B. Holtzer, A. Vreede, \& G. Weigt, (eds.) Bonn, Germany: Bielefeld. Pp. 297-302

Doom, Ruddy and Koen Vlassenroot

1999 Kony's Message: A New Koine? The Lord's Resistance Army in Northern Uganda. African Affairs 98:5-36. 
Dunn, Kevin C.

2004 Uganda: The Lord's Resistance Army. Review of African Political Economy 31(99):139-142.

Dunn, Peter, Roy Hanes, Susan Hardie, and Judy MacDonald

2006 Creating Disability Inclusion Within Canadian Schools of Social Work. Journal of Social Work in Disability \& Rehabilitation 5(1):1-19.

Farmer, Paul, Bruce Nizeye, Sara Stulac, and Salmaan Keshavjee

2006 Structural Violence and Clinical Medicine. Public Library of Science (PLoS) Med 3(10):1686-1691.

Farmer, Paul

1999 Pathologies of Power: Rethinking Health and Human Rights. American Journal of Public Health 89(10):1486-1496.

Farmer, Paul

1996 On Suffering and Structural Violence: A View from Below. Daedalus 125(1):261-283.

Finnegan, Amy C.

2010 Forging Forgiveness: Collective Efforts Amidst War in Northern Uganda. Sociological Inquiry 80(3):424:447.

Finnstrom, Sverker

2006 Wars of the Past and War in the Present: The Lord's Resistance Movement/Army in Uganda. Africa 76(2):200-220.

Fisher, Bernice and Roberta Galler

1988 Friendship and Fairness: How Disability Affects Friendship Between Women. In Women with Disabilities: Essays in Psychology, Culture, and Politics. Michelle Fine and Adrienne Asch, (eds.) Philadelphia: Temple University Press. Pp. 172-194.

Geertz, Clifford

1984 From the Natives Point of View: On the Nature of Anthropological Understanding. In Culture Theory: Essays on Mind, Self, and Emotion. R. Shweder and R. Levine, (eds). New York: Cambridge University Press. Pp.123-136.

Gitterman, Alex and Lawrence Schulman

1986 Mutual Aid Groups and the Life Cycle. Itasca, IL: F.E. Peacock Publishers. 
Goffman, Erving

1963 Stigma: Notes on the management of spoiled identity. Englewood Cliffs: Prentice-Hall

Goldin, Carol S.

1984 The Community of the Blind: Social Organization, Advocacy, and Cultural Redefinition. Human Organization 43(2):121-131.

Grech, Shaun

2009 Disability, poverty, and development: critical reflections on the majority world debate. Disability \& Society 24(6):771-784

Groce, Nora Ellen

2005 HIV/AIDS and Individuals with Disability. Health and Human Rights $8(2): 215-224$.

Herskovits, Elizabeth J. and Linda S Mitteness

1994 Transgressions and Sickness in Old Age. Journal of Aging Studies 8(3):327-340.

Holzer, Brigitte, Arthur Vreede, and Gabriele Weight

1999 Disability in different cultures: Reflections on local concepts. Bonn, Germany: Bielefeld.

Hoogeveen, Johannes G.

2003 Measuring Welfare for small Vulnerable Groups Poverty and Disability in Uganda. Journal of African Economies 14(4):603-631.

Hughes, Diane and Kimberly DuMont

1993 Using Focus Groups to Facilitate Culturally Anchored Research. American Journal of Community Psychology 21(6):775-806.

Hulme, David and Andrew Shepherd

2003 Conceptualizing Chronic Poverty. World Development 31(3): 403-423.

Hutchinson, Sally

1988 Education and Grounded Theory. In Qualitative Research in Education: Focus and Methods. Robert R. Sherman and Rodman B. Webb, (eds). London, UK: Falmer Press. Pp. 122-139.

Ingstad, Benedicte and Susan Reynolds Whyte

1995 Disability and culture. Berkeley, CA: University of California Press. 
Ingstad, Benedicte and Susan Reynolds Whyte

2007 Introduction: Disability Connections. In Disability in Local and Global Worlds. Benedicte Ingstad and Susan Reynolds Whyte, (eds.) Berkeley, CA: University of California Press. Pp. 1-29.

International Disability and Development Consortium (IDDC)

1999 Seen and Heard: Promoting the Rights of Disabled Children Globally. Seminar Report: Brighton, UK.

Kangere, Maria

2003 Development and Disability: The Uganda Experience. Kampala, Uganda:

Community Based Rehabilitation Alliance (COMBRA). Pp. 1-7.

Karna, G.N.

1999 United Nations and the Rights of Disabled Persons: A Study in Indian Perspective. Society for Disability and Rehabilitation Studies: New Delhi, India.

Kasnitz, Devva and Russell P. Shuttleworth

2001 Anthropology and Disability Studies. In Semiotics \& Dis/ability. Linda J. Rogers and Beth Blue Swadener, (eds.) New York: State University of New York Press. Pp. 19-41.

Katsui, Hisayo and Jukka Kumpuvouri

2008 Human Rights Based Approach to Disability in Development in Uganda: A Way to Fill the Gap between Political and Social Spaces? Scandinavian Journal of Disability Research 10(4):227-236.

Kitzinger, Jenny

1995 Introducing focus groups. British Medical Journal 311:299-302.

Kleinman, Arthur, Veena Das, and Margaret Lock

1996 Introduction. Daedalus, 125(1):xi-xx

Kristensen, Kirsten, Martin Omagor-Loican, Negris Onen, and Daniel Okot

2006 Opportunities for inclusion? The education of learners with special educational needs and disabilities in special schools in Uganda. British Journal of Special Education 33(3):139-147.

Laclave, Martha Mary

2005 From Corporeal Bantustans to Abakhubazekile: Disability and Identity in South Africa from a Human Rights Perspective. Unpublished $\mathrm{PhD}$ Dissertation: East Lansing, MI: Michigan State University. 
Langness, Lewis L. and Gelya Frank

1981 Lives: an anthropological approach to biography. Novato, CA: Chandler and Sharp Publishers.

Lowenfeld, Bethold

1975 The Changing Status of the Blind: From Segregation to Integration. Charles C Springfield, IL: Thomas Publisher.

Luborsky, Mark R.

1994 The Cultural Adversity of Physical Disability: Erosion of Full Adult Personhood. Journal of Aging Studies 8(3):239-253.

Lukoff, Irving

1960 A Sociological Appraisal of Blindness. In Social Casework and Blindness. Samuel Finestone, (ed.) New York, NY: American Foundation for the Blind. Pp. 19-44.

Lwanga-Ntale, Charles

2003 Chronic Poverty and Disability in Uganda. GLADNET Collection, Paper 320. Ithaca, NY: Cornell University.

Lwanga-Ntale, Charles and Kimberly McLean

2003 The Face of Chronic Poverty in Uganda as seen by the Poor Themselves. Kampala, Uganda: Chronic Poverty Research Centre.

Mathiesen, Kay

2008 Access to Information as a Human Right. Tucson, AZ: University of Arizona

McDermott, Ray and Varenne Herve

1995 Culture as disability. Anthropology and Education Quarterly, 26(3), 324348.

Messer, Ellen

1993 Anthropology and Human Rights. Annual Review of Anthropology 22:221-249.

Michael, Onsongo

2006 Playing down abilities can be demoralising for children with disabilities. In Inside Voices: Stories of CBR Workers. Joan Okune, (ed.) Nairobi: CAN Publication. Pp. 8-12.

Monbeck, Michael E.

1973 The Meaning of Blindness: Attitudes Towards Blindness and Blind People. Bloomington and London: Indiana University Press. 
Monks, Judith and Ronald Frankenberg

1995 Being Ill and Being Me: Self, Body, and Time in Multiple Sclerosis Narratives. In Disability and Culture. Benedicte Ingstad and Susan Reynolds Whyte, (eds.) Berkeley, CA: University of California Press. Pp. 107-134.

Mont, Daniel

2004 Diability Employment Policy. GLADNET Collection, Paper 431. Ithaca, NY: Cornell University Press.

Morgan, Lynn M.

1996 Fetal Relationality in Feminist Philosophy: An Anthropological Critique. Hysteria 11(3):47-70.

Morsy, Soheir

1996 Political economy in medical anthropology. In Medical anthropology: Contemporary theory and method. C.F. Sargent \& T.M. Johnson, (eds.) New York, NY: Praeger. Pp. 21-40.

Mpagi, J.S.

2002 Government's Role in CBR. In Community-Based Rehabilitation (CBR) as a Participatory Strategy in Africa. GLADNET Collection, Paper 60:8696. Ithaca, NY: Cornell University Press.

Mulindwa, Innocent Najjumba

2003 Study on Reproductive Health and HIV/AIDS Among Persons with Disabilities in Kampala, Katakwi, and Rakai Districts: Knowledge, Attitudes, and Perspectives. Kampala, Uganda: Disabled Women's Network and Resource Organisation (DWNRO).

Mumba, Mumba

2009 Students with Disabilities in Zambia's Higher Education System. In The Challenge of Change in Africa's Higher Education in the 21st Century. Kenneth Kaoma Mwenda and Gerry Nkombo Muuka, (eds.) Amherst, NY: Cambria Press. Pp. 241-262

Murphy, Robert

2001[1987] The body silent: The different world of the disabled. New York: Norton.

Murphy, Robert F., Jessica Scheer, Yolanda Murphy, and Richard Mack

1988 Physical Disability and Social Liminality: A Study in the Rituals of Adversity. Social Science and Medicine 26(2):235-242. 
Muyinda, Herbert and Susan R. Whyte

2011 Displacement, mobility, and poverty in northern Uganda. In Disability and Poverty: A Global Challenge. Arne H. Eide and Benedicte Ingstad, (eds.) Bristol, UK: The Policy Press. Pp. 119-136.

Ndwai, Obert P.

2002 The Role of Legislation in Facilitating CBR in Zimbabwe. . In Community-Based Rehabilitation (CBR) as a Participatory Strategy in Africa. GLADNET Collection, Paper 60:97-105. Ithaca, NY: Cornell University Press.

Ng'ang'a, S.K.

2004 Delivering Services to the Visually Impaired Through Public Libraries:

The Kenyan Experience. Information Development 20(2):130-134.

Nicolaisen, Ida

1995 Persons and Nonpersons: Disability and Personhood among the Punan Bah of Central Borneo. In Disability and Culture. Benedicte Ingstad and Susan Reynolds Whyte, (eds.) Berkeley, CA: University of California Press. Pp. 38-55.

NUDIPU

2010 NUDIPU Baseline Report: In Acholi Sub-Region (Gulu, Amuru, Kitgum, and Pader). Compiled by: Sennoga Martin, Atwikukire Justus, and Ulla Fomsgaard. Kampala, Uganda.

Okidi, John A. and Gloria K. Mugambe

2002 An Overview of Chronic Poverty and Development Policy in Uganda. Kampala, Uganda: Chronic Poverty Research Centre, Working Paper 11.

Percival, John and Julienne Hanson

2006 'I do not want to live for the day any more': visually impaired people's access to support, housing, and independence. British Journal of Visual Impairment 25(1):51-67.

Peters, Susan

2010 Is There a Disability Culture? A Syncretisation of Three Possible World Views. Disability and Society 15(4):583-601.

Powdermaker, Hortense

1966 Stranger and Friend: The Way of an Anthropologist. New York, NY: Norton. 
Ramos, Danny

2010 The War of the Acholi: The Lord's Resistance Army in Northern Uganda. In University of Florida International Review. Ian Charles Proctor, Mel Rose Burat, Ross Mittiga, Gayane Margaryan, and Yevgen Sautin, (eds.) Gainesville, FL: University of Florida. Pp 57-71.

Reid-Cunningham, Allison Ruby

2009 Anthropological Theories of Disability. Journal of Human Behavior in the Social Environment 19(1):99-111.

Robben, Antonius C. G. M.

2007 Reflexive Ethnography: Introduction. In Ethnographic Fieldwork: An Anthropological Reader. Antonius C. G. M. Robben and Jeffrey A. Sulka, (eds.) Oxford: Blackwell Publishing. Pp: 513-519.

Scott, Robert A.

1969 The Making of Blind Men: A Study of Adult Socialization. New York, NY: Russell Sage Foundation.

Sentumbwe, Nayinda

1995 Sighted Lovers and Blind Husbands: Experiences of Blind Women in Uganda. In Disability and Culture. Benedicte Ingstad and Susan Reynolds Whyte, (eds.) Berkeley, CA: University of California Press. Pp. 159-173

Shakespeare, T. and Nicholas Watson

2001 The social model of disability: an outdated ideology? In Research in social science and disability, Vol. 2. Pp. 9-28.

Shuttleworth, Russell P.

2004 Disability/Difference. In Encyclopedia of Medical Anthropology: Health and Illness in the World's Cultures. Carol R. Ember and Melvin Ember, (eds.) Pp. 360-373. Kluwer Academic/Plenum Publishers: New York, NY.

Shweder, R. and E. Bourne

1984 Does the Concept of the Person Vary Cross-Culturally? In Culture Theory: Essays on Mind, Self; and Emotion. R. Shweder and R. Levine, (eds.) New York: Cambridge University Press.

Singer, Merrill

2004 Critical Medical Anthropology. In Encyclopedia of Medical Anthropology: Health and Illness in the World's Cultures. Carol R. Ember and Melvin Ember, (eds.) Pp. 23-30. Kluwer Academic/Plenum Publishers: New York, NY. 
Sluka, Jeffrey A. and Antonius C. G. M. Robben

2007 Fieldwork in Cultural Anthropology: An Introduction. In Ethnographic Fieldwork: An Anthropological Reader. Antonius C. G. M. Robben and Jeffrey A. Sulka, (eds.) Oxford: Blackwell Publishing. Pp: 1-48

Smithson, Janet

2000 Using and analyzing focus groups: Limitations and possibilities. International Journal of Social Research Methodology 3(2):103-119

Stiker, Henri-Jacques

1999 Using historical anthropology to think disability. In Disability in different cultures: Reflections on local concepts. B. Holtzer, A. Vreede, \& G. Weigt, (eds.) Bonn, Germany: Bielefeld. Pp 352-380.

Susman, Joan

1994 Disability, stigma and deviance. Social Science \& Medicine 36(1), 15-22.

Tedlock, Barbara

1991 From Participant Observation to the Observation of Participation: The Emergence of Narrative Ethnography. Journal of Anthropological Research 47(1):69-94.

Thomas, Carol

2004 How is disability understood? An examination of sociological approaches. Disability \& Society 19(6): 569-583.

Turner, Victor

1967 The Forest of Symbols: Aspects of Ndembu Ritual. London: Cornell University Press.

Turner, Victor

1969 The Ritual Process: Structure and Anti-structure. Chicago: Aldine.

Turner, Victor

1985 On the Edge of the Bush. Tucson, AZ: University of Arizona Press.

Turner, Victor

1992 Blazing the Trail. Tucson, AZ: The University of Arizona Press.

Udvardy, Monica and Maria Cattell

1992 Gender, Aging and Power in Sub-Saharan Africa: Challenges and Puzzles. Journal of Cross-Cultural Gerontology 7:275-288. 
Uganda National Action on Physical Disability (UNAPD)

2010 Publication of Selected Legal Provisions in Domestic and International Laws on Physical Accessibility. Kampala, Uganda.

Warr, Deborah J.

2005 "It was fun . . . but we do not usually talk about these things": Analyzing Sociable Interaction in Focus Groups. Qualitative Inquiry 11(2):200-225.

Wasserman, H. and H. Danforth

1988 The Human Bond: Support Groups and Mutual Aid. New York, NY: Springer Publishing Company.

Willett, Jeffrey, and Mary Jo Deegan

2001 Liminality and Disability: Rites of Passage and Community in Hypermodern Society. Disability Studies Quarterly 21(3):137-152.

Wilson, Valerie

1997 Focus Groups: a useful qualitative method for educational research? British Educational Research Journal 23(2):209-224.

Whyte, Susan Reynolds and Herbert Muyinda

2007 Wheels and New Legs: Mobilization in Uganda. In Disability in Local and Global Worlds. Benedicte Ingstad and Susan Reynolds Whyte, (eds.) Berkeley, CA: University of California Press. Pp. 287-310.

Whyte, Susan Reynolds

1995 Disability between Discourse and Experience. In Disability and Culture. Benedicte Ingstad and Susan Reynolds Whyte, (eds.) Berkeley, CA: University of California Press. Pp. 267-291.

Yeo, Rebecca and Karen Moore

2003 Including Disabled People in Poverty Reduction Work: "Nothing About Us, Without Us." World Development 31(3):571-590.

Yeo, Rebecca

2001 Chronic Poverty and Disability. Chronic Poverty Research Centre, Paper No. 4. Somerset: Action on Disability and Development (ADD). 